Reconhecimento de Candida albicans por fibroblastos murinos: avaliação do envolvimento de receptores de reconhecimento de patógenos (TLR2 e CD14) e a proteína adaptadora MyD88 



\section{Reconhecimento de Candida albicans por fibroblastos murinos: avaliação do envolvimento de receptores de reconhecimento de patógenos (TLR2 e CD14) e a proteína adaptadora MyD88}

Tese apresentada à Faculdade de Odontologia de Bauru, Universidade de São Paulo, como pré-requisito para a obtenção do título de Doutor em Ciências Odontológicas Aplicadas, área de Estomatologia e Biologia Oral.

Orientadora: $\operatorname{Prof}^{\mathrm{a}} \mathrm{Dr}^{\mathrm{a}}$ Ana Paula Campanelli Coorientador: Prof. Dr. Carlos Ferreira dos Santos

Versão Corrigida 


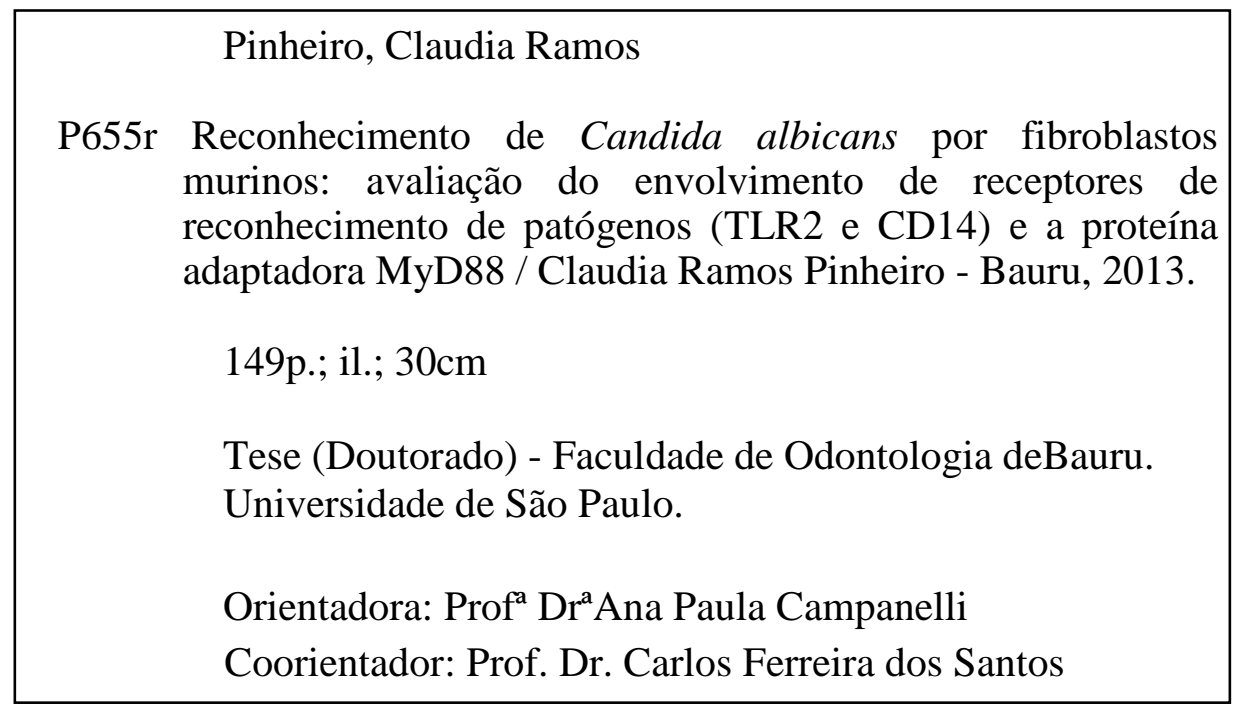

Nota: a versão original desta tese encontra-se disponível no Serviço de Biblioteca e Documentação da Faculdade de Odontologia de Bauru - FOB/USP.

Autorizo, exclusivamente para fins acadêmicos e científicos, a reprodução parcial desta tese, por processos fotocopiadores e/ou meios eletrônicos.

Assinatura do autor:

Data:

Comitê de Ética em Pesquisa da FOB-USP:

Projeto de pesquisa aprovado em 12 de maio de 2010

Número do protocolo: 039/2009 
Trabalho realizado no Laboratório de Microbiologia e Imunologia do Departamento de Ciências Biológicas da Faculdade de Odontologia de Bauru, Universidade de São Paulo.

Apoio: CAPES (Coordenação de Aperfeiçoamento Pessoal de Nível Superior), CNPq (Conselho Nacional de Desenvolvimento Científico e Tecnológico). 

Dedico esse trabalho para aqueles que mais amo: meu marido, pais e irmãos.

\section{Meu marido Marcus Vinícius,}

Se eu estou conseguindo realizar esse grande sonho é porque pude contar com seu apoio incondicional. Mais do que meu marido, você é meu melhor amigo.

Só peço a Deus para poder viver e envelhecer ao seu lado.

Amo você com todas as forças do meu coração.

\section{Meus pais Marli e José,}

Vocês são meus grandes exemplos de honestidade, fortaleza e coragem.

Poucas pessoas sabem tudo o que nós três já passamos na vida. Ainda assim, nunca perdemos nossa fé em Deus e nem deixamos de acreditar em nossos ideais.

Sou parte de vocês e VOCÊS SÃO TUDO PARA MIM!!!

\section{Meu irmão Marcelo,}

Entendo quando as mães dizem que para elas seus filhos nunca crescem.

Para mim você sempre será aquele bebê fofo que eu cuidava, cantava músicas e contava histórias antes de dormir.

Maravilhosos são os desígnios de Deus. Agradeço a Ele por ter você em nossa família.

Sei que seu futuro será repleto de alegrias e realizações!

\section{Meu irmão Maurício (IN MEMORIAM),}

Nunca me esqueço do nosso anjinho de cachos dourados e olhos verdes e sinto sua presença em cada passo do meu caminho.

Um dia tenho certeza de que iremos nos reencontrar e você estará me esperando com seus braços abertos e um lindo sorriso no rosto. 



\section{AGRADECIMENTOS}

À minha orientadora Profa. Dra. Ana Paula Campanelli, por seu exemplo inigualável de pesquisadora e orientadora; mas, sobretudo pela paciência, generosidade e excelência na orientação do meu trabalho. Muito obrigada por ter entendido meus receios, dificuldades e por todo apoio sempre. Minha gratidão por você é eterna.

\section{Aos queridos professores e amigos Cory Hogaboam, Ana Lúcia Coelho e Karen}

Cavassani (extensivo ao querido Danilinho), a participação de vocês na realização dessa Tese foi fundamental. Não tenho palavras para agradecer pelo carinho com que me receberam na Universidade e na vida de vocês. Muito obrigada!

Ao meu coorientador Prof. Dr. Carlos Ferreira dos Santos, pela gentileza em sempre oferecer ajuda durante o desenvolvimento desse trabalho.

Ao Prof. Dr. Sérgio Aparecido Torres, por ter me orientado durante minha residência no Centrinho e pela agradável convivência durante esses quatro anos de doutorado.

Ao Prof. Dr. Celso Kenji Nishiyama, por todo o conhecimento e ensinamentos tão importantes para a minha formação como endodontista e professora. Agradeço pelo incentivo, oportunidade e confiança.

Ao Prof. Dr. Gustavo Pompermaier Garlet, pelo aprendizado e grande exemplo de pesquisador.

Ao Prof. Dr. João Santana da Silva, pela solicitude e ajuda em ceder os camundongos 'knockout', sem os quais seria impossível a realização desse estudo.

A Prof. Dra. Sandra Helena Penha de Oliveira, pela gentileza em ter cedido o anticorpo $\alpha$-actina para realização dos ensaios de imunofluorescência.

Aos funcionários e amigos do Departamento de Microbiologia e Imunologia, Lívia Maria de Melo, Edilene Zapater, Rafael, Dalvinha Ribeiro de Oliveira e André Luís da Silva (que me apresentou oficialmente para a Profa. Dra. Ana Paula), agradeço pela maravilhosa acolhida durante esses anos, pela harmoniosa convivência, pelas gargalhadas, reuniões de confraternização e por toda ajuda. 

Aos técnicos e funcionários do Departamento de Ciências Biológicas, Thiago Dionísio, Vera Lúcia Rufino, Telma Lopes da Silva, Fátima Aparecida Silveira e Divina, pela disponibilidade em ajudar sempre que necessário.

Agradeço à Márcia Graeff pelo cuidado e atenção durante a captação das imagens de imunofluorescência.

Aos funcionários do Biotério da Faculdade de Odontologia de Bauru, Luís, Erasmo, Elias e Richard, pelo auxílio no cuidado com os animais e pela simpatia com que sempre me trataram.

Ao funcionário do Biotério da Faculdade de Medicina de Ribeirão Preto, Júlio Anselmo Siqueira pela gentileza e ajuda prestada todas as vezes que eu fui a Ribeirão Preto buscar os animais.

Aos queridos sogros Arleida e Osmar, por sempre me tratarem como uma filha. Obrigada por me prestigiarem e também por todo apoio e carinho.

Aos meus cunhados Leo, Fernandinha e Fred, agradeço não só pelos momentos felizes, mas também por se fazerem presentes, mesmo distantes.

Aos meus 'pais alfenenses D.Chica e Sr.Olício', muito obrigada pela torcida e pelas preces.

À minha amiga Thaís Helena Gasparoto, quero agradecer não só por tudo aquilo que me ensinou, mas também por todas as vezes que deixou de fazer suas coisas para me ajudar (e sempre com muito carinho e bom humor). Sua amizade sincera foi um grande presente que ganhei com o doutorado e se alguém é merecedora de realizar seus sonhos, esse alguém é você! Muitíssimo obrigada por tudo.

À minha querida amiga Carine Ervolino de Oliveira, você é uma das pessoas mais inteligentes que eu conheço e tem um valor inestimável a todos aqueles que assim como eu, amam você. Tenho certeza de que todo o auxílio que me prestou durante esses quatro anos de doutorado irá voltar para você em muitas felicidades e realizações. Obrigada por todas as maravilhas que trouxe para minha vida e isso inclui a amizade da Carol, do Juninho e da Sonetes. 

À minha amiga Sônia Maria Ervolino (Sonetes), pelo exemplo de garra, alegria e perseverança.

Ao meu amiguinho Lucas C. Machado, por me lembrar de como é doce e agradável a convivência com uma criança e também por me fazer reviver um passado que guardo com muito carinho. Tia Claudia deseja a você muitas alegrias!

Aos colegas do curso de pós-graduação Ronan Jacques Delgado, Carla Renata Sipert, Andreia Espíndola, Carlos Repeke, Élcia Silveira, Gabriela Genaro, Heliton de Lima, Bruna, Taísa, Juliana Pires, Lucas Bermejo, Clarissa, Gabriela Neubern, Gabriela Tiburcio, Daiane Wensceslau e Nádia, por todos os bons momentos compartilhados.

Às alunas de Iniciação Científica Aneli Abe, Marina Vicente e as que trabalharam comigo (Thalita Dalboni e Rayssa Fonseca), meus sinceros agradecimentos.

Aos queridos Ana Lúcia Gasparoto (Minke), Hayana Ramos Lima, Maria Carolina Vaz Goulart (Preta) e Daniel Brozoski, vocês fizeram parte de uma parte muito especial do meu doutorado.

Às minhas amigas especiais Márcia Regina Caramigo (Bara), Renatinha Pardini Hussne, Lidiane de Castro, Rafaela Rangel Rosa e Adriana Simionatto Guinesi, pelo grande apoio e incentivo dado durante os momentos mais difíceis. Vocês moram no meu coração!

Aos meus amigos Jose Burgos Ponce (Pepe), Túlio Olano Dextre, Danieli Colaço, Janaína Moraes, Marcelo Vitoriano, Bruno Guimarães, Angélica Boin Bonacci e Sabrina Pulzato Merlini, meus agradecimentos pelas palavras de carinho e apoio.

A minha amada "Chiquinha" por trazer alegria para o meu lar e estar comigo durante todo o tempo em que escrevi esse trabalho. 



\section{AGRADECIMENTOS INSTITUCIONAIS}

À Faculdade de Odontologia de Bauru - Universidade de São Paulo, na pessoa de seu diretor, Prof. Dr. José Carlos Pereira.

À Comissão de Pós-Graduação da Faculdade de Odontologia de Bauru - USP, na pessoa de seu presidente, Prof. Dr. Paulo César Rodrigues Conti.

Ao Programa de Ciências Odontológicas Aplicadas com ênfase em Estomatologia e Biologia Oral da Faculdade de Odontologia de Bauru-USP, na pessoa do seu Chefe de Departamento, Prof. Dr. Antônio de Castro Rodrigues.

Ao Departamento de Microbiologia e Imunologia da Faculdade de Odontologia de Bauru, por esses anos de trabalho harmônico e acolhimento.

À Coordenação de Aperfeiçoamento de Pessoal de Nível Superior (CAPES), pela concessão de minha bolsa de doutorado.

Ao Conselho Nacional de Desenvolvimento Científico e Tecnológico - (CNPq), pelo incentivo financeiro.

À Pro-Reitoria de Pós Graduação da Universidade de São Paulo pelo auxílio financeiro que me permitiram a participação em Congresso e em Estágio nos Estados Unidos da América.

À Universidade de Michigan (UMICH), por ser um centro de referência de Ensino e Pesquisa, no qual tive a oportunidade de fazer um Estágio durante 40 dias. 

Agradeço a Deus por me fazer tão feliz e por ter tantos a quem agradecer...

\section{Pegadas na areia}

"Uma noite eu tive um sonho.

Sonhei que estava andando na praia com o Senhor e através do Céu, passavam cenas da minha vida.

Para cada cena que se passava, percebi que eram deixados

dois pares de pegadas na areia;

Um era meu e o outro do Senhor.

Quando a última cena da minha vida passou

Diante de nós, olhei para trás, para as pegadas

$\mathrm{Na}$ areia e notei que muitas vezes, no caminho da

Minha vida havia apenas um par de pegadas na areia.

Notei também, que isso aconteceu nos momentos

Mais difíceis e angustiosos do meu viver.

Isso entristeceu-me deveras, e perguntei

Então ao Senhor.

"- Senhor, Tu me disseste que, uma vez que eu resolvi Te seguir, Tu andarias sempre

comigo, todo o caminho mas, notei que durante as maiores atribulações do meu viver

havia na areia dos caminhos da vida, apenas um par de pegadas. Não compreendo porque nas horas que mais necessitava de $\mathrm{Ti}$,

Tu me deixastes."

O Senhor me respondeu:

"- Meu precioso filho. Eu te amo e jamais te deixaria nas horas da tua prova e do teu sofrimento.

Quando vistes na areia, apenas um par de pegadas, foi exatamente aí que EU, nos braços...Te carreguei."

(Autoria: José Spera) 




\section{RESUMO}

Os tecidos pulpar e periodontal são frequentemente agredidos por fatores ambientais como calor, trauma mecânico e micro-organismos, sendo estes considerados o fator etiológico principal das periodontopatias e periapicopatias. Dentre as células residentes desses tecidos, especial atenção tem sido dada ao papel dos fibroblastos no desenvolvimento da resposta imune. Fibroblastos são células que respondem à estímulos microbianos e existem evidências do papel de receptores do tipo Toll (TLR) no reconhecimento desses estímulos. Dessa forma, o presente trabalho teve como objetivo principal avaliar o reconhecimento de Candida albicans por fibroblastos gengivais e pulpares. Para tal, fibroblastos isolados a partir de tecido gengival e pulpar de camundongos do grupo controle e deficientes de TLR2, CD14 e MyD88 foram avaliados quanto à expressão de TLRs e moléculas de superfície, resposta proliferativa e produção de citocinas (TGF- $\beta$, IL-1 $\beta$, TNF- $\alpha$, IL-13 e IL-6), após a estimulação com

agonistas de TLR2, TLR4 e C. albicans. Fibroblastos gengivais e pulpares, apesar de provenientes de tecidos diferentes, apresentaram características morfológicas semelhantes. Contudo, a cinética de crescimento dos fibroblastos gengivais deficientes de MyD88 foi mais lenta, e fibroblastos pulpares demoraram mais tempo para surgir a partir dos fragmentos de tecido. A ausência de TLR2 e da molécula adaptadora MyD88 não afetaram a produção de colágeno Tipo I pelos fibroblastos gengivais. Entretanto, fibroblastos deficientes de CD14 apresentaram baixa produção de colágeno. Ademais, os fibroblastos gengivais expressaram TLR2, TLR3, TLR4, assim como as moléculas de adesão ICAM-1 e CD44. A ausência de TLR2 e CD14 interferiu na resposta proliferativa de fibroblastos gengivais e pulpares, respectivamente. $\mathrm{O}$ reconhecimento de $C$. albicans por fibroblastos gengivais e pulpares modulou a produção das citocinas. A produção de TNF- $\alpha$ foi dependente da sinalização via MyD88, CD14 e TLR2, enquanto que a produção de IL-1 $\beta$ e IL-13 foi dependente de TLR2.

Palavras-chave: Candida albicans, citocinas, fibroblastos e Receptores do Tipo Toll 

Abstract 



\begin{abstract}
Pulpal and periapical tissue are frequently injured by heat, mechanical trauma and microorganisms, which are considered the main etiological factor of periodontal and endodontic diseases. Among these tissue resident cells, special attention has been given to fibroblasts in the immune response. Fibroblasts are cells that recognize pathogens through Toll like receptors (TLR). The aim of this study was to evaluate the recognition of Candida albicans by pulpal and gingival fibroblasts from TLR2, CD14, MyD88 knockout mice and control group mice. The results were analyzed concerning the expression of TLR(s) and surface molecules, proliferative response and citokynes production (TGF- $\beta$, IL-1 $\beta$, TNF- $\alpha$, IL-13 e IL-6) after the cells stimulation with TLR2, TLR4 and C.albicans agonists. Gingival and Pulpal fibroblasts, even isolated from different tissue, showed morphological similarities; however, gingival fibroblast deficient of MyD88 show lower proliferative response and pulpal fibroblasts needed more time to detach from tissue fragments. The production of Type I collagen was affected in gingival cells deficient of CD14. Gingival fibroblasts expressed TLR2, TLR3, TLR4, and the adhesion molecules (ICAM-1 and CD44). The absence of TLR2 and CD14 interfered with the proliferative response of pulpal and gingival fibroblasts, respectively. The recognition of $C$. albicans by gingival and pulpal fibroblasts modulated the citokynes production. TNF- $\alpha$ production after the recognition of $C$. albicans was dependent from MyD88, CD14 and TLR2 molecules, whereas the production of IL-1 $\beta$ and IL-13 was dependent of TLR2.
\end{abstract}

Key words: Candida albicans, Citokynes, fibroblasts and Toll like receptors (TLR). 



\section{LISTA DE FIGURAS}

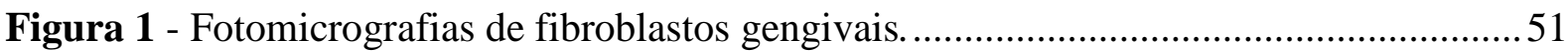

Figura 2 - Fotomicrografias de fibroblastos gengivais e pulpares. .....................................53

Figura 3 - Fotomicrografias representativas da análise por microscopia confocal do fenótipo de fibroblastos gengivais.

Figura 4 - Análise fenotípica de fibroblastos gengivais por citometria de fluxo.

Figura 5 - Análise fenotípica de fibroblastos gengivais por citometria de fluxo.

Figura 6 - Expressão de TLR2 após a estimulação com agonistas de TLR2, TLR4 e Candida albicans.

Figura 7 - Expressão de TLR3 após a estimulação com agonistas de TLR2, TLR4 e Candida albicans.

Figura 8 - Expressão de TLR4 após a estimulação com agonistas de TLR2, TLR4 e Candida albicans.

Figura 9 - Expressão de ICAM após a estimulação com agonistas de TLR2, TLR4 e Candida albicans.

Figura 10 - Expressão de CD44 após a estimulação com agonistas de TLR2, TLR4 e Candida albicans. ..... 70

Figura 11 - Resposta proliferativa de fibroblastos gengivais. 72

Figura 12 - Resposta proliferativa de fibroblastos pulpares. 74

Figura 13 - Análise da expressão de colágeno Tipo I por fibroblastos gengivais após a estimulação com LPS.

Figura 14 - Análise da expressão de colágeno Tipo I por fibroblastos gengivais após a estimulação com Pam3CSK4.

Figura 15 - Análise da expressão de colágeno Tipo I por fibroblastos gengivais após a estimulação com $C$. albicans morta (1:10).

Figura 16 - Produção de IL-1 $\beta$ por fibroblastos gengivais. 84 

Figura 17 - Produção de IL-1 $1 \beta$ por fibroblastos gengivais. .............................................. 85

Figura 18 - Produção de TGF- $\beta$ por fibroblastos gengivais. ................................................. 87

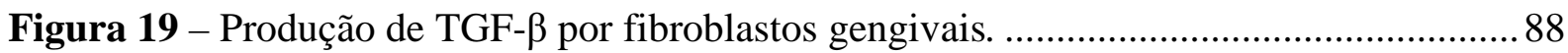

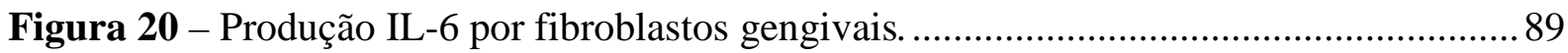

Figura 21- Produção IL-6 por fibroblastos gengivais......................................................... 90

Figura 22 - Produção IL-13 por fibroblastos gengivais. ................................................. 91

Figura 23 - Produção IL-13 por fibroblastos gengivais. ................................................... 92

Figura 24 - Produção de TNF- $\alpha$ por fibroblastos gengivais. ............................................... 94

Figura 25 - Produção de TNF- $\alpha$ por fibroblastos gengivais. …........................................... 95

Figura 26 - Produção de IL-1 $\beta$ por fibroblastos pulpares. .................................................. 97

Figura 27 - Produção de TGF- $\beta$ por fibroblastos pulpares. ................................................ 98

Figura 28 - Produção de IL-6 por fibroblastos pulpares. .................................................... 99

Figura 29 - Produção de IL-13 por fibroblastos pulpares. ............................................... 100

Figura 30 - Produção de TNF- $\alpha$ por fibroblastos pulpares. .................................................. 101 



\section{LISTA DE ABREVIATURAS E SÍMBOLOS}

AH ............................ Ácido hialurônico

A. fumigatus...........Aspergillus fumigatus

A. actinomycetemcomitans Aggregatibacter actinomycetemcomitans

AIDS........................Acquired Immunodeficiency Syndrome (Síndrome da Imunodeficiência Adquirida)

AP-1 .........................Activator Protein 1

BSA ........................ Bovine serum albumin (Albumina sérica bovina)

C. albicans ............... Candida albicans

CD .......................... Cluster of differentiation

CD14KO ................. Camundongo geneticamente deficiente de CD14

CFSE ...................... Carboxyfluorescein succinimidyl ester

$\mathrm{CO}_{2}$......................... Dióxido de carbono

CpG DNA ............... Oligodeóxidonucleotídeo contendo frações CpG não metiladas

CXCL..................... $C$ - $X$ - $C$ chemokine ligand

COX ....................... cicloxigenase

DAPI ......................4', 6-diamidino-2-phenylindole

DMEM ..................... Dulbecco modified Eagle's medium

DNA ......................... Ácido desoxirribonucléico

DO .......................... Densidade óptica

E. coli .....................Escherichia coli

ELISA ...................... Enzyme-linked immunosorbent assay (Ensaio imuno-enzimático)

EUA.......................Estados Unidos da América

FCF ....................... Fator de Crescimento de Fibroblastos

FITC....................... Fluorescein isothiocyanate (Isotiocianato de fluoresceína)

FL ............................. Fluorescent light (Canal de fluorescência)

FSC.......................... Forward scatter (Parâmetro de análise celular por tamanho)

g........................... gravidade

g............................ grama

GM-CSF ................ Granulocyte-macrophage colony-stimulating factor

HIV ........................... Human immunodeficiency virus

ICAM-1................... Intercellular Adhesion Molecule (CD54)

IFN ........................ Interferon

IL ........................... Interleucina 

IRAK........................ Interleuukin-1 Receptor Associated Kinase-1

IRF ........................... Interferon Regulatory Factor

KO ............................. Knockout

LRR......................... leucine-rich repeat (sequências ricas em leucina)

LPS.......................... Lipopolissacarídeo

LTA .......................... Lipoteichoic acid (Ácido lipoteicoico)

MD-2 ...................... Myeloid Differentiation

MEC........................ matriz extracelular

mg........................... miligramas

MHC ...................... Major histocompability complex(Complexo principal de histocompatibilidade)

MIP ........................ Macrophage Inflammatory Proteins

MAPK .....................Mitogen-activated protein kinases

mL ........................... mililitro

mM ......................... milimolar

MyD88 ..................... Myeloid differentiation primary response gene (88)

MyD88KO................ Camundongo geneticamente deficiente de MyD88KO

NF-кB..................... Nuclear factor kappa-light-chain-enhancer of activated B cells

nm.............................. nanômetros

NK ......................... Célula natural killer

PAMPs ..................... Pathogen-associated molecular patterns (Padrões moleculares associados ao patógeno)

PAMP3CSK4 ......... Lipopeptídeo sintético triacilado

PBS......................... Phosphate buffered saline (Solução salina tamponada em fosfato)

PE ......................... phycoerythrin

PGE ......................... prostaglandina

pH........................... potencial hidrogeniônico

P. gingivalis ............. Porphyromonas gingivalis

Pz............................. zona de atividade de fosfolipase

RIO........................ Intermediários reativos de oxigênio

RNA ........................ ÁcidoRibonucleico

RPMI-1640 ............. Meio de cultura celular

SAP........................... Secreted Aspartyl Proteinases 

SD. Standard deviation (desvio padrão)

SFB Soro fetal bovino

SSC. Side scatter (Parâmetro de análise celular por granularidade)

STAT Signal Transducer and Activator of Transcription

WT . Wild type

TGF Tumoral growth factor

Th Linfócito T auxiliar (helper)

TIR Toll and Interleukin 1 Receptor

TLR ........................... Toll like receptor(receptor do tipo Toll)

TLR2KO.................. Camundongo geneticamente deficiente de TLR2

TNF Tumor Necrosis Factor

TRAF TNF receptor-associated factor

TRAM TRIF-Related Adaptor Molecule(molécula adaptadora relacionada ao TRIF)

TIRAP Toll-interleukin 1 receptor (TIR) domain containing adaptor protein TRIF Toll-interleukin 1 receptor (TIR) domain containing adaptor inducing IFN- $\beta$

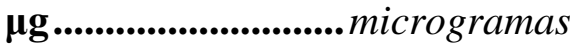

$\boldsymbol{\mu} \mathbf{L}$........................... microlitros

$\boldsymbol{\mu M}$......................... micromolar 



\section{SUMÁRIO}

1 INTRODUÇÃO E REVISÃO DA LITERATURA ................................................19

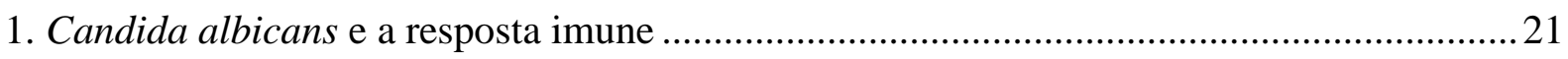

2. Candida albicans e sua associação com as Periodontopatias e

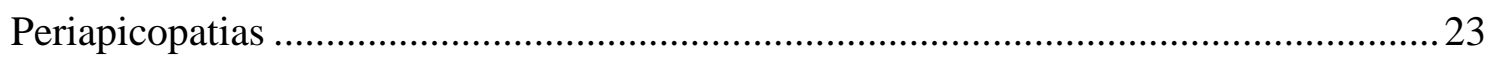

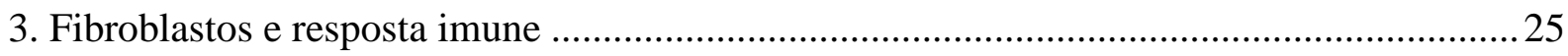

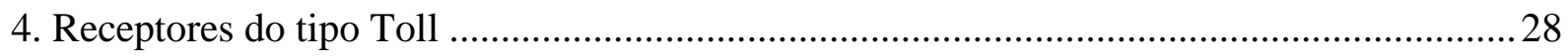

5. O papel de receptores do tipo Toll no reconhecimento de diferentes patógenos por fibroblastos gengivais e pulpares...................................................... 31

2 PROPOSIÇÃ

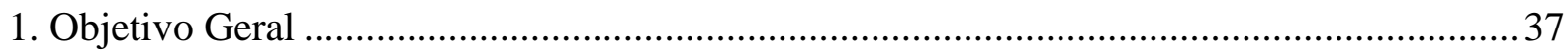

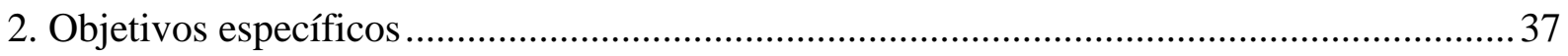

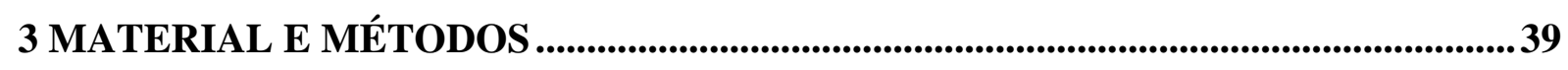

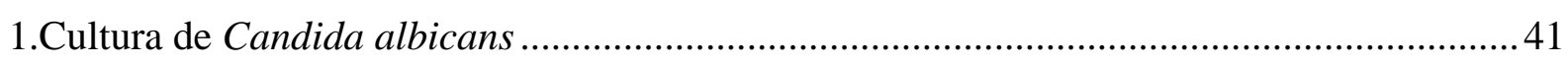

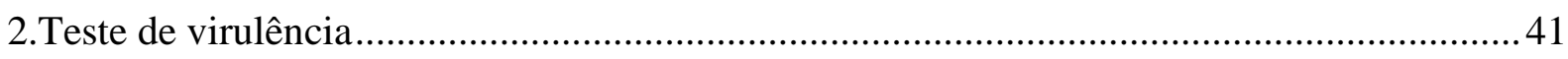

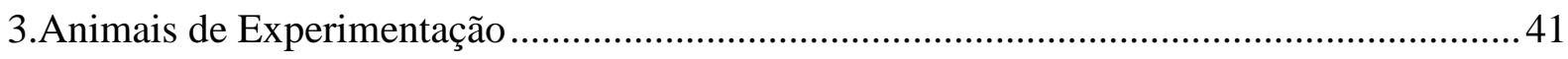

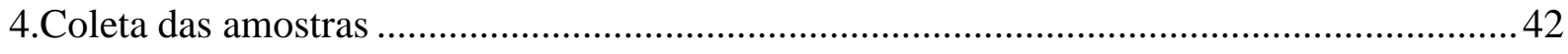

5.Cultura Primária de Fibroblastos Gengivais e Pulpares .................................................... 42

6.Estimulação de Fibroblastos Gengivais e Pulpares ........................................................... 43

7.Anticorpos usados para Citometria de Fluxo e Imunofluorescência ..................................... 43

8.Citometria de fluxo para a análise de expressão de moléculas de superfície ....................... 43

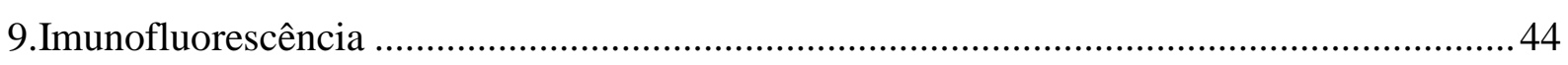

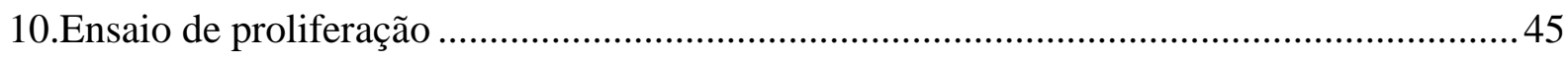

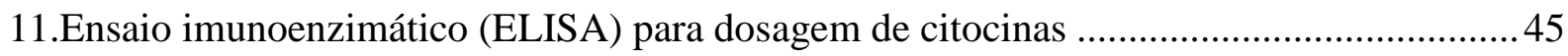

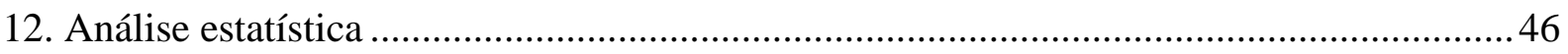

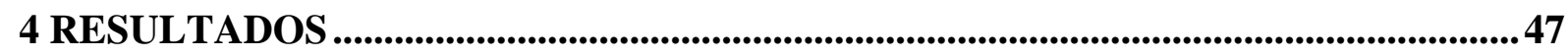



1.Caracterização morfológica e fenotípica de fibroblastos gengivais e pulpares

1.1. Análise morfológica de fibroblastos gengivais e pulpares.

1.2. Análise fenotípica de fibroblastos gengivais por microscopia confocal

1.3. Análise fenotípica de fibroblastos gengivais por citometria de fluxo

2. Avaliação dos efeitos de agonistas de TLR2, TLR4 e Candida na ativação de fibroblastos gengivais e pulpares

2.1. Análise da expressão de moléculas de superfície por fibroblastos gengivais após a estimulação com agonistas de TLR2, TLR4 e Candida albicans

2.2. Proliferação de fibroblastos gengivais após a estimulação com agonistas de TLR2, TLR4 e Candida albicans

2.3. Proliferação de fibroblastos pulpares

3. Análise da expressaõ de colágeno Tipo I por fibroblastos gengivais após a

estimulação com agonistas de TLR2, TLR4 e Candida albicans.....

4. Produção de citocinas por fibroblastos gengivais e pulpares após a estimulação com agonistas de TLR2, TLR4 e Candida albicans.

4.1. Produção de TGF- $\beta$, IL-1 $\beta$, TNF- $\alpha$, IL-13 e IL-6 por fibroblastos gengivais .....

4.2. Produção de TGF- $\beta$, IL-1 $\beta$, TNF- $\alpha$, IL-13 e IL-6 por fibroblastos pulpares 

Introdução e Revisão da Literatura 



\section{Candida albicans e a resposta imune}

A infecção por fungos do gênero Candida é limitada geralmente à pele e às mucosas, sendo a candidíase mucocutânea a apresentação da doença mais encontrada. Pacientes com esta micose podem apresentar manifestações na cavidade oral, vaginal e na pele e, em alguns casos, infecção sistêmica pode ser observada, especialmente em pacientes com imunossupressão severa. $\mathrm{O}$ trato gastrointestinal, a traquéia, os pulmões, o fígado, os rins e o sistema nervoso central são os órgãos e tecidos mais envolvidos durante a infecção sistêmica.

A candidíase é causada predominantemente por $C$. albicans, embora outras espécies de Candida possam estar envolvidas. Candida é um micro-organismo comensal da microbiota normal da cavidade bucal, em aproximadamente $30 \%$ a $50 \%$ da população, e pode levar a infecção oportunista quando há fatores de predisposição. A integridade das mucosas é fundamental para manutenção da relação de comensalismo de Candida sp e uma quebra na barreira mucocutâneo facilitaria o início da infecção. Outros fatores que favorecem o estabelecimento de candidíase são: AIDS, agentes quimioterapêuticos, corticosteróide, radiação, terapia com ciclosporina, neutropenia, uso de antibióticos de amplo espectro (desequilíbrio de microbiota), diabetes, cateterismo, que permitem a formação de biofilme e desnutrição (DELSING et al., 2012).

O estabelecimento desta micose está associado a fatores relacionados ao fungo e ao hospedeiro. Em relação aos mecanismos inerentes ao fungo, pode-se destacar o grau de virulência e de patogenicidade. Tem-se postulado que componentes da parede celular do fungo, liberados no foco inflamatório teriam papel relevante.

C. albicans é o principal agente etiológico da candidíase em humanos, e apresenta-se, geralmente, na forma de leveduras arredondadas, podendo ocorrer também na forma de hifas (micélio) e pseudo-hifas. Na fase de levedura, o fungo tem forma esférica ou ovóide, e as hifas podem se estender a algumas centenas de micrometros e são compostas de longas ramificações, septadas ou filamentosas. Estudos de candidíase em humanos e animais mostraram que a forma comensal é leveduriforme e a invasiva, miceliana. Em meio de cultura forma uma estrutura de resistência, de parede espessa e refringente, conhecida como clamidósporo (RADFORD; CHALLACOMBE; WALTER, 1999; FARAH; ASHMAN; CHALLACOMBE, 2000; CALDERONE; FONZI, 2001). Dados da literatura evidenciam que após a transição da forma de levedura para hifa, C. albicans aumenta suas propriedades 
adesivas e produção de proteases, fundamentais para infecções invasivas (WHITE; AGABIAN, 1995; SENET, 1997). Durante o processo, C. albicans libera grandes quantidades de intermediários reativos de oxigênio (RIO), que lesam as células do hospedeiro, facilitando a migração do fungo através do epitélio (SCHRÖTER et al., 2000).

Vários fatores de virulência que contribuem para a patogenicidade de $C$. albicans foram descritos, tais como: adesinas (glico e manoproteínas), produção de enzimas extracelulares como proteases e fosfolipases, produção da proteína p43 (imunossupressão), variabilidade antigênica, mudanças fenotípicas, hidrofobicidade e imunomodulação; produção de catalase; produção de hialuronidases e condroitinosulfatases; formação de biofilmes, produção de colagenases, elastases e hemolisinas (MARTÍNEZ et al., 1998; CALDERONE; FONZI, 2001; SCHRÖTER et al., 2000; SHIMIZU et al., 1995; COTTER; KAVANAGH, 2000). As manoses encontradas na parede celular deste fungo são relacionadas à aderência, modulação e supressão da resposta imune celular (KAPTEYN et al., 2000; LITTLE et al., 2000). Enquanto os oligossacarídeos presentes na parede celular de C. albicans permitem a ligação às células epiteliais e macrófagos (MIYAKAWA et al., 1992). As proteinases aspárticas (SAPs) produzidas por C. albicans são codificadas por uma família de genes que contêm informações para ao menos 10 tipos de SAPs. As SAPs degradam proteínas da matrix extracelular (MEC), mucina, a fração Fc dos anticorpos IgA e IgG, complemento, hemoglobina e proteínas do citoesqueleto, como a vimentina (GOLDMAN et al., 1995; DE BERNARDIS et al., 1999). No modelo experimental, dados apontam para o fato de que o nível de atividade das SAPs correlaciona-se diretamente com o grau de virulência (CHUNG; HILL et al., 1970).

Com relação ao hospedeiro os principais fatores são: o estado imunitário do hospedeiro, a susceptibilidade genética, o uso de antibióticos, imunossupresão e estresse (DELSING et al., 2012). Dados obtidos de estudos clínicos e modelos experimentais têm demonstrado que tanto os mecanismos de imunidade inata quanto de imunidade inespecífica são importantes para o controle desta infecção fúngica. Vários trabalhos apontam a grande importância da resposta imune celular no controle da infecção, com a participação de neutrófilos, macrófagos, células $\mathrm{T}$ e seus produtos de secreção. Isto se dá pelo fato de que as citocinas do padrão $\mathrm{Th}_{1}$ (IFN- $\gamma$, IL-12) ativam os fagócitos para um estado fungicida enquanto aquelas produzidas por células $\mathrm{Th}_{2}$ (IL-4 e IL-10) exacerbam a doença por 
desativarem propriedades protetoras das células fagocíticas contra fungos (D'OSTIANI et al., 2000).

As citocinas IL-4 e IL-10 são as principais responsáveis por respostas de supressão aos mecanismos microbicidas de macrófagos, opondo-se a IFN- $\gamma$ e, diminuindo a expressão de MHC II, produção de intermediários oxidativos (ROMANI; PUCCETTI; BISTONI, 1997). Demonstrou-se que IFN- $\gamma$ é uma citocina essencial para a proteção contra esta infecção fúngica. Na ausência de IFN- $\gamma$, a produção de óxido nítrico por macrófagos diminui o que gera menos proteção ao hospedeiro (KÁPOZTA et al., 1998). Camundongos infectados oralmente com $C$. albicans mostraram que a recuperação da infecção orofaríngea correlacionava-se com aumento de TNF- $\alpha$ nos tecidos orais (FARAH et al., 2003). Além de TNF- $\alpha$, outras citocinas pró-inflamatórias estão envolvidas com a resolução da candidíase, entre elas IL-6, GM-CSF, IFN- $\gamma$, IL-12 e IL-8. Os neutrófilos são responsáveis pelos principais mecanismos de defesa do hospedeiro contra a candidíase disseminada e invasiva (VERWEIJ et al., 1999; YAMAMOTO et al., 1995). Entre as ações antifúngicas dos neutrófilos está a capacidade de eliminar as pseudo-hifas e hifas, que são as formas invasivas de $C$. albicans, através de mecanismos oxidativos e não oxidativos (KULLBERG et al., 1998), além de eliminar blastoconídios de C. albicans intracelularmente, dentro de seus fagolisossomos (TORRES; CARSON; BALISH, 1994). Os neutrófilos secretam citocinas que tem uma ação muito importante na defesa do hospedeiro contra a infecção por C. albicans, tendo um controle sobre o desenvolvimento da resposta Th, entre elas a IL-10 e a IL-12 (MENCACCI et al., 1998). Assim, a baixa resposta imune celular caracteriza um distúrbio imunoregulatório que pode resultar em multiplicação do fungo, já que a imunidade celular efetiva correlaciona-se com um melhor prognóstico da doença (BROWN et al., 2011).

\section{Candida albicans e sua associação com as Periodontopatias e Periapicopatias}

As doenças periodontais são o resultado da destruição dos tecidos periodontais pela ação dos produtos tóxicos liberados na região subgengival pelos periodontopatógenos específicos como também pela resposta inflamatória desencadeada pela presença de microorganismos e seus subprodutos tóxicos. A inflamação leva à produção local de citocinas e mediadores biológicos. Desequilíbrios na regulação das células de defesa e alterações na microbiota patogênica podem resultar no aparecimento dos sinais clínicos da doença 
(GENCO, 1982; ALLENPACH-PERZILKA; GUGGENHEIN, 1983;CHRISTERSSON et al., 1989). Da mesma maneira, micro-organismos exercem papel fundamental na indução e, principalmente, na perpetuação das patologias pulpares e perirradiculares, as quais são de natureza inflamatória e de etiologia microbiana (MÖLLER et al., 1981; TAKAHASHI, 1998).

A ocorrência de fungos nas periapicopatias e periodontopatias tem sido cada vez mais relatada, contribuindo para o crescente interesse em se determinar o seu papel nas patologias endodônticas e periodontais (MIRANDA et al., 2009; ZHANG et al. 2010; CANABARRO et al. 2012; RUBIO et al. 2012). A maioria das espécies isoladas pertence ao gênero Candida, sendo a espécie Candida albicans a mais frequente. A habilidade das espécies de Candida em sobreviver a um ambiente com escassez de nutrientes e de resistir à ação de medicamentos pode fornecer importante vantagem para a sobrevivência desses micro-organismos nos canais radiculares (WALTIMO et al., 2003) e nas bolsas periodontais (CANABARRO et al., 2012; RUBIO et al., 2012).

A Periodontite crônica se caracteriza por perda clínica de inserção, em decorrência da destruição do ligamento periodontal e perda de osso de suporte. Em alguns casos, esta perda de inserção pode progredir, a despeito de um extensivo tratamento, caracterizando a periodontite refratária, que pode ocorrer em situações de fracasso da terapia periodontal convencional em eliminar micro-organismos infecciosos, ou resultar no aparecimento de patógenos oportunistas superinfectantes como Candida albicans (SARDI et al., 2010). Além disso, há um aumento no isolamento dessa espécie no sulco gengival de pacientes com gengivite severa (SARDI; ALMEIDA; MENDES GIANNINI, 2008), doença periodontal crônica tratados com antibióticos (HELOVUO; HAKKARAINEN; PAUNIO, 1993; SARDI; ALMEIDA; MENDES GIANNINI, 2008), na microbiota subgengival de pacientes com abscessos periodontais (HELOVUO; HAKKARAINEN; PAUNIO, 1993; SARDI et al., 2010), periodontites avançadas de pacientes com HIV (RAMS, 1981; CASSONE; CAUDA, 2012) e pacientes com periodontite juvenil localizada (GONZALEZ et al., 1987; ASIF, KOTHIWALE, 2010).

A utilização de antibacterianos de amplo espectro como auxiliares no tratamento periodontal tem sido um dos mais relevantes fatores para o desenvolvimento de infecções por bactérias resistentes e por leveduras do gênero Candida, inclusive em pacientes imunodeprimidos, que além de terem sua imunidade comprometida, são submetidos a 
tratamentos prolongados com antibacterianos para curar ou prevenir infecções bacterianas (CASSONE; CAUDA, 2012).

Em relação à ocorrência de fungos nas periapicopatias, dados demonstram que as espécies de Candida podem invadir os túbulos dentinários, e secretar proteases que destroem uma variedade de proteínas do tecido e contribuem para condições de sobrevivência em períodos de baixa oferta nutricional e alterações fenotípicas que permitem adaptação em condições ambientais desfavoráveis (WALTIMO et al., 2003; SIQUEIRA Jr; SEN, 2004; NING et al., 2013). Embora Candida albicans possa ser ocasionalmente encontrada em infecções endodônticas primárias, a presença desse micro-organismo tem sido mais atribuída a infecções secundárias ou persistentes, muitas vezes associada ao fracasso do tratamento de canal radicular (MOHAMMADI; DUMMER, 2011). Normalmente, Candida albicans está associada com outros patógenos na formação do biofilme, acarretando em maior resistência as soluções e medicações utilizadas na terapia endodôntica (NING et al., 2013).

\section{Fibroblastos e resposta imune}

Os fibroblastos são células presentes em todos os tecidos, sendo as mais abundantes da polpa dentária e dos tecidos que compõem os periodontos de sustentação e proteção (ZVAIFLER et al., 2000). Os fibroblastos são extremamente versáteis além de terem uma notável capacidade de se diferenciar em outras células, incluindo cartilagem, osso, adipócitos e células do músculo liso (HARRIS, 1994). Fibroblastos de diferentes regiões anatômicas exibem fenótipos que se mantêm mesmo após períodos prolongados em cultura, o que sugere que muitos fibroblastos têm um fenótipo característico que pode ser considerado estável. Apesar dos fibroblastos não serem uma população homogênea, mesmo em um único tecido, os mesmos se apresentam como subconjuntos de células, assim como macrófagos e células dendríticas teciduais (MARINOVA-MUTAFCHIEVA et al., 2000). Os precursores de fibroblastos circulam no sangue periférico (ZVAIFLER et al., 2000), e compartilham muitas propriedades de células-tronco do estroma da medula óssea, sendo capazes de se diferenciar em várias linhagens de células (WHETTON; GRAHAM, 1999; BIANCO; ROBEY, 2000). Esta diversidade de fenótipos e função pode desempenhar um papel relevante na susceptibilidade intrínseca de diferentes órgãos a agressões e processos inflamatórios. 
Os fibroblastos provenientes de tecidos doentes apresentam um fenótipo completamente diferente de fibroblastos provenientes de tecidos sadios, mesmo sendo do mesmo tecido (HOGABOAM et al. 1998; BROUTY-BOYE et al., 2000; PAP et al., 2000). Fibroblastos sinoviais de pacientes com artrite reumatóide exibem propriedades únicas e secretam um padrão distinto de citocinas comparado com fibroblastos sinoviais de articulações sadias (PAP et al., 2000). Fibroblastos pulmonares isolados de camundongos com granulomas induzidos experimentalmente do tipo T-helper $1\left(\mathrm{Th}_{1}\right)$ e $\mathrm{T}$ helper $2\left(\mathrm{Th}_{2}\right)$ expressaram diferentes padrões de quimiocinas e produziram diferentes tipos de matriz extracelular, sugerindo que os fibroblastos conseguem estabelecer um equilíbrio entre as respostas Th1 e Th2 no tecido inflamado (HOGABOAM et al., 1999).

Atualmente, está bem estabelecido que fibroblastos em resposta a estímulo microbiano e injúria mecânica podem secretar citocinas (EKUNI et al., 2010). Na presença de antígenos, como bactérias e fungos, fibroblastos produzem citocinas que vão estimular a deposição de colágeno para substituir o tecido conjuntivo destruído (EKUNI et al., 2010). TGF- $\beta$ é um potente fator mitótico, contribuindo não apenas para a maior produção de colágeno, mas também para a produção de fibronectina e proteoglicanos por essas células (CHEN; HOSHI; MC KEEHAN, 1987, KIN; CORTING, 1998; OKIJI; HARDGREAVES; GOODIS, 2002). IL-1 $\beta$ é sintetizada por fibroblastos, estimula a síntese de colágeno, colagenase, fibronectina e prostaglandinas (OKADA; MURAKAMI, 1998). No processso inflamatório, quando produzida em altos níveis, está intimamente associada com destruição tecidual e reabsorção óssea periodontal (ALVARES et al., 1995, SAWADA et al., 2013).

A ativação de fibroblastos leva não só à produção de citocinas, mas também de quimiocinas e prostaglandinas, tais como $\mathrm{PGE}_{2}$. Além disso, a interação entre fibroblastos e leucócitos através dos receptores CD40/CD40L, resulta na ativação do fator nuclear (NF)-kB com níveis elevados de interleucina 6 (IL-6), IL-8 e ciclooxigenase-2 (SMITH et al., 1997). Similar ao que se observa durante as interações linfócitos e células apresentadoras de antígeno pode-se inferir que tanto a ligação CD40-CD40L quanto as moléculas co-estimulatórias da família B7 podem desempenhar um papel crítico na interação entre fibroblastos e células do sistema imune (MUELLER, 2000). IL-6 é secretada fibroblastos e elevados níveis dessa citocina correlacionam-se com aumento na produção de colágeno (COKER; LAURENT, 1998). IL-6 é uma das principais mediadoras da resposta inflamatória e imune, da injúria tecidual e da reabsorção óssea (SAWADA et al., 2013). TNF- $\alpha$ é uma citocina que induz 
síntese de IL-1 e prostaglandinas. TNF- $\alpha$ parece ser um mediador importante in vitro da fibrose pulmonar (COKER; LAURENT, 1998), por estimular a proliferação de fibroblastos pulmonares e aumentar a síntese de colágeno.

Apesar do fibroblasto ser a célula mais abundante no estroma, estas células permanecem relativamente mal caracterizados em termos moleculares (HUGHES, 2008). Esta ausência de marcadores específicos de fibroblastos fez com que a caracterização de subconjuntos de fibroblastos seja difícil. Cada vez mais, proteínas específicas são identificadas e possibilitam a fenotipagem de fibroblasto, estas incluem: a fibronectina, CD90, colágeno do tipo I, do tipo III, do tipo IV e o pró-colágeno (PILLING et al., 2009). O colágeno tipo I é o mais abundante, encontrado no tecido conjuntivo, sendo principalmente produzido por células produtoras da matriz orgânica como osteoblastos, odontoblastos e fibroblastos (FLUG; KOPF-MAIER, 1995).

As ICAM-1 são moléculas de adesão constituídas de polipeptídio transmembrana encontradas no epitélio, nas células endoteliais e nos fibroblastos (VALERA et al., 2011). Atuam favorecendo migração e adesão celular. O processo de adesão ocorre em vários eventos biológicos como: morfogênese, crescimento, organização tecidual, inflamação, resposta do hospedeiro às injúrias, cicatrização e respostas imunoreguladoras. A ação próinflamatória das ICAM-1 ao permitir migração e adesão ao endotélio determina seu papel na patogênese de variadas doenças vasculares como a arteriosclerose (VALERA et al., 2011).

CD44 é uma glicoproteína transmembrana que tem participação em diversas atividades celulares como interação célula-célula, célula-matriz extracelular, migração celular, apresentação de fatores de crescimento, citocinas, sobrevivência celular e proliferação (HUEBENER et al., 2008). Uma das principais características do CD44 é pertencer a um grupo de proteínas que se liga ao ácido hialurônico (AH). O AH é o principal componente da matriz extracelular dos tecidos de mamíferos (TOOLE et al., 2001). As proteínas do CD44 podem ser encontradas em três estágios de acordo com a ligação do AH: CD44 inativo, o qual não se liga ao $\mathrm{AH}$; $\mathrm{CD} 44$ induzido, não se liga ao $\mathrm{AH}$, porem pode ser ativado por estímulos fisiológicos; e o CD44 ativo que pode ligar-se ao AH (LESLEY et al., 2003). Além disso, o domínio extracelular do cd4 pode possuir sulfato e que o sulfato de heparan permitindo a ligação de fatores de crescimento, como o fator de crescimento de fibroblastos (FCF) (MISRA et al., 2001). Outros componentes da matriz extracelular também podem ligar-se ao CD44, como a osteopontina, colágeno e metaloproteinases (DESA et al., 2009). CD44 é 
expresso por vários tipos de células que possuem a função de adesão celular, dentre elas células mielóides, células da glia do sistema nervoso central e fibroblastos (PILLING et al., 2009). Esse receptor está relacionado com a ativação, direcionamento e posicionamento das células de adesão e linfócitos nos órgãos linfóides primários e secundários.

Células de origem mesenquimal, tais como fibroblastos, desempenham um papel crítico na modulação do comportamento e função dos leucócitos. Estas células possuem um repertório variado biossintético e, em conjunto com os macrófagos dos tecidos, atuam como sentinelas do sistema imunológico (BUCKLEY et al., 2001). Como resultado da produção de quimiocinas e de matriz extracelular, os fibroblastos são responsáveis por definir ativamente o microambiente dos tecidos, além de desempenharem um papel importante na transição da inflamação aguda na imunidade adquirida, uma vez que a produção inapropriada de quimiocinas e componentes da matriz por fibroblastos têm efeitos severos sobre as células do sistema imune adquirido, levando ao estabelecimento de inflamação crônica. Sendo assim, o entendimento do microambiente do estroma, e dos fibroblastos nos tecidos pode ser um alvo importante para a terapia anti-inflamatória (BUCKLEY et al., 2001).

\section{Receptores do tipo Toll}

O conceito de inespecificidade da resposta imune inata foi recentemente contestado após a descoberta de uma classe de receptores, os receptores do tipo Toll (TLRs), que reconhecem estruturas moleculares conservadas (PAMPs) presentes tanto na superfície quanto nas estrututras que compõem os patógenos. Estes receptores foram inicialmente descritos em drosófilas como um receptor transmembrana do tipo I, com papel importante no desenvolvimento dorso-ventral do embrião da drosófila (UNDERHILL; OZINSKY, 2002; MEDZHITOV, 2001). Adicionalmente, a ausência deste receptor resultou em diminuição de resposta contra bactérias gram-positivas e fungos (A. fumigatus e C. albicans). Estes dados iniciais sugeriram que os receptores do tipo Toll são componentes importantes da defesa das drosófilas, porque induzia a expressão de drosomicina, uma defensina antifúngica (LAMAITRE, 1997). Em mamíferos, foram identificados 11 diferentes receptores envolvidos no reconhecimento de micro-organismos e na ativação da resposta imune inata (UNDERHILL; OZINSKY, 2002). 
Neste contexto, a descoberta dos receptores do tipo Toll (TLRs) revolucionou os mecanismos envolvidos no reconhecimento do sistema imune inato. Os TLRs são moléculas transmembranas que contêm um domínio externo à membrana com sequiências ricas em leucina (LRR), e uma cauda intracelular que mostra grande homologia com o domínio intracelular do receptor para a IL-1 (IL-1R), chamada domínio Toll/IL-1R (TIR) (TAKEDA; AKIRA, 2004). A ativação do TLR por seus ligantes induz o recrutamento de proteínas adaptadoras específicas. Até o momento, quatro proteínas adaptadoras foram descritas: fator de diferenciação mielóide 88 (MyD88), proteína associada ao TIR (MALT/TIRAP), Toll/IL1R domain containing adaptador inducing IFN-beta (TRIF) e molécula adaptadora relacionada ao TRIF (TRAM) (TAKEDA; AKIRA, 2004). Essas proteínas adaptadoras transduzem o sinal do TIR, ativando quinases e fatores de transcrição como o NF-kB e STAT1 (TAKEDA; AKIRA, 2004). Dá-se, dessa maneira, a produção de diferentes moléculas efetoras, citocinas pró-inflamatórias, entre outros mediadores, responsáveis pelas diferentes respostas geradas a partir do reconhecimento de estruturas padrões dos patógenos.

Estudos mostraram a importância dos receptores do tipo Toll (TLRs) na fase inicial de reconhecimento de diferentes patógenos. A família dos receptores do tipo Toll compreende, até o momento, onze proteínas identificadas em mamíferos (11 receptores identificados em camundongos e 10 receptores em humanos) (SABROE, et al. 2002). TLR -1, $-2,-4,-5$, e -6 são expressos na superfície celular e possuem a função de reconhecer especificamente produtos bacterianos, incluindo as lipoproteínas bacterianas (TLR2 como um heterodímero com TLR1 ou TLR6), LPS (TLR4), ou flagelina (TLR5) (TAKEDA; AKIRA, 2004). TLR -3, -7, -8, e -9 são localizados nos compartimentos intracelulares (AHMADNEJAD et al., 2002; HEIL et al., 2003; MATSUMOTO et al., 2003) e especializam-se na detecção de DNA dupla fita (TLR3), o RNA viral (TLR7), ou as sequiências CpG das bactérias e dos vírus (TLR9) (TAKEDA; AKIRA, 2004). Os neutrófilos humanos expressam o mRNA para todos os TLRs, exceto TLR3 (NEUFERT et al., 2001) e sua ligação com os respectivos ligantes levam à secreção de citocinas inflamatórias (AAP, 1996; AAP, 1999, ADA, 1996; TERPENING et al., 2001; SHIMAZAKI et al., 2001; HUYOEL et al., 2000; SOIKKNEN et al., 2000; LI et al., 2000; FOWLER 2001; BECK 1999; MEYER et al., 1998; DONGARI et al., 1996) com exceção da seqüência $\mathrm{CpG}$, que requer o pré-tratamento dos neutrófilos com GM-CSF (NEUFERT et al., 2001). Adicionalmente, o DNA bacteriano pode ativar os neutrófilos via TLR9 de uma maneira CpG independente, mecanismo este que ainda precisa ser identificado (TREVANI et al., 2003). TLR4 é capaz de mediar a indução de 
citocinas pró-inflamatórias após estimulação com fungos e bactérias, enquanto o reconhecimento desse micro-organismo por TLR2 conduz, principalmente, à liberação de citocinas antinflamatórias. Assim, é provável que as diferenças nos componentes de superfície celular dos micro-organismos, sejam responsáveis pela ligação a diferentes TLRs e induzam a produção de diferentes padrões de citocinas após o contato entre micro-organismos e célula hospedeira. A produção de citocinas como TNF- $\alpha$, IL-1, IL-6, IL-8, IL-10 e IL-12 é observada em estudos in vitro, após estímulo de macrófagos e monócitos com diferentes micro-organismos (XIONG et al., 2000; VESCHIARELLIA et al., 1999; PARISE-FORTES, 2000), demonstrando que essas células podem ser fontes importantes de citocinas. A sinalização dos TLR(s) ativa a indução dos genes de citocinas inflamatórias como TNF- $\alpha$, IL6, IL-1, IL-12, IL-13, TGF- $\beta$, IL-8, IFN- $\gamma$ induzindo a expressão de moléculas coestimulatórias da imunidade como linfócitos, macrófagos, células dendríticas, neutrófilos e fibroblastos.

Cada TLR recruta uma combinação específica de moléculas adaptadoras para ativar diferentes fatores de transcrição que darão origem a resposta apropriada contra o patógeno estimulador (KAWAI; AKIRA, 2007). Dependendo do estímulo, podem ser ativados os fatores de transcrição (NF)-kB e AP-1 para a produção de citocinas inflamatórias e/ou IRF(s) para a produção de interferons tipo I (IFN- $\alpha$ e $\beta$ ). A proteína adaptadora MyD88 é usada por todos os TLR(s), a exceção de TLR3, e ativa (NF)-kB e as vias das MAPK(s) para induzir a produção de citocinas. Por outro lado, TLR3 utiliza a molécula TRIF para sinalizar a produção de IFN tipo 1 para a produção de citocinas inflamatórias, via ativação dos fatores de transcrição, IRF3 e (NF)-kB, respectivamente (CERVANTES et al., 2012). As moléculas adaptadoras TRAM e TIRAP são utilizadas pelo TLR4 para recrutar TRIF e pelo TLR2 e TLR4 para recrutar MyD88, respectivamente. Dessa maneira, a sinalização dos TLR(s) pode ser classificada em duas formas: via dependente de MyD88 e via dependente de TRIF. TLR4 é o único receptor que utiliza as quatro moléculas adaptadoras para desencadear a sua sinalização. A produção de citocinas inflamatórias via esse receptor necessita de MyD88 e TRIF para ativação de (NF)-kB. Para que seja possível o reconhecimento de lipopolissacarídeo (LPS), além das quatro moléculas adaptadoras, a sinalização dependente de TLR4 requer a presença da molécula acessória CD14 solúvel ou de membrana, que atua como opsonina (proteína ligante de LPS) (ADEREM; ULEVITCH, 2000; LANDMANN; MÜLLER; ZIMMERLI, 2000; MEDZHITOV; JANEWAY Jr., 2000). A expressão de CD14 pode ser modulada por citocinas, tais como IL-4, IFN- $\gamma$, TNF- $\alpha$ e pelo próprio LPS 
(MEDZHITOV; JANEWAY Jr., 2000). A ativação de (NF)-kB mediada pelo LPS envolve também a proteína secretada MD-2, que se liga ao domínio extracelular de TLR4 (SHIMAZU et al., 1999; FINLAY; HANCOCK, 2004).

\section{O papel de receptores do tipo Toll no reconhecimento de diferentes patógenos por} fibroblastos gengivais e pulpares

Os fibroblastos são as células mais abundantes da polpa dentária e dos tecidos que compõem os periodonto de sustentação e proteção. Essas células possuem capacidade de reparo, de diferenciação em odontoblastos e de síntese de proteínas da matriz (CHAN et al., 2005; OLIVEIRA; SANTOS, 2011). Produzem fatores de crescimento e citocinas como TGF$\beta$ e IL-1 $\beta$, que estão envolvidos com o aumento da deposição de colágeno (BARKHORDAR et al., 2002; CHAN et al., 2005).

Os fibroblastos não estão envolvidos apenas nos processos de reparo tecidual, mas também exercem um papel importante na resposta imune, pois quando estão ativados, estão envolvidos com a produção de citocinas e quimiocinas. Essa ativação pode ser feita diretamente pelos patógenos, pois as células possuem receptores específicos como CD14 e outros responsáveis pelo reconhecimento de manose e produtos microbianos como (TLR) (MAHANONDA et al., 2007; UEHARA; TAKADA, 2007; WARA-ASWAPATI et al., 2012; GUTIERREZ-VENEGAS; ARREQUIN-CANO; HERNANDEZ-BERMUDEZ, 2012).

A expressão de receptores do tipo Toll foi não somente detectada por fibroblastos gengivais (AKIRA; UEMATSU; TAKEUCHI, 2006; MAHANONDA et al., 2007; UEHARA; TAKADA, 2007), mas também por fibroblastos do ligamento periodontal (HATAKEYAMA et al., 2003; TANG et al., 2011; SCHERES et al., 2011) e pulpares (HIRAO et al., 2009; HIRAO et al., 2010; PARK et al., 2010; KELLER et al., 2010).

O reconhecimento de LPS por fibroblastos de gengiva humana é mediado via TLR-4 e leva a produção de IL-1 $\beta$ (WANG et al., 2000). Da mesma forma, fibroblastos de gengiva de camundongos reconhecem antígenos microbianos a partir da interação via TLR-4 e CD14 (AHMAD-NEJAD et al., 2002). Fibroblastos de gengiva de camundongos expressam CD14 após o estímulo por LPS, o que torna essas células responsivas ao LPS de Escherichia coli e Porphyromonas gingivalis (BOTERO et al., 2006). De modo relevante, alta expressão do 
receptor CD14 foi detectada em fibroblastos de gengiva humana contrastando com discreta expressão desse receptor em fibroblastos de ligamento periodontal (HATAKEYAMA et al., 2003). Fibroblastos do ligamento periodontal de pacientes com periodontite apresentaram um aumento na expressão de CD14 antes e após o estímulo por Porphyromonas gingivalis (SCHERES et al., 2011). A expressão de outros receptores do tipo Toll (TLR-1 a TLR-9) também foi avaliada em fibroblastos de gengiva e demonstrou-se que o reconhecimento de patógenos via esses receptores levou a produção de altos níveis de IL-8 (MAHANONDA et al., 2007). Estudos evidenciam que em resposta a estímulos variados, os fibroblastos gengivais e pulpares secretam citocinas: IL-1 $\beta$, TNF- $\alpha$. IL-8 IL-1 $\beta$, IL-8 e TNF- $\alpha$ são citocinas essenciais para iniciar reações imunes inflamatórias e são secretadas por fibroblastos na presença de um antígeno, acarretando na migração e recrutamento de neutrófilos que são as células mais prevalentes na inflamação aguda (SILVA et al., 2009). A produção destas citocinas é mediada por sinalização via TLR-2 e TLR-4 (AKIRA, UEMATSU, TAKEUCHI, 2006; UEHARA; TAKADA, 2007) e MyD88 (MOCHIZUKI et al., 2004). IFN- $\gamma$ aumenta a expressão de CD14/TLR-4 e MyD88 em fibroblastos gengivais e, consequentemente, a responsividade destas células ao LPS de A. actinomycetemcomitans (MOCHIZUKI et al., 2004).

A polpa dentária vem sendo objeto de estudo não apenas pelas implicações clínicas dos seus processos patológicos, mas também devido a fatores específicos como sua localização interna a um tecido duro, seu suprimento vascular particular e dinâmica celular (TAKAHASHI, 1998). Em fibroblastos pulpares humanos, o reconhecimento microbiano ocorre através dos receptores TLR2, TLR3 e TLR4, acarretando na produção de citocinas como IFN- $\gamma$, quimiocinas como CXCL10 e a cicloxigenase 2 (COX-2) (HIRAO et al., 2009; HIRAO et al., 2010; PARK et al., 2010; KELLER et al., 2010; NAHUM et al., 2012).

Os receptores do tipo Toll 2 e 4 são os principais responsáveis pelo reconhecimento de $C$. albicans (NETEA et al., 2002; NETEA et al., 2004; VILLAMÓN et al., 2004; GIL; GOZALBO, 2006). Camundongos com ausência de receptor do tipo Toll 2 (TLR2 KO) sobrevivem menos à infecção por $C$. albicans do que camundongos normais, apresentando baixa produção de TNF- $\alpha$ e da quimiocina MIP-2. Camundongos com ausência do receptor do tipo Toll TLR4 (TLR4KO) se mostram mais susceptíveis a infecção com C. albicans. Essa susceptibilidade está relacionada com a baixa expressão de quimiocinas e à falha no recrutamento de neutrófilos (VILLAMÓN et al., 2004). Há relatos de que blastoconídios e 
hifas de $C$. albicans diferem no estímulo da resposta do hospedeiro; pois os blastoconídios estimulam ambos os receptores do tipo Toll 2 e 4 e o último é o responsável pela produção de IFN- $\gamma$ por monócitos e de TNF- $\alpha$ por macrófagos peritoniais. Hifas, por sua vez, não são reconhecidas por TLR4 e induzem grande produção de IL-10, por meio de TLR2, mas não a produção de IFN- $\gamma$ (VAN DE GRAAF et. al., 2005).

Os receptores Dectina-1, TLR2 e TLR4 para $\beta$-glucana foram identificados em macrófagos. Macrófagos incubados com C. albicans fagocitam os blastoconídeos, com aumento da produção de TNF- $\alpha$, IFN- $\gamma$, de superóxidos e da capacidade fungicida; no entanto, na fagocitose de hifas, o receptor Dectina-1 não está envolvido e disso resulta uma resposta antinflamatória, com a produção de IL-10, diminuição da produção de superóxidos e da capacidade fagocítica (GANTNER; SIMMONS; UNDERHILL, 2005).

Considerando que TLRs e a molécula adaptadora MyD88 têm papel relevante na ativação de células da imunidade, dentre elas os fibroblastos, a avaliação do envolvimento de tais receptores no reconhecimento de $C$. albicans por fibroblastos gengivais e pulpares trariam importante contribuição para o entendimento da resposta inflamatória nas Periodontopatias e Periapicopatias. 



\section{Proposição}





\section{Objetivo Geral:}

Avaliar o reconhecimento de Candida albicans por fibroblastos gengivais e pulpares.

\section{Objetivos específicos:}

2.1. Estabelecer cultura de fibroblastos gengivais e pulpares de camundongos C57BL/6 (WT), TLR2KO, MyD88KO e CD14KO;

2.2. Analisar o fenótipo de fibroblastos de camundongos C57BL/6 (WT), TLR2KO, MyD88KO e CD14KO;

2.3. Analisar a expressão de moléculas de superfície por fibroblastos gengivais após a estimulação com agonistas de TLR2, TLR4 e Candida albicans;

2.4. Analisar a resposta proliferativa de fibroblastos gengivais e pulpares após a estimulação com agonistas de TLR2, TLR4 e Candida albicans;

2.5. Avaliar a produção das citocinas TGF- $\beta$, IL- $1 \beta$, TNF- $\alpha$, IL-13 e IL-6 por fibroblastos gengivais e pulpares após a estimulação com agonistas de TLR2, TLR4 e Candida albicans. 

Material e Métodos 



\section{Cultura de Candida albicans}

As amostras de Candida albicans foram gentilmente cedidas pelo Laboratório de Imunologia II da Faculdade de Odontologia da Universidade Estadual Paulista (UEL), e são provenientes de pacientes imunodeprimidos infectados com o vírus HIV. As amostras foram devidamente identificadas por métodos microbiológicos e bioquímicos convencionais (Wild Heerbrugg, Switzerland, MS 23358). No laboratório, Candida albicans foi mantida por repiques sucessivos em tubos contendo meio Ágar-Sabouraud-Dextrose (DIFCO ${ }^{\circledR}$ Becton Dickson Company, San Jose, USA) acrescido de cloranfenicol (50 mg/L) e mantidas em estufa a $35^{\circ} \mathrm{C}$ por 48 horas. Após este período, cinco colônias foram isoladas e adicionadas em meio líquido e mantidas em estufa a $35^{\circ} \mathrm{C}$ por 48 horas, sob agitação. Após este período, a suspensão foi centrifugada a $1000 x g$ por 10 minutos a $4^{\circ} \mathrm{C}$. As leveduras foram contadas em câmara de Neubauer e o número ajustado para 5 x $10^{6}$ leveduras $/ \mathrm{mL}$.

\section{Teste de virulência}

A produção de fosfolípase foi verificada utilizando-se o método do ágar gema de ovo em placa, de acordo com estudo realizado por (KANTARCIOGLU; YUCEL, 2002). As placas de Petri foram incubadas a $37^{\circ} \mathrm{C}$ e os diâmetros das colônias e das colônias mais zonas de precipitação foram mensuradas após 7 dias de cultivo. A zona de atividade de fosfolipase (Pz) foi calculada como descrito previamente (PRICE; WILKINSON; GENTRY, 1982), em termos do índice do diâmetro da colônia dividido pelo diâmetro da colônia mais a zona de precipitação. A produção de proteinase foi evidenciada através de halos claros em torno das colônias, em placas de ágar contendo albumina de soro bovina (BSA), conforme Kantarcioglu e Yucel. $\mathrm{O}$ índice $\mathrm{Pz}$ foi determinado da mesma forma que para a fosfolípase (PRICE; WILKINSON; GENTRY, 1982).

\section{Animais de Experimentação}

Foram utilizados 50 camundongos C57BL/6, do tipo selvagem (WT), 50 camundongos geneticamente deficiente de receptores do tipo Toll 2 (TLR2 ${ }^{\mathrm{KO}}$ ), 50 camundongos geneticamente deficientes da molécula $\mathrm{CD} 14\left(\mathrm{CD} 14^{\mathrm{KO}}\right)$ e 50 camundongos geneticamente deficientes do fator de transcrição $\mathrm{MyD} 88\left(\mathrm{MyD} 88^{\mathrm{KO}}\right.$ ), fêmeas, com idade aproximada de seis 
semanas, criados e mantidos no biotério de animais isogênicos da área de Pós-Graduação de Imunologia Básica e Aplicada da Faculdade de Medicina de Ribeirão Preto/USP (FMRP). No decorrer do experimento, os animais eram mantidos em microisoladores com livre acesso à água e ração, com iluminação e temperatura controladas. A pesquisa foi submetida e aprovada pelo Comitê de Ética no Ensino e Pesquisa em Animais da Faculdade de Odontologia de Bauru (CEEPA-Proc. Nº39/2009).

\section{Coleta das amostras}

Para a obtenção de tecido gengival palatino foram realizados cortes nas comissuras labiais dos animais com tesoura cirúrgica para melhor visibilidade do palato. A seguir, a antisepsia da área foi feita com solução bucal à base de clorexidina $0,12 \%$ (PerioGard/Colgate ${ }^{\circledR}$ ) em gazes esterilizadas, seguida de duas incisões na região palatina, uma na mesial e outra na distal dos molares, ambas perpendiculares à linha média. A terceira incisão foi feita paralelamente à linha média, unindo as duas incisões previamente realizadas. $\mathrm{O}$ tecido gengival foi removido com auxílio de curetas, hollembacks e pinças clínicas cirúrgicas. Para o isolamento dos fibroblastos, as biópsias eram colocadas temporariamente em meio de cultura DMEM suplementado com $15 \%$ soro fetal bovino $\left(\right.$ Gibco $^{\circledR}$, Nova Iorque, NY, USA) e imediatamente processadas.

Para a obtenção do tecido pulpar, a mandíbula foi seccionada e colocada em uma placa de Petri, e o tecido aderido foi removido com curetas de Gracey 1/2 (Hu-Friedy ${ }^{\circledR}$, Rio de Janeiro, RJ, Brasil). Com o auxílio de uma lâmina de bisturi n. 15 foi feita uma incisão longitudinal (bordo incisal ao forame apical) para que a polpa fosse removida. Para o isolamento dos fibroblastos as biópsias eram colocadas temporariamente em meio de cultura (DMEM) e imediatamente processadas.

\section{Cultura Primária de Fibroblastos Gengivais e Pulpares}

Para o isolamento dos fibroblastos gengivais e pulpares, as biopsias eram depositadas em placa de petri e levadas ao fluxo laminar. No fluxo laminar, a biopsia era lavada três vezes com meio de cultura DMEM suplementado com 15\% de soro bovino fetal, $100 \mathrm{UI} / \mathrm{L}$ de penicilina, $100 \mu \mathrm{g} / \mathrm{L}$ de estreptomicina $\left(\right.$ Gibco $\left.{ }^{\circledR}\right)$ e $250 \mathrm{ng} / \mathrm{L}$ de anfotericina $\mathrm{B}(\mathrm{Gibco} 囚)$ 
Após este procedimento, as biopsias eram picotadas com tesouras cirúrgicas gerando pequenos fragmentos teciduais (explants) que foram, cuidadosamente, posicionadas em garrafas de cultura com tampa lateral removível (TPP) e realizadas as retenções com lâmina de bisturi para possibilitar a maior aderência dos fragmentos. Os fragmentos foram cultivados em meio de cultura DMEM suplementado e mantidos em estufa a $37^{\circ} \mathrm{C}$ e a $5 \% \mathrm{CO}_{2}$. As culturas foram monitoradas diariamente até a confluência dos fibroblastos e as trocas de meio realizadas a cada 2-3 dias. Os fibroblastos foram repicados até a $4^{\text {a }}$ passagem.

\section{Estimulação de Fibroblastos Gengivais e Pulpares}

Fibroblastos, obtidos como descrito anteriormente, foram distribuídos em placas de 06 poços $\left(5 \times 10^{5}\right.$ células/poço) e cultivados por 12 horas em estufa umidificada a $37^{\circ} \mathrm{C}$ em atmosfera saturada em $5 \%$ de $\mathrm{CO}_{2}$. Após este período, as células foram cultivadas na presença ou ausência de Candida albicans viável e morta na proporção de 1:5 e 1:10, TGFbeta [10ng/ml] (BD Bioscience ${ }^{\circledR}$, San Diego, CA, EUA), PAMP3CSK4 [1 $\left.1 \mu \mathrm{g} / \mathrm{ml}\right]$ $\left(\right.$ InvivoGen $^{\circledR}$, San Diego, CA, EUA) e LPS [100ng/ml] (InvivoGen ${ }^{\circledR}$ ) por 24, 48, 96 e 120 horas em estufa umidificada a $37^{\circ} \mathrm{C}$ em atmosfera saturada em $5 \%$ de $\mathrm{CO}_{2}$ (YANG et al., 2003; SILVA et al., 2009). As células permaneceram em cultura, por diferentes períodos de tempo, de acordo com o procedimento a ser empregado: ensaios de proliferação (48, 96 e 120 horas), fenotipagem por citometria de fluxo e imunofluorescência (24 horas), e obtenção de sobrenadante para a dosagem de citocinas por ELISA (24 e 48 horas).

\section{Anticorpos usados para Citometria de Fluxo}

Foram utilizados anticorpos monoclonais purificados ou conjugados à ficoeritrina (PE) e isotiocianato de fluoresceína (FITC), para os ensaios de fenotipagem por citometria de fluxo e imunofluorescência. Os anticorpos usados foram: $\alpha$-mouse-CD14, $\alpha$-CD282, $\alpha$-CD44, $\alpha$ CD54, $\alpha$-CD283, $\alpha-C D 284$ todos provenientes da BD Bioscience. 


\section{Citometria de fluxo para a análise de expressão de moléculas de superfície}

A análise fenotípica de fibroblastos foi realizada por citometria de fluxo conforme protocolo padrão. As células ( 1 x $10^{6}$ células) foram lavadas e incubadas em meio RPMIsuplementado com $20 \%$ de soro de coelho e $5 \%$ de albumina sérica bovina (para bloqueio de ligações inespecíficas), por 60 minutos a $4^{\circ} \mathrm{C}$. Em seguida, 1,5 $\mu \mathrm{g}$ de anticorpo específico foi adicionado e, incubado por 30 minutos a $4^{\circ} \mathrm{C}$. Após a incubação com os anticorpos, as amostras foram lavadas duas vezes com PBS, sendo centrifugadas a 250 g por 10 minutos e armazenadas em $100 \mu \mathrm{L}$ de PBS formol a $4^{\circ} \mathrm{C}$ por 3 dias. As amostras foram adquiridas em FACScan (Becton and Dickson, San Jose, CA USA) utilizando o canal de fluorescência 1 (FL1) para os anticorpos marcados com FITC e o canal de fluorescência 2 (FL2) para os marcados com PE. As análises foram feitas usando programas Cell Quest (Becton and Dickson) e Win Midi (Joseph Trotter) os quais permitiram analisar todas as células adquiridas (10.000/amostra), ou apenas determinadas populações individualizadas por janelas ("gates") estabelecidas com base em parâmetros de tamanho (FSC), granulosidade (SSC) ou fluorescência (FL).

\section{Análise Fenotípica das células através do Ensaio de Imunofluorescência}

A análise foi realizada sobre lâminas com câmara de 8 poços (Lab-Tek, Hatfield, PA, EUA) onde os fibroblastos foram cultivados como descrito no item 5. A reação de imunofluorescência iniciava-se com o descongelamento das lâminas, à temperatura ambiente por 30 minutos. Logo em seguida, as lâminas eram pós-fixadas com acetona $100 \%$ a -20C, por 10 minutos, e lavados em PBS (pH 7,2). Todas as lavagens eram realizadas por dez vezes consecutivas.

Posteriormente, seguia-se o bloqueio de ligações inespecíficas, por meio da incubação das lâminas com soro de leite a 3\% em água destilada (leite desnatado Molico) por 20 minutos. Em seguida, dispensando-se dessa vez as lavagens, as laminas foram incubadas com os anticorpos primários, em câmara úmida, em temperatura de 4C por uma noite.

Os anticorpos utilizados foram os seguintes: anticorpo monoclonal de anti-colágeno Tipo I (Millipore ${ }^{\circledR}$ Corporation, Billerica, MA, USA), e anti-actina, na diluição 1/100. Todos os anticorpos foram diluídos em PBS. Após esse período, realizaram-se as lavagens 
consecutivas e, posteriormente, a incubação, à temperatura ambiente por 45 minutos, com o anticorpo marcado com fluorocromo (1/200 em PBS) correspondentes: anticorpo de anti-IgG de coelho (Vector Laboratories ${ }^{\circledR}$, Burlingame, CA, USA) marcado com Alexa Flúor 488, (Fluorocromo FITC). Posterior às lavagens consecutivas com PBS, procedeu-se a adição de $100 \mathrm{uM}$ de 4,6-diamidino-2-fenilindole, dihidroclorídrico (DAPI, Vector Laboratories), substância que marca o DNA, $50 \mathrm{uL}$ por poço, por 5 minutos. As lâminas foram montadas com o Kit de Montagem (Vector Laboratories), deixadas secar e fotografadas no dia seguinte. As lâminas foram analisadas em microscópio Confocal TCS-SPE (Leica Microsystems, Alemanha) com aumento de 63X, e as imagens processadas usando o software SlideBook (Intelligent Immaging Innovations, Inc., Denver, CO).

\section{Ensaio de proliferação}

Para determinar a proliferação de fibroblastos gengivais e pulpares, as células foram incubadas com 1,25 $\mu \mathrm{M}$ de CFSE (diacetato/succinimidil éster de carboxifluoresceína, Molecular Probes, Invitrogen ${ }^{\circledR}$, Burlington, Canada) e distribuídas em placas de 6 poços $\left(5 \times 10^{5}\right.$ células/poço). Em seguida, os fibroblastos foram cultivados com LPS (100ng/ml), PAM3CSK4 (1 $\mu \mathrm{g} / \mathrm{ml}), C$. albicans nas proporções 1:5, 1:10 e 1:50. Após a cultura, as células foram lavadas duas vezes e resuspensas em $300 \mu \mathrm{L}$ de meio RPMI. Após este procedimento, as células foram imediatamente adquiridas em FACS Callibur ${ }^{\mathrm{TM}}$ (BD Immunocytometry Systems, Franklin Lakes, NJ) utilizando o canal de fluorescência 1 (FL1) para CFSE. As análises foram feitas usando programas Cell Quest (Becton and Dickson) e Win Midi (Joseph Trotter) os quais permitem analisar todas as células adquiridas (100.000/amostra), ou apenas determinadas populações, individualizadas por janelas ("gates") estabelecidas com base em parâmetros de tamanho (FSC), granulosidade (SSC) ou fluorescência (FL).

\section{Ensaio imunoenzimático (ELISA) para dosagem de citocinas}

A presença das citocinas IL-13 (eBioscience San Diego, CA,USA) e TGF- $\beta$, TNF- $\alpha$, IL-6, IL-1 $\beta$ foi determinada no sobrenadante das culturas por ELISA (Opteia, BD Bioscience, EUA). Para tanto, placas de 96 poços foram recobertas com o respectivo anticorpo primário diluído em Coating Buffer e incubadas durante 18h em geladeira. Após o tempo de 
incubação, as placas foram lavadas com PBS + Tween 20 (BD Bioscience $\left.{ }^{\circledR}\right)(0,05 \%)$ e bloqueadas durante $2 \mathrm{~h}$, em temperatura ambiente, com Assay diluent (BD Bioscience). As placas foram lavadas com PBS+Tween e incubadas com quantidades conhecidas de recombinante durante $18 \mathrm{~h}$ a $4^{\circ} \mathrm{C}$. Após este período, as placas foram novamente lavadas e incubadas com anticorpo biotinilado e estreptavidina diluídas em Assay diluent por $2 \mathrm{~h}$ em temperatura ambiente. As placas foram lavadas novamente e o substrato peróxido de hidrogênio e tetrametilbenzidina na proporção de 1:1 (BD Bioscience) foi adicionado conforme as instruções do fabricante. Após 30 minutos, a solução de paralisação da reação (ácido sulfúrico $4 \mathrm{~N}$ ) foi adicionada e a leitura foi realizada em espectrofotômetro ajustado para o comprimento de onda de 450nm (Bio-Rad, EUA).

\section{Análise estatística}

Os resultados foram expressos como média \pm desvio padrão (SD) dos resultados obtidos para cada grupo. A análise estatística foi realizada aplicando-se o teste adequado a cada ensaio utilizando o programa Instat (INSTAT software, Prisma GraphPad 5, EUA). Todos os valores foram considerados significativos quando $P<0,05$. 


\section{Resultados}





\section{Caracterização morfológica e fenotípica de fibroblastos gengivais e pulpares}

Mesmo utilizando células cultivadas em meio seletivo para fibroblastos (DMEM), e que permaneceram em cultura após a quarta passagem, é necessário confirmar a pureza da cultura de fibroblastos. Desta forma, inicialmente analisamos as características morfológicas das células isoladas de tecido gengival e pulpar de camundongos do grupo controle (WT), TLR2KO, CD14KO e MyD88KO (Figura 1 e 2).

Os fibroblastos isolados do tecido gengival de camundongos do grupo controle (WT), TLR2KO e CD14KO apresentaram velocidade de crescimento maior que fibroblastos de animais MyD88KO (Figura 1). Após quatro dias de cultura, observou-se que os fibroblastos gengivais emergiram dos fragmentos de camundongos do grupo controle (WT), TLR2KO e CD14KO. Enquanto que no grupo MyD88KO observou-se o aparecimento das células sete dias após o início da cultura. Após 10 dias de cultura primária, realizou-se a primeira subcultura de fibroblastos do grupo controle (WT), TLR2KO e CD14KO. De modo contrário, os fibroblastos de animais MyD88KO cresceram mais lentamente e a primeira subcultura foi realizada apenas 20 dias após o início do cultivo.

Em relação à análise dos fibroblastos pulpares, os resultados evidenciaram que estas células apresentaram surgimento e proliferação celular extremamente lentos, quando comparadas com fibroblastos gengivais, contudo, não foram observadas diferenças significativas nestes parâmetros quando comparamos os fibroblastos pulpares isolados de animais do grupo controle e deficientes de CD14. Fibroblastos pulpares provenientes do grupo TLR2 e MyD88KO não entraram em confluencia e, por permanecerem um longo período em cultura as células ficavam vacuolizadas e senescentes. A baixa proliferação dos fibroblastos pulpares influenciou na realização de alguns experimentos.

As fotomicrografias apresentadas na Figura 2 demonstram a presença de fibroblastos exibindo formato fusiforme com núcleo central e típicos prolongamentos citoplasmáticos. Não foram observadas diferenças morfológicas entre os fibroblastos isolados de camundongos do grupo controle e deficientes para as moléculas TLR2 e CD14 e o fator de transcrição MyD88, ao longo do tempo. Referente à confluência celular, não foi observada diferenças significativas entre as células quanto ao empilhamento, distribuição ou morte celular. 


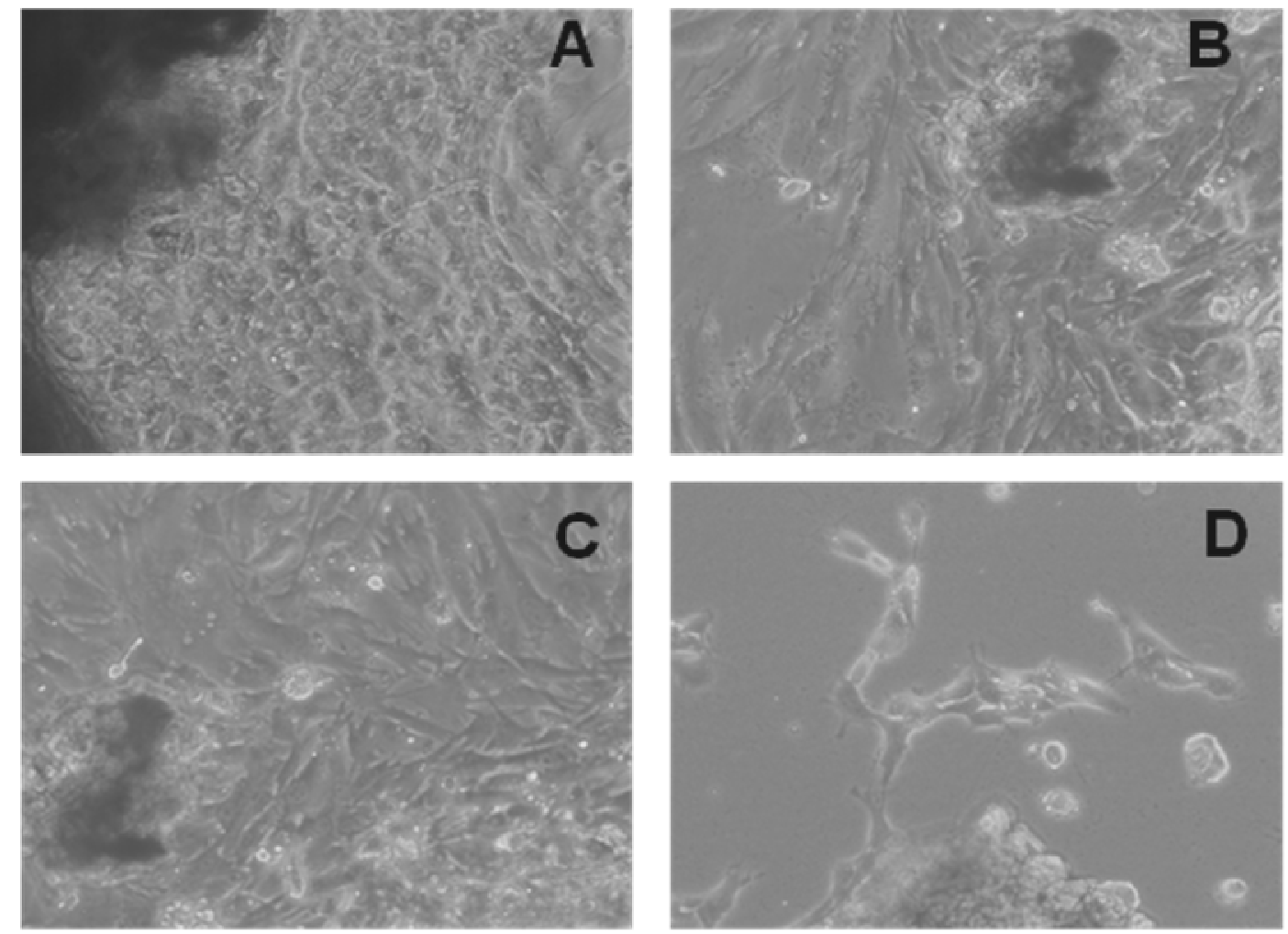

Figura 1 - Fotomicrografias de fibroblastos gengivais. Cultura primária de fibroblastos gengivais de camundongos do grupo controle (WT) (A), TLR2KO (B), CD14KO (C) e MyD88KO (D) foram analisadas em microscópio de luz. Aumento de 40x. 


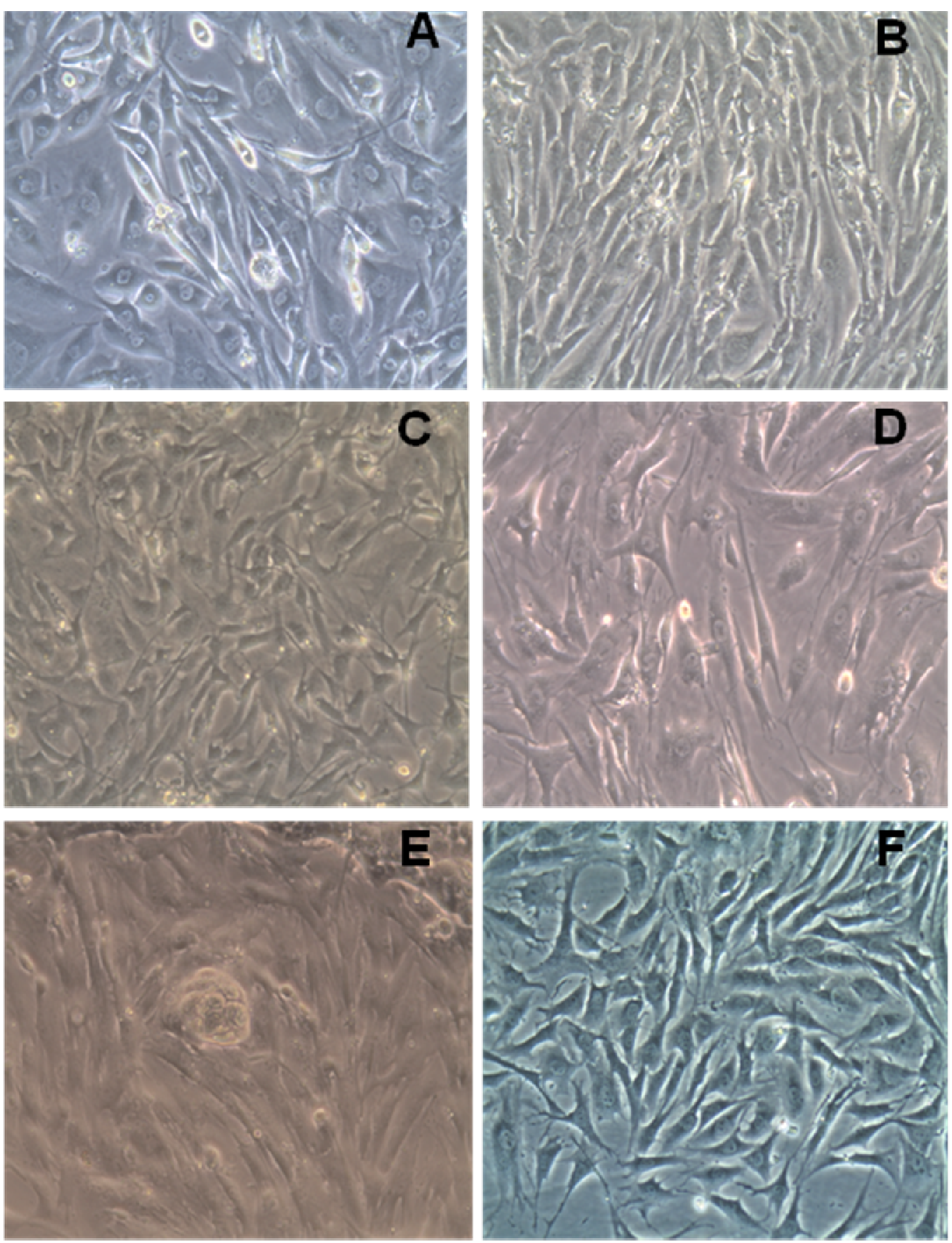

Figura 2 - Fotomicrografias de fibroblastos gengivais e pulpares. Cultura primária de fibroblastos gengivais de camundongos WT (A), TLR2KO (B), CD14KO (C) e MyD88KO (D) e pulpar de camundongos WT (E) e CD14KO (F) foram analisadas em microscópio de luz. Aumento de 40x. 



\subsection{Análise fenotípica de fibroblastos gengivais por microscopia confocal}

Os fibroblastos isolados de diferentes tecidos apresentam variações órgão-específicas sendo que estas variações influenciam a expressão de alguns marcadores de superfície (BARKSBY et al., 2007). Os marcadores de fibroblastos são bem estabelecidos, porém sabese que nenhum deles é exclusivo de fibroblastos e tampouco expresso por todas as linhagens de fibroblastos. Os fibroblastos derivados de tecido gengival são altamente heterogêneos (GUO et al., 2011), com base nessas informações, utilizamos nesse estudo, para identificação de fibroblastos, anticorpos específicos contra actina e colágeno tipo I. A coloração verde representa a positividade para os marcadores testados e a cor azul corresponde à marcação nuclear (DAPI).

Os resultados evidenciaram que fibroblastos gengivais isolados de camundongos do grupo controle (WT), TLR2KO e MyD88KO apresentaram positividade similar para actina e colágeno tipo I (Figura 3). Devido à positividade para este marcador, e possível inferir que as células apresentam características fenotípicas de fibroblastos. 


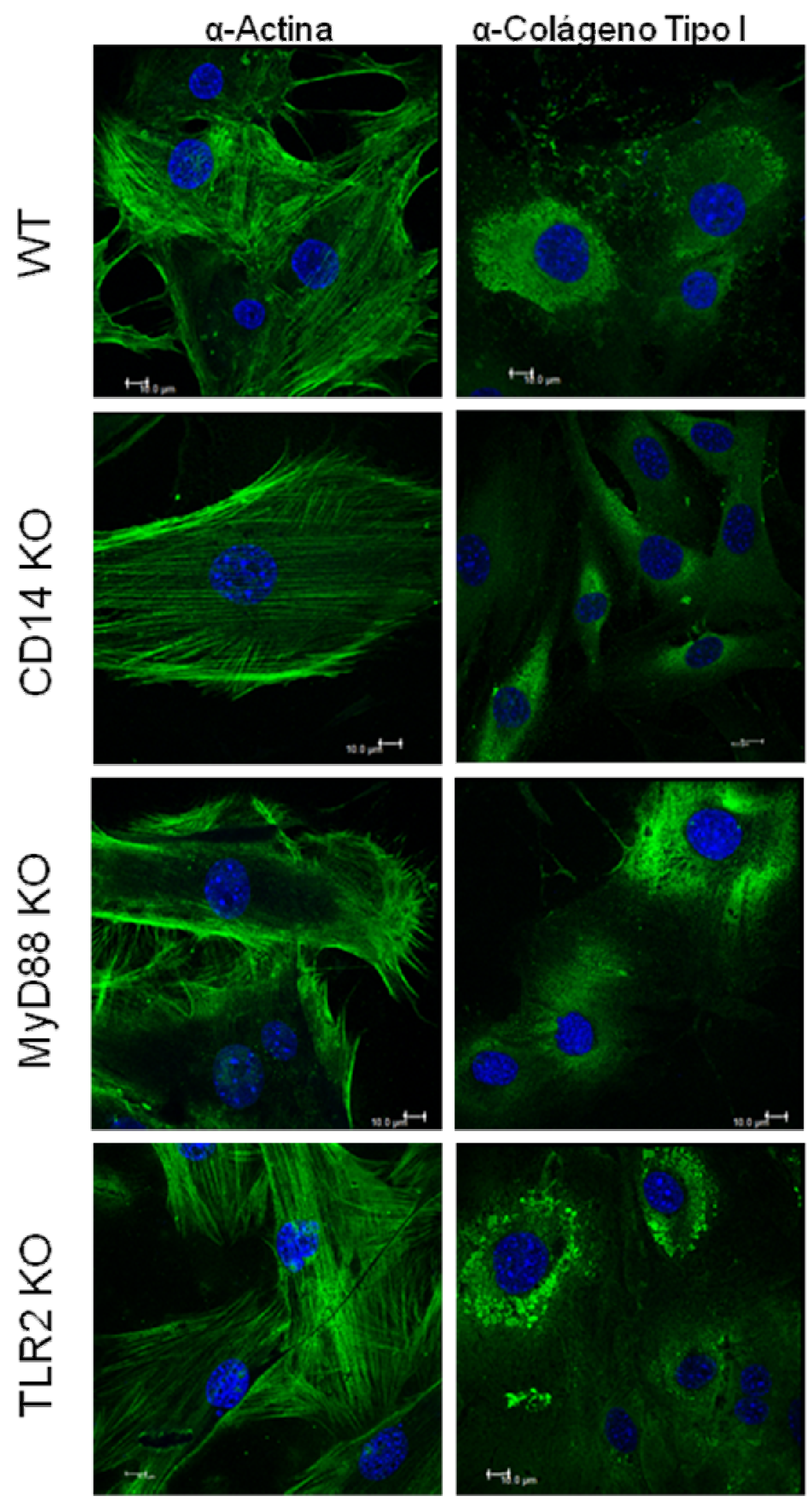

Figura 3 - Fotomicrografias representativas da análise por microscopia confocal do fenótipo de fibroblastos gengivais. Fibroblastos gengivais de camundongos WT, TLR2KO, CD14KO e MyD88KO foram analisadas por imunofluorescência para a detecção de $\alpha$-actina e $\alpha$-colágeno tipo I (verde), como indicado nas imagens. O núcleo foi marcado com DAPI (azul). Barra de escala $=10 \mu \mathrm{m}$. 



\subsection{Análise da expressão de moléculas de superfície por citometria de fluxo}

Após a caracterização morfológica dos fibroblastos, analisou-se o perfil de expressão de moléculas de superfície CD14, CD284 (TLR4), CD54 (ICAM), CD283 (TLR3), CD44 e CD282 (TLR2) por citometria de fluxo. Os resultados demonstraram que há diferenças significativas quanto à expressão destes receptores por fibroblastos gengivais de camundongos do grupo controle e deficientes de TLR2, CD14 e MyD88.

Em relação à expressão de CD282 (TLR2), a percentagem de fibroblastos TLR2 ${ }^{+}$foi maior nas amostras de animais do grupo controle, quando comparada com os dados de animais TLR2KO, CD14KO e MyD88KO (Figura 4A).

A expressão de TLR3 (CD283) foi maior por fibroblastos do grupo controle, MyD88KO e TLR2KO, sendo mais evidente por fibroblastos do grupo MyD88KO (Figura 4B). Fibroblastos gengivais provenientes de animais C14KO apresentaram baixa expressão de TLR3, quando comparado com os outros grupos (Figura 4B).

Em relação à expressão de TLR4 (CD284), baixa percentagem de fibroblastos expressando essa molécula foi detectada no grupo TLR2KO e CD14KO, quando comparado ao controle (Figura 4C). Fibroblastos gengivais provenientes de animais MyD88KO apresentaram maior expressão de TLR4, quando comparado com os outros grupos, porém estes valores não foram significativos (Figura 4C).

Em relação à expressão de CD14, os resultados mostraram que a expressão de CD14 foi significativamente maior por células do grupo controle e TLR2KO em comparação com as dos grupos MyD88KO e CD14KO (Figura 4D).

A análise da expressão de ICAM (CD54) por fibroblastos gengivais evidenciou que não existe diferença significativa na expressão desta molécula por células dos grupos analisados (Figura 5A), mas há uma maior percentagem de fibroblastos gengivais expressando ICAM em amostras do grupo controle e CD14KO.

Em relação à proporção de fibroblastos expressando CD44, observou-se uma percentagem estatisticamente maior de células positivas para essa molécula no grupo CD14KO em comparação ao grupo TLR2KO, MYD88KO e controle (Figura 5B). Fibroblastos isolados de tecido gengival de animais do grupo TLR2 apresentaram alta expressão de CD44, contudo estes valores não foram significativos quando comparado com o grupo controle (Figura 5B). 


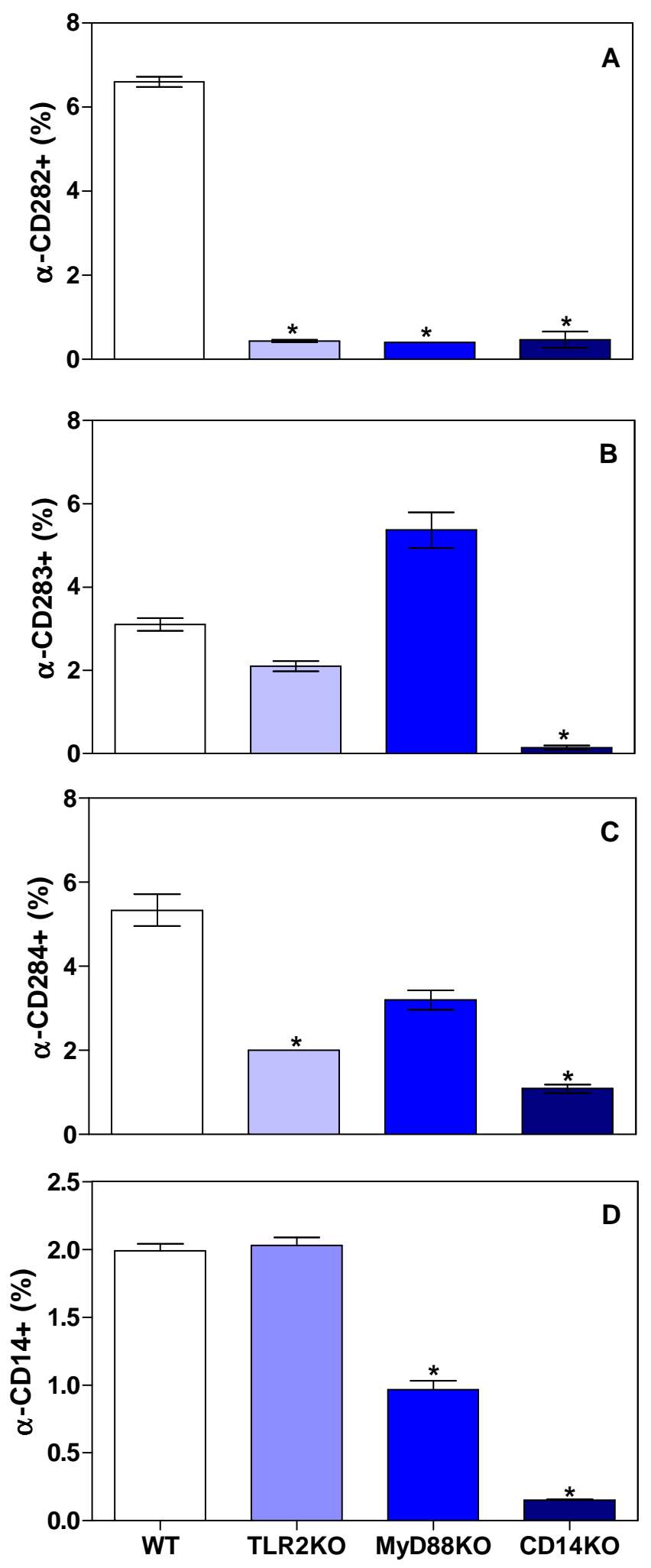

Figura 4 - Análise fenotípica de fibroblastos gengivais por citometria de fluxo. Fibroblastos isolados de camundongos do grupo controle (WT, barra aberta), deficientes de TLR2 (azul claro), MyD88KO (barra azul royal) e CD14KO (barra azul marinho) foram caracterizados por citometria de fluxo. Cada coluna representa a percentagem de células que expressam CD282 (A), CD283 (B), CD284 (C) e CD14 (D). Os dados representam a média SEM dos valores obtidos para grupo analisado individualmente. $* \mathrm{P}<0,005$ : Test de Tukey. 

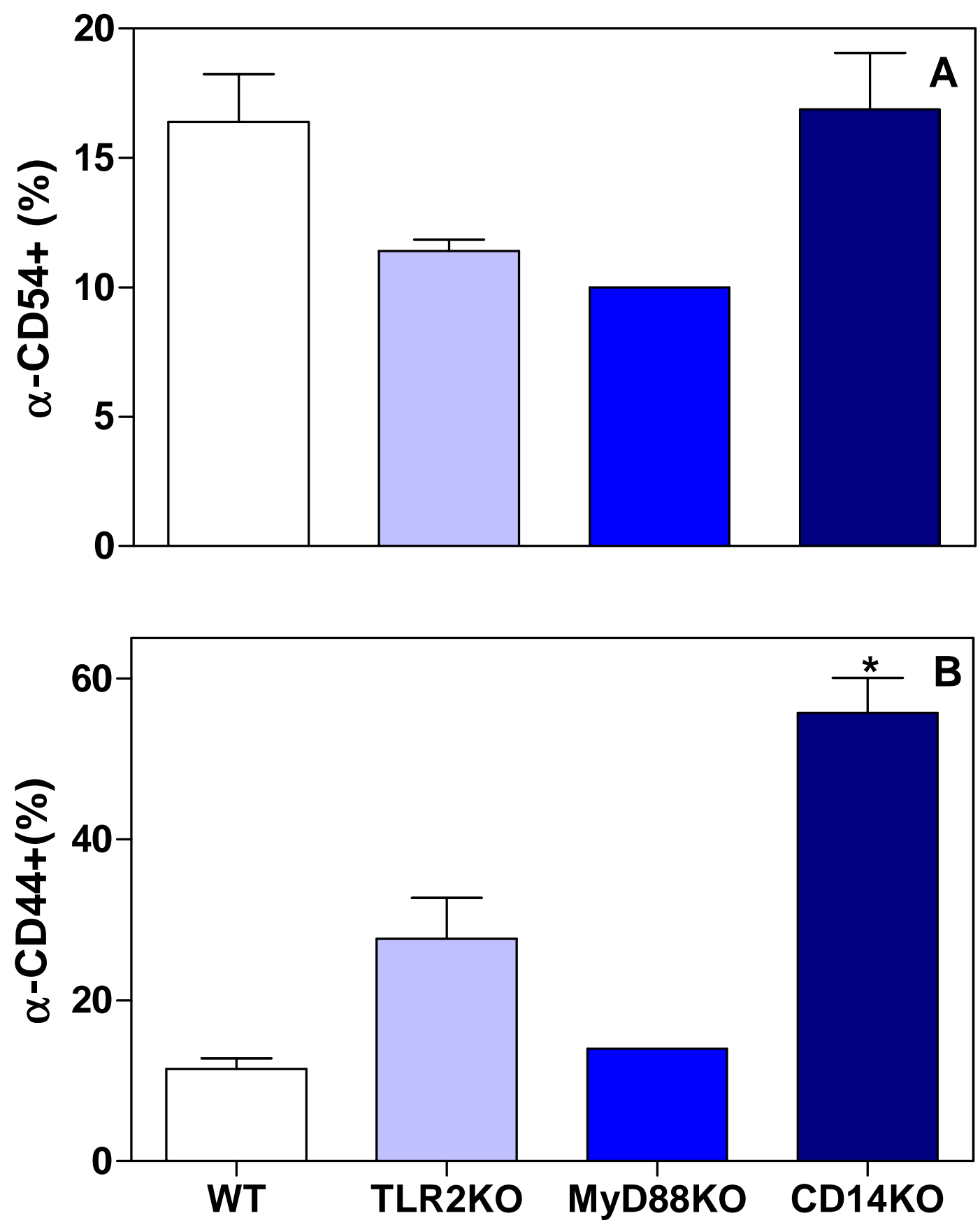

Figura 5 - Análise fenotípica de fibroblastos gengivais por citometria de fluxo. Fibroblastos isolados de camundongos do grupo controle (WT, barra aberta), deficientes de TLR2 azul claro), MyD88KO (barra azul Royal) e CD14KO (barra azul marinho) foram caracterizados por citometria de fluxo. Cada coluna representa a percentagem de células que expressam CD54 (ICAM) (A) e CD44 (B). Os dados representam a média SEM dos valores obtidos para grupo analisado individualmente. ${ }^{*} \mathrm{P}<0,005$ : Test de Tukey. 
2. Avaliação dos efeitos de agonistas de TLR2, TLR4 e Candida na ativação de fibroblastos gengivais e pulpares.

\subsection{Análise da expressão de moléculas de superfície por fibroblastos gengivais após a estimulação com agonistas de TLR2, TLR4 e Candida albicans.}

Com o intuito de avaliar o envolvimento de receptores de reconhecimento de patógenos e da proteína adaptadora MyD88 no reconhecimento de C. albicans; fibroblastos de camundongos dos grupos controles (WT), TLR2KO, MyD88KO e CD14KO foram cultivados por 24hs na presença de Candida. Em seguida, a expressão de CD282 (TLR2), CD283 (TLR3), CD284 (TLR4), CD54 (ICAM) e CD44 foram avaliadas por citometria de fluxo.

Em relação à expressão de TLR2 (CD282) (Figura 6), os resultados revelaram que a estimulação com LPS, Pam3C e C. albicans viva (1:5) induziram significativamente aumento na percentagem de fibroblastos $\mathrm{TLR}^{+}$em amostras do grupo controle (Figura 6A). A estimulação com Candida morta (1:10) induziu um leve aumento na percentagem de fibroblastos expressando TLR2 ${ }^{+}$em amostras do grupo controle (WT) (Figura 6A), mas este valor não foi significante, quando comparado com as células cultivadas apenas na presença de meio. Os resultados evidenciaram baixa percentagem de fibroblastos TLR2 ${ }^{+}$em amostras provenientes de animais TLR2KO, MyD88KO e CD14KO após a estimulação com todos os antígenos testados (Figura 6). A estimulação com TGF- $\beta$ não induziu a alteração na percentagem de células expressando TLR2 (Figura 6). 

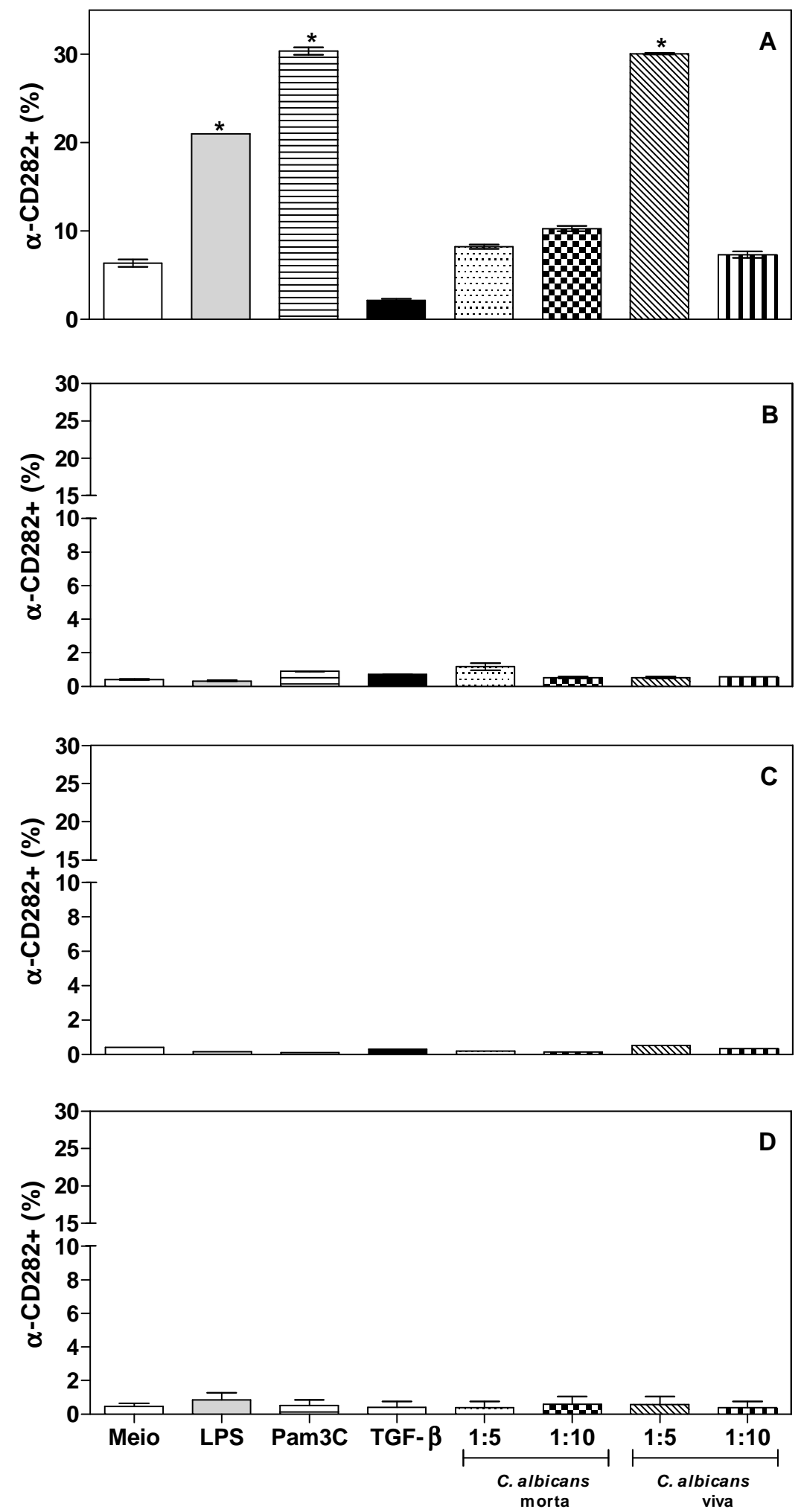

Figura 6 - Expressão de TLR2 após a estimulação com agonistas de TLR2, TLR4 e Candida albicans. Fibroblastos gengivais de camundongos do grupo controle (WT) (A), TLR2 KO (B), MyD88 KO (C) e CD14 KO (D) foram cultivados com LPS (100ng/ml), PAM3C $(1 \mu \mathrm{g} / \mathrm{ml})$, TGF- $\beta(10 \mathrm{ng} / \mathrm{ml}), C$. albicans viva, $C$. albicans morta nas proporções $1: 5$ e 1:10. Após 24 horas, a percentagem de células que expressam TLR2 (CD282) foi avaliada por citometria de fluxo. Dados representativos de três experimentos independentes. Os resultados foram avaliados pelo teste de ANOVA seguido pelo teste de Bonferroni. ${ }^{*} \mathrm{p}<0,05$. 
Em relação à expressão de TLR3 (CD283) (Figura 7), os dados revelaram que a estimulação com Pam3C (agonista de TLR2) induziu aumento significativo na percentagem de células expressando TLR3 em amostras do grupo controle e do grupo MYD88KO (Figura 7A e 7C). LPS e TGF- $\beta$ induziram aumento da percentagem de fibroblastos $\mathrm{TLR}^{+}$em amostras do grupo controle, mas este aumento não foi significativo (Figura 7A). A estimulação com Candida morta (1:5) induziu aumento significativo da percentagem de fibroblastos $\mathrm{TLR}^{+}$em amostras provenientes de camundongos TLR2KO (Figura 7B). De modo diferente, a estimulação com Candida viva induziu aumento significativo na expressão deste receptor por células de animais MyD88KO (Figura 7C). Os resultados evidenciaram ainda baixa percentagem de fibroblastos $\mathrm{TLR}^{+}$em amostras de animais CD14KO (Figura 7D).

Os resultados revelaram que a estimulação com $C$. albicans viva (1:5) e C. albicans morta (1:10) diminuiu significativamente percentagem de fibroblastos TLR4 ${ }^{+}$(CD284) (Figura 8) em amostras do grupo controle, quando comparado com as células cultivadas apenas na presença de meio (Figura 8A). A estimulação com $C$. albicans viva (1:5) inibiu a expressão de TLR4 por fibroblastos de animais TLR2KO (Figura 8B), enquanto que $C$. albicans viva (1:10) estimulou a expressão dessa molécula. Pam3C induziu aumento na percentagem de células expressando TLR4 em amostras de animais MyD88KO, enquanto LPS induziu aumento na percentagem de células expressando TLR4 em amostras de animais CD14KO, mas estes valores não foram significativos. Os dados revelaram que a estimulação com os antígenos não alterou significantemente a percentagem de fibroblastos TLR $4^{+}$em amostras de camundongos do grupo MyD88KO e CD14KO (Figura 8C e 8D). 

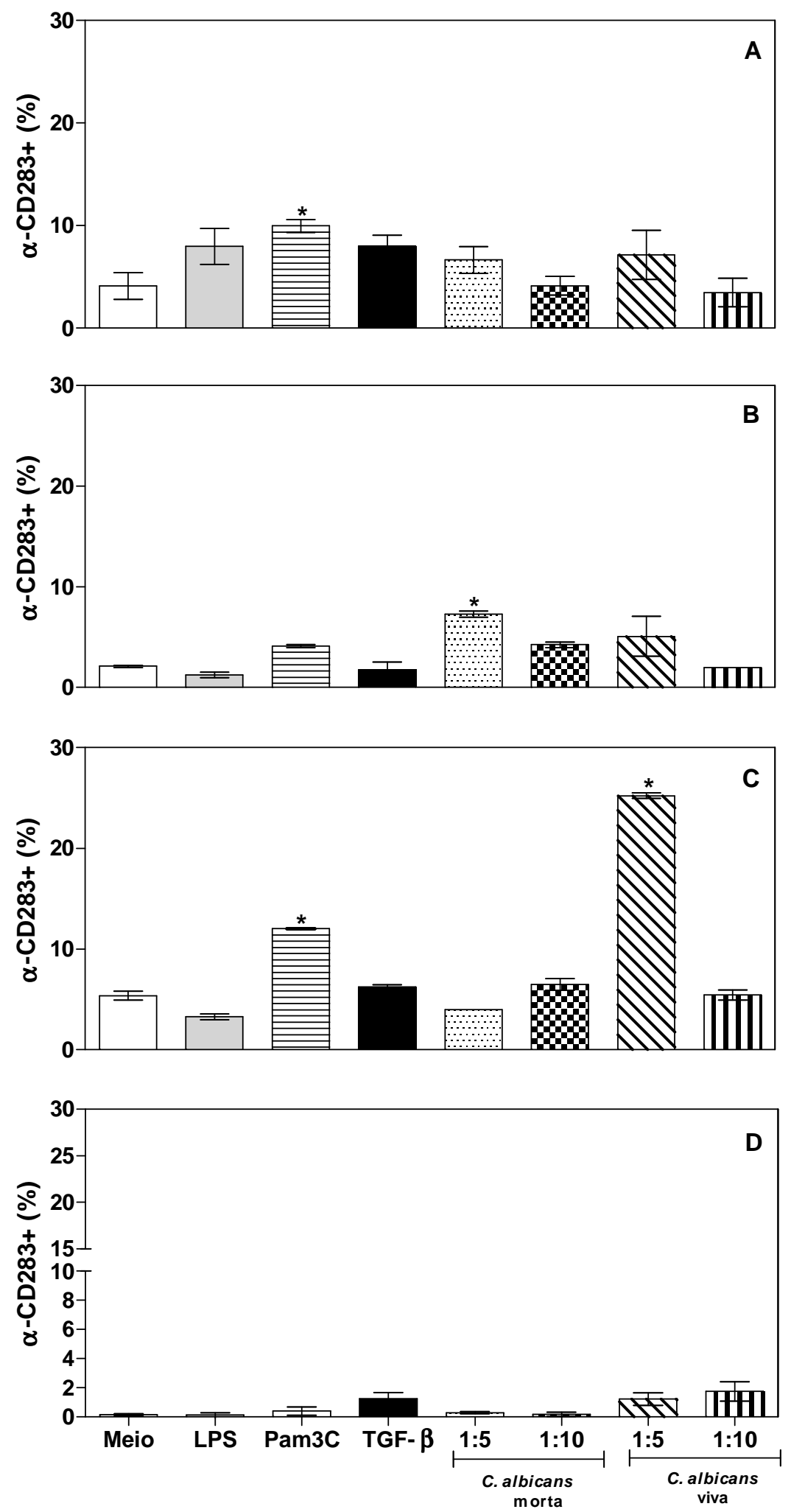

Figura 7 - Expressão de TLR3 após a estimulação com agonistas de TLR2, TLR4 e Candida albicans. Fibroblastos gengivais de camundongos do grupo controle (WT) (A), TLR2 KO (B), MyD88 KO (C) e CD14 KO (D) foram avaliados por citometria quanto à expressão TLR3 (CD283). Dados representativos de três experimentos independentes. Os resultados foram avaliados pelo teste de ANOVA seguido pelo teste de Bonferroni. ${ }^{*} \mathrm{p}<0,05$. 

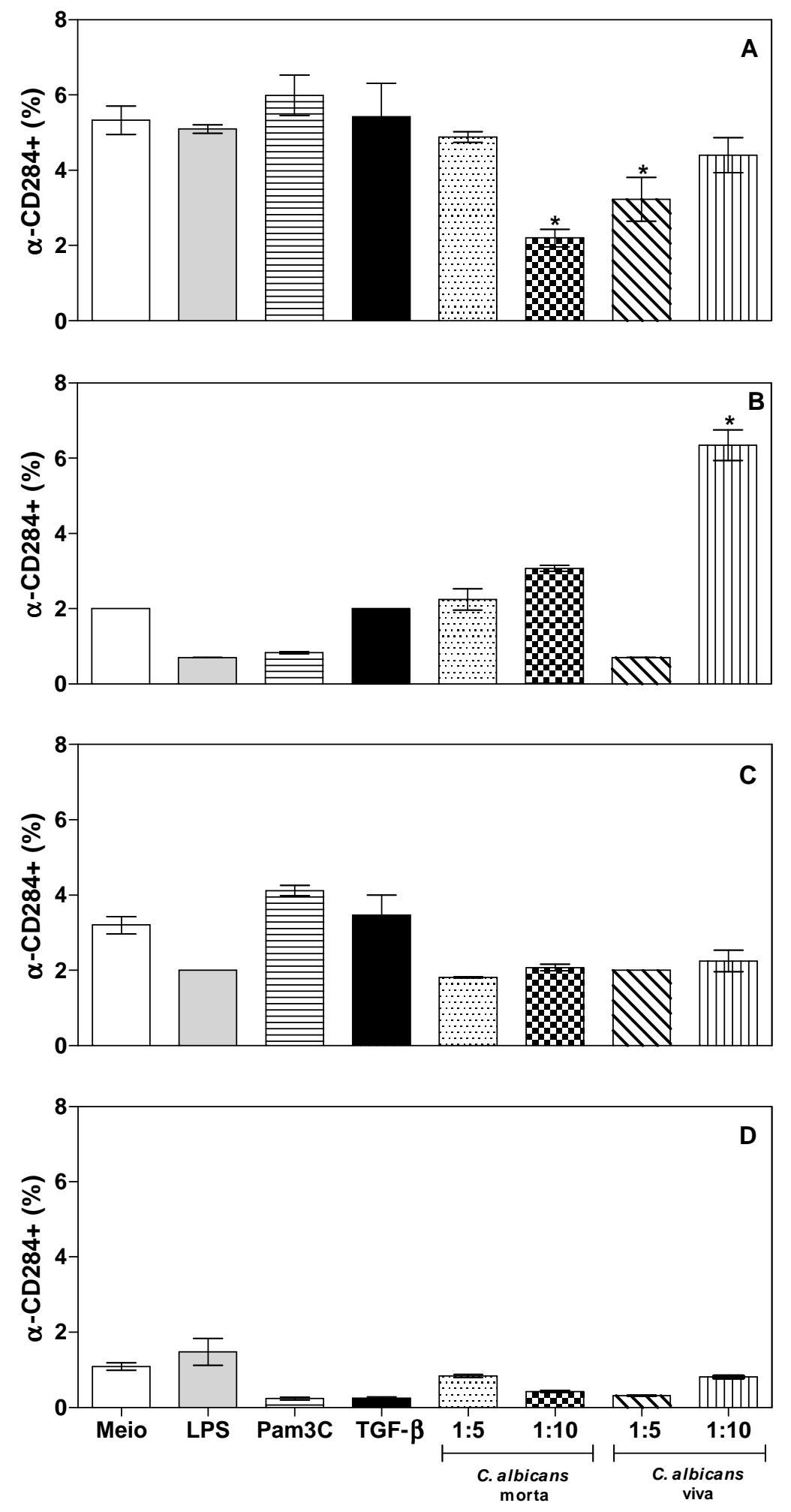

Figura 8 - Expressão de TLR4 após a estimulação com agonistas de TLR2, TLR4 e Candida albicans. Fibroblastos gengivais de camundongos do grupo controle (WT) (A), TLR2KO (B), MyD88KO (C) e CD14KO (D) foram avaliados por citometria quanto à expressão TLR4 (CD284). Dados representativos de três experimentos independentes. Os resultados foram avaliados pelo teste de ANOVA seguido pelo teste de Bonferroni. ${ }^{*} \mathrm{p}<0,05$. 
Os resultados mostraram que LPS induziu a expressão de ICAM-1 por fibroblastos do grupo controle (Figura 9A) e TLR2KO (Figura 9B), não se detectando diferenças significantes entre os grupos após o estimulo com os diferentes antígenos testados (Figura 9).

Em relação à expressão de CD44 (Figura 10), os resultados evidenciaram que Pam3C induziu aumento significativo na percentagem de células expressando CD44 apenas em amostras do grupo controle (Figura 10A). C. albicans morta (1:5) induziu aumento na percentagem de fibroblastos $\mathrm{CD} 44^{+}$em amostras do grupo controle e diminuiu a percentagem de células positivas para este marcador em amostras do grupo TLR2KO (Figura 10A e 10B). A estimulação com $C$. albicans viva (1:5) diminuiu a percentagem de fibroblastos $\mathrm{CD} 44^{+} \mathrm{em}$ amostras do grupo TLR2KO e CD14KO (Figura 10B e 10D). De modo relevante, a estimulação com LPS levou a diminuição na percentagem de fibroblastos CD44 ${ }^{+}$em amostras de animais CD14KO. A estimulação com TGF- $\beta$ não alterou significantemente a percentagem de fibroblastos $\mathrm{CD}_{4} 4^{+}$em todas as amostras analisadas (Figura 10). 

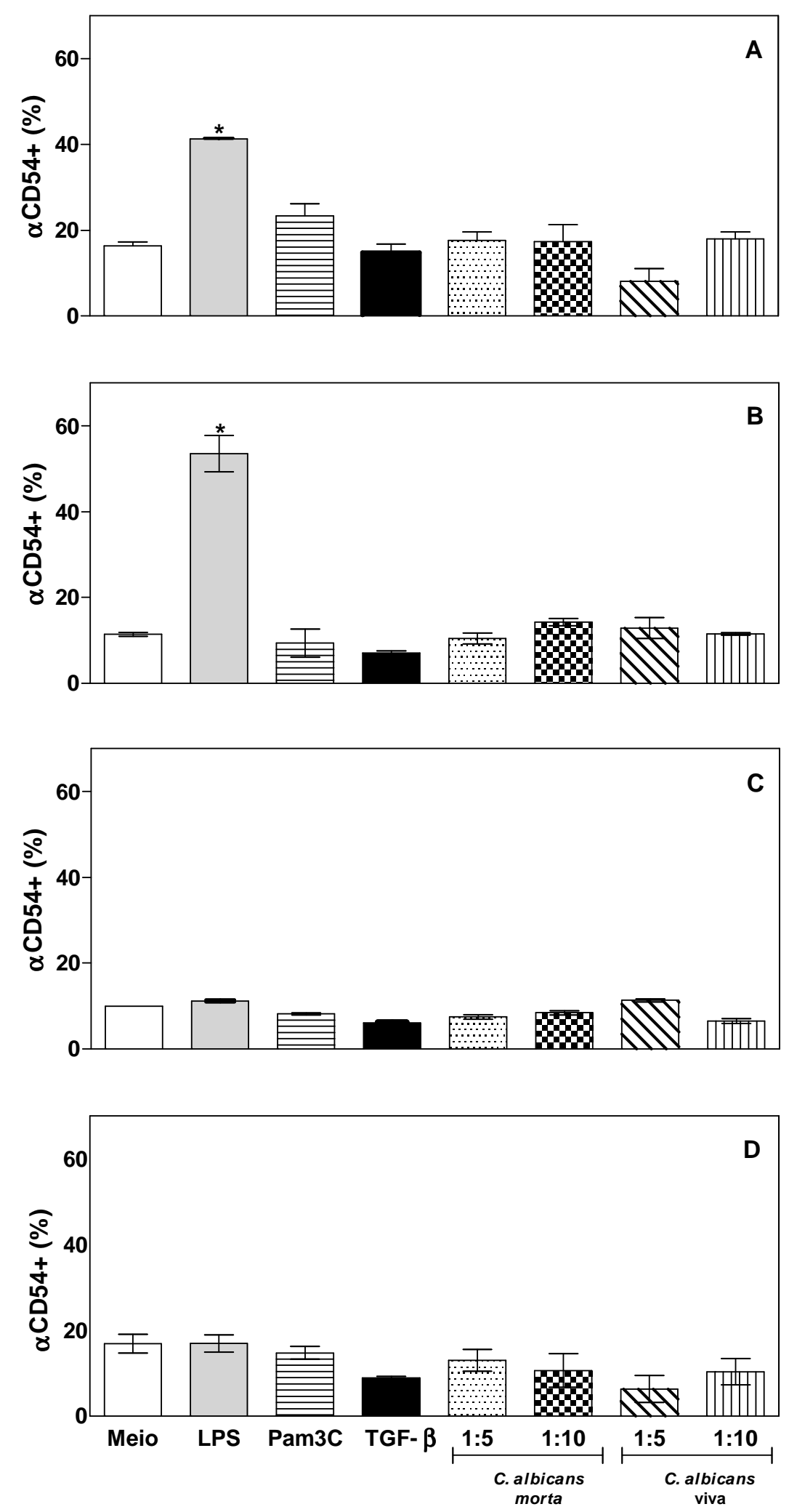

Figura 9 - Expressão de ICAM após a estimulação com agonistas de TLR2, TLR4 e Candida albicans. Fibroblastos gengivais de camundongos do grupo controle (WT) (A), TLR2KO (B), MyD88KO (C) e CD14KO (D) foram avaliados por citometria quanto à expressão ICAM (CD54). Dados representativos de três experimentos independentes. Os resultados foram avaliados pelo teste de ANOVA seguido pelo teste de Bonferroni. *p<0,05. 

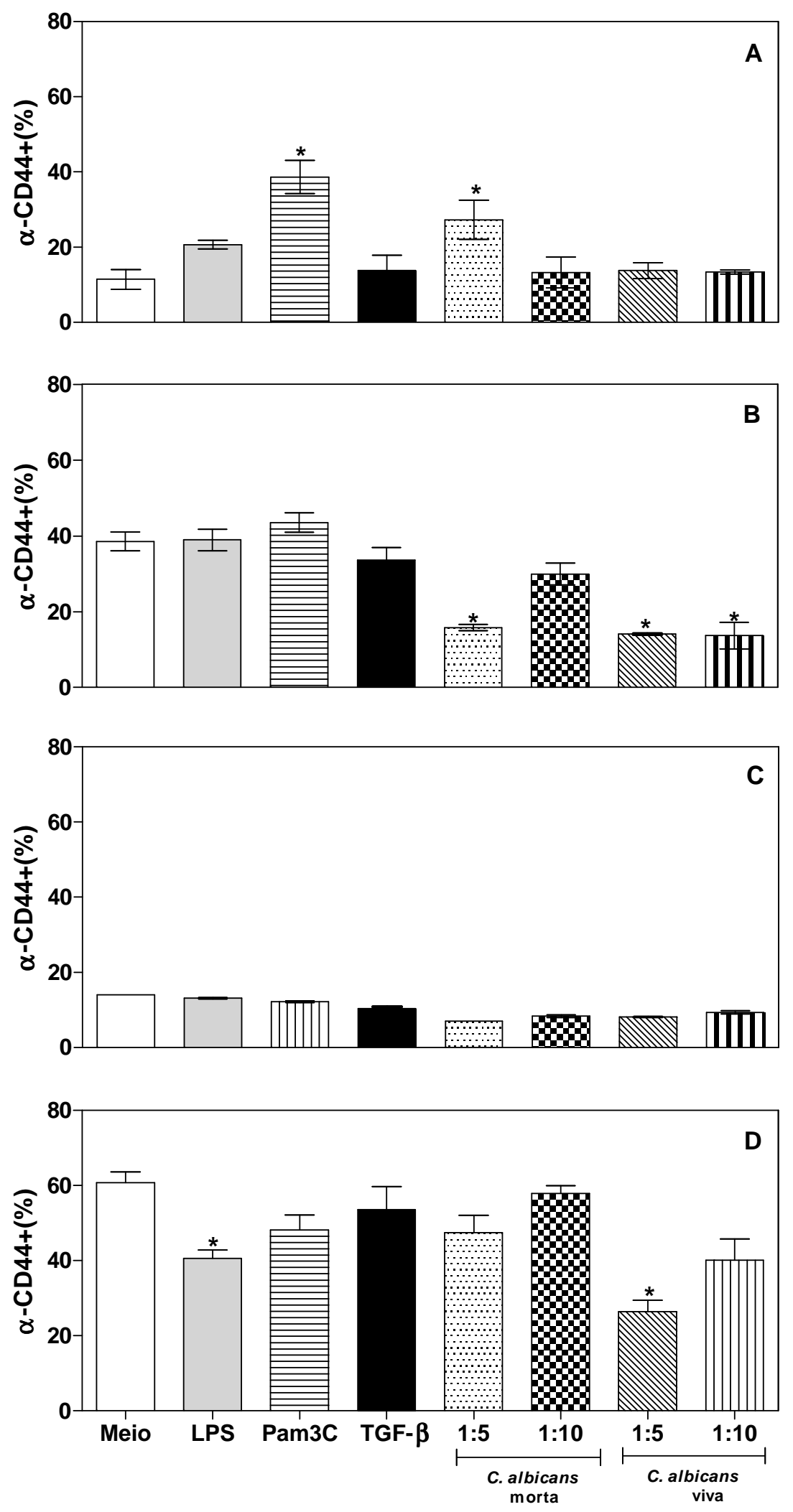

Figura 10 - Expressão de CD44 após a estimulação com agonistas de TLR2, TLR4 e Candida albicans. Fibroblastos gengivais de camundongos do grupo controle (WT) (A), TLR2KO (B), MyD88KO (C) e CD14KO (D) foram avaliados por citometria de fluxo quanto à expressão de CD44. Dados representativos de três experimentos independentes. Os resultados foram avaliados pelo teste de ANOVA seguido pelo teste de Bonferroni. ${ }^{*} \mathrm{p}<0,05$. 


\subsection{Proliferação de fibroblastos gengivais após a estimulação com agonistas de TLR2, TLR4 e Candida albicans.}

Relatos na literatura têm demonstrado que fibroblastos gengivais apresentam alta resposta proliferativa frente a antígenos. Para avaliar o perfil da resposta proliferativa, fibroblastos de camundongos do grupo controle (WT), TLR2KO, MyD88KO e CD14KO foram marcados com CFSE, um marcador fluorescente, e distribuídos em placas de seis poços ( $5 \times 10^{5}$ células/poço). As células foram cultivadas por até $120 \mathrm{~h}$ com LPS, Pam3C e $C$. albicans morta e a análise da resposta proliferativa foi realizada por citometria de fluxo.

Os resultados evidenciaram que ao longo do tempo houve aumento na proliferação de fibroblastos gengivais de todos os grupos analisados (Figura 11). Contudo, a ausência do receptor TLR2 em fibroblastos gengivais (TLR2KO) pode ter interferido no potencial proliferativo destas células (Figura 11B). Os resultados evidenciaram baixa resposta proliferativa após 48 e 96 horas, em comparação com os outros grupos analisados (Figura 11).

A estimulação com LPS e Pam3C não induziu alterações significativas na resposta proliferativa de fibroblastos do grupo controle, TLR2KO, MyD88KO e CD14KO (Figura 11). A estimulação com leveduras de Candida morta induziu alterações no perfil proliferativo dos fibroblastos, sendo que as maiores diferenças foram observadas na cultura de células provenientes de animais TLR2KO (Figura 11B). Após 96h de estimulação, os resultados evidenciaram maior resposta proliferativa de fibroblastos TLR2KO após o estímulo com $C$. albicans na proporção 1:50 (Figura 11B). Considerando as diferenças entre os grupos, podese constatar que a ausência da TLR2 interfere na capacidade de proliferação dos fibroblastos e que $C$. albicans (1:50) modula positivamente a ativação destas células. 

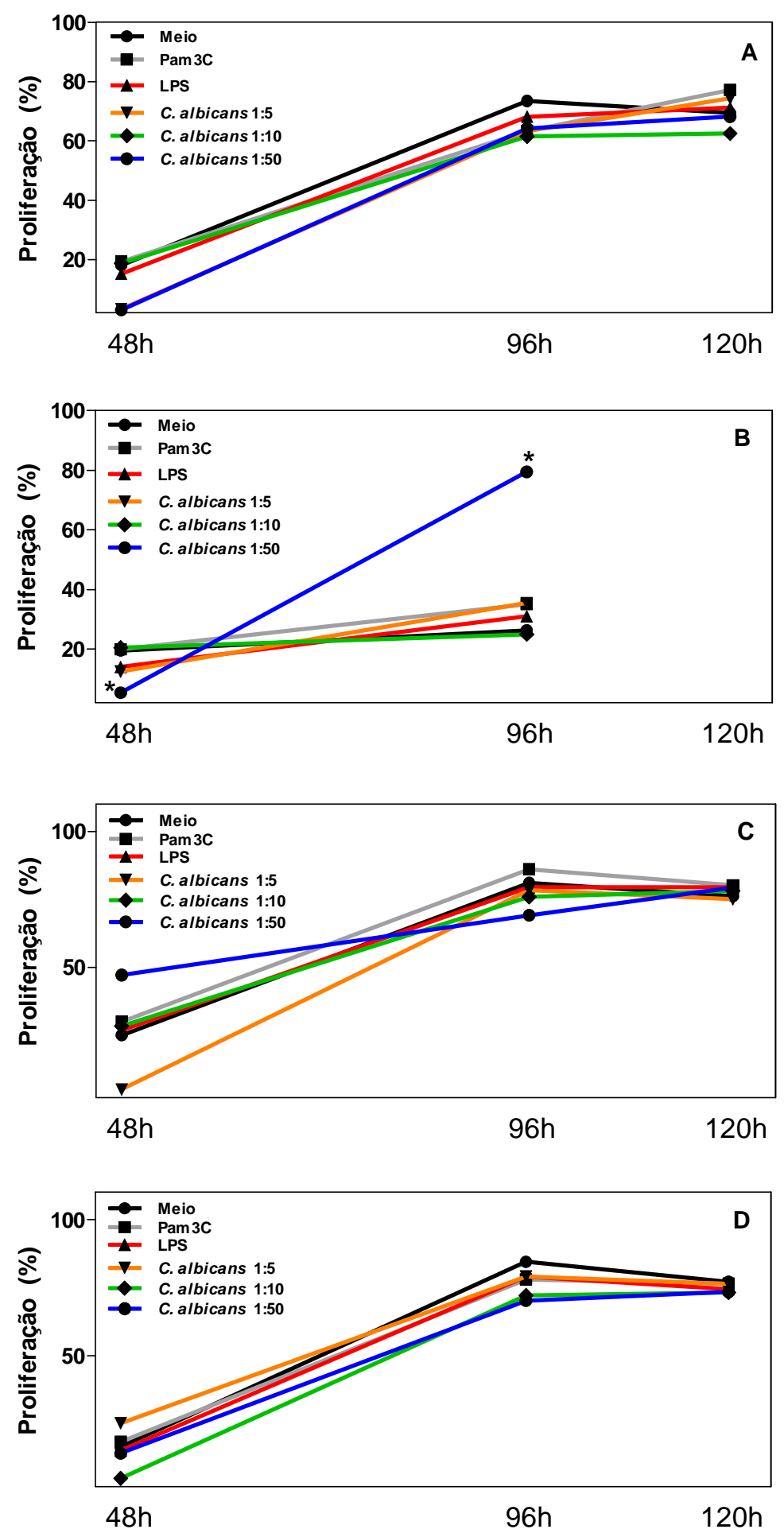

Figura 11 - Resposta proliferativa de fibroblastos gengivais. Fibroblastos gengivais de camundongos do grupo controle WT (A), TLR2KO (B), MyD88 KO (C) e CD14 KO (D) foram marcados com CFSE e cultivados na ausência de estímulo (meio), com LPS $(100 \mathrm{ng} / \mathrm{ml})$, PAM3C $(1 \mu \mathrm{g} / \mathrm{ml}), C$. albicans morta nas proporções 1:5, 1:10 e 1:50. Após 48horas, 96horas e 120horas as células foram coletadas e analisadas quanto à resposta proliferativa por citometria de fluxo. Dados representativos de três experimentos independentes. Os resultados foram avaliados pelo teste de ANOVA seguido pelo teste de Bonferroni. ${ }^{*} \mathrm{p}<0,05$. 


\subsection{Proliferação de fibroblastos pulpares}

Fibroblastos pulpares de camundongos do grupo controle e CD14KO foram incubados com CFSE, marcador fluorescente, distribuídos em placas de seis poços ( $5 \times 10^{5}$ células/poço). As células foram estimuladas com diferentes antígenos e a análise proliferativa foi realizada após 48h (Figura 12).

Os resultados evidenciaram diferenças na resposta proliferativa de fibroblastos pulpares do grupo controle e CD14KO (Figura 12). Fibroblastos do grupo controle apresentaram maior proliferação, na ausência de estimulo, quando comparado com as células de camundongos CD14KO (Figura 12). A estimulação com Pam3C e LPs não induziu aumento significativo na resposta proliferativa de fibroblastos do grupo controle e CD14KO, observando-se a maior proliferação de células do grupo controle. A estimulação com $C$. albicans (1:5) induziu aumento na resposta proliferativa de fibroblastos pulpares de camundongos do grupo controle e CD14KO, sendo este aumento mais significante quando se avalia os dados de fibroblastos CD14KO. De modo contrário, a estimulação com C. albicans morta nas proporções de 1:10 e 1:50 não induziu a proliferação de fibroblastos do grupo controle, mas induziu a proliferação de fibroblastos pulpares de animais CD14KO (Figura 12). Estes resultados podem indicar que a ausência do receptor CD14 influencia na resposta proliferativa de fibroblastos pulpares, mas não interferem com o reconhecimento de Candida albicans. 

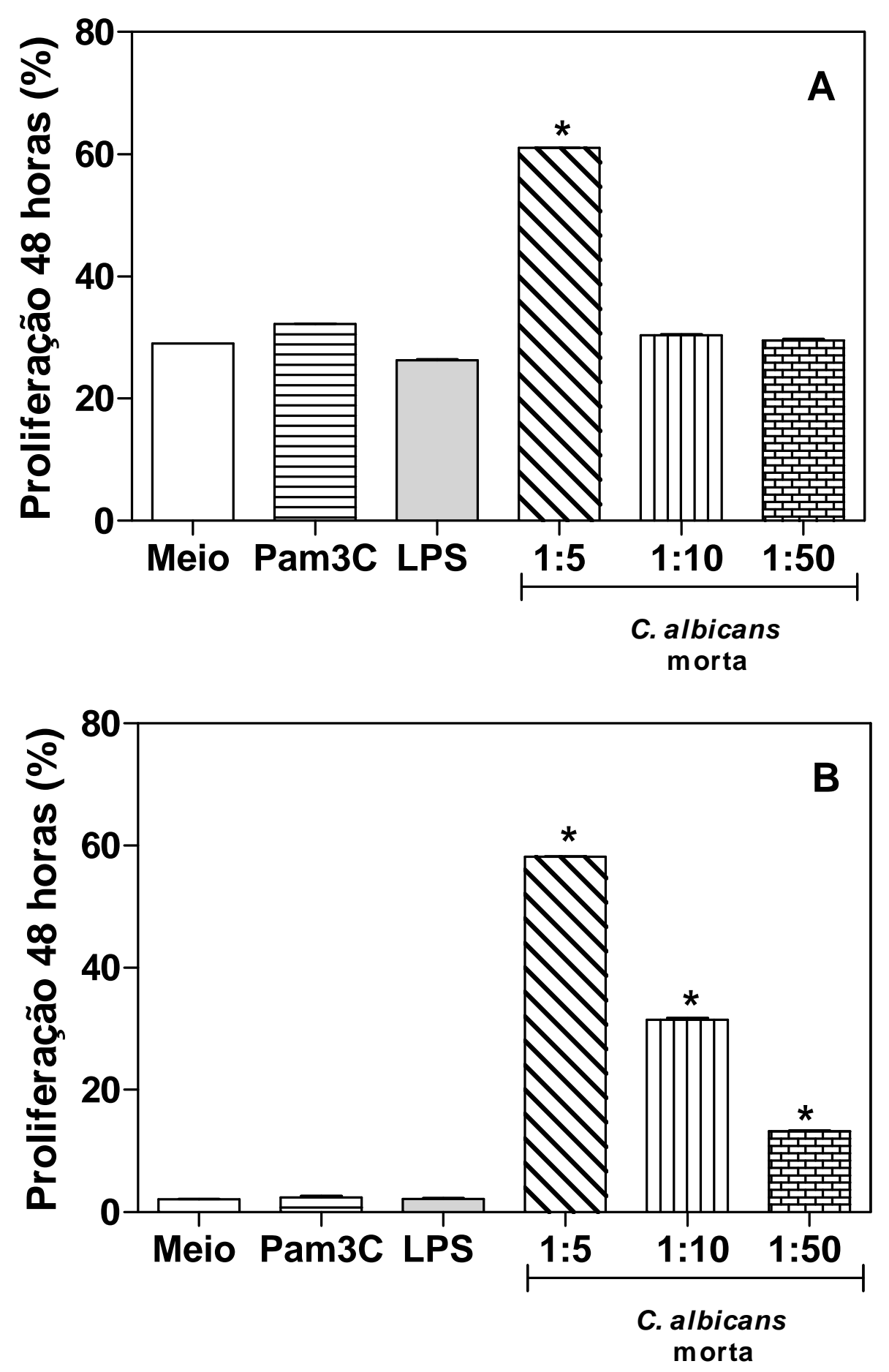

Figura 12 - Resposta proliferativa de fibroblastos pulpares. Fibroblastos pulpares de camundongos do grupo controle WT (A) e CD14 KO (B) foram marcados com CFSE e cultivados na ausência de estímulo (meio), com LPS $(100 \mathrm{ng} / \mathrm{ml})$, PAM3C $(1 \mu \mathrm{g} / \mathrm{ml}), C$. albicans morta nas proporções 1:5, 1:10 e 1:50. Após 48horas, as células foram coletadas e analisadas quanto à resposta proliferativa por citometria de fluxo. Dados representativos de três experimentos independentes. Os resultados foram avaliados pelo teste de ANOVA seguido pelo teste de Bonferroni. * $\mathrm{p}<0,05$. 
3. Análise da expressão de colágeno Tipo I por fibroblastos gengivais após a estimulação com agonistas de TLR2, TLR4 e Candida albicans

Após a análise dos efeitos dos diferentes antígenos na proliferação dos fibroblastos gengivais, analisou-se se a estimulação com os antígenos alteraria a expressão de colágeno Tipo I. Para tal, as células foram estimuladas com diferentes antígenos por 24 horas e analisadas por imunofluorescência para a detecção de colágeno tipo I.

A estimulação com LPS não alterou de forma significante a expressão de colágeno por fibroblastos dos grupos controle, MyD88KO e TLR2KO (Figura 13). Contudo, fibroblastos de animais CD14KO apresentaram baixa imunomarcação para colágeno Tipo I e a estimulação com LPS não alterou o perfil de expressão desta molécula (Figura 13). Resultados similares foram observados após a estimulação de fibroblastos gengivais com Pam3C e Candida albicans morta 1:10 (Figura 14 e 15). 



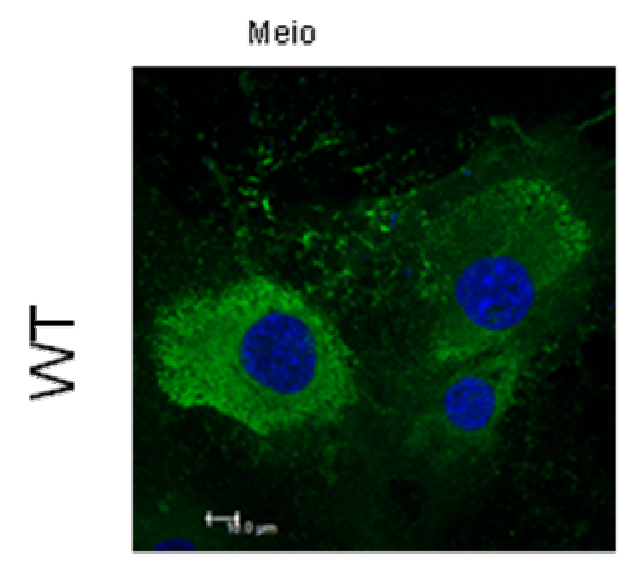

$$
\text { LPS }
$$
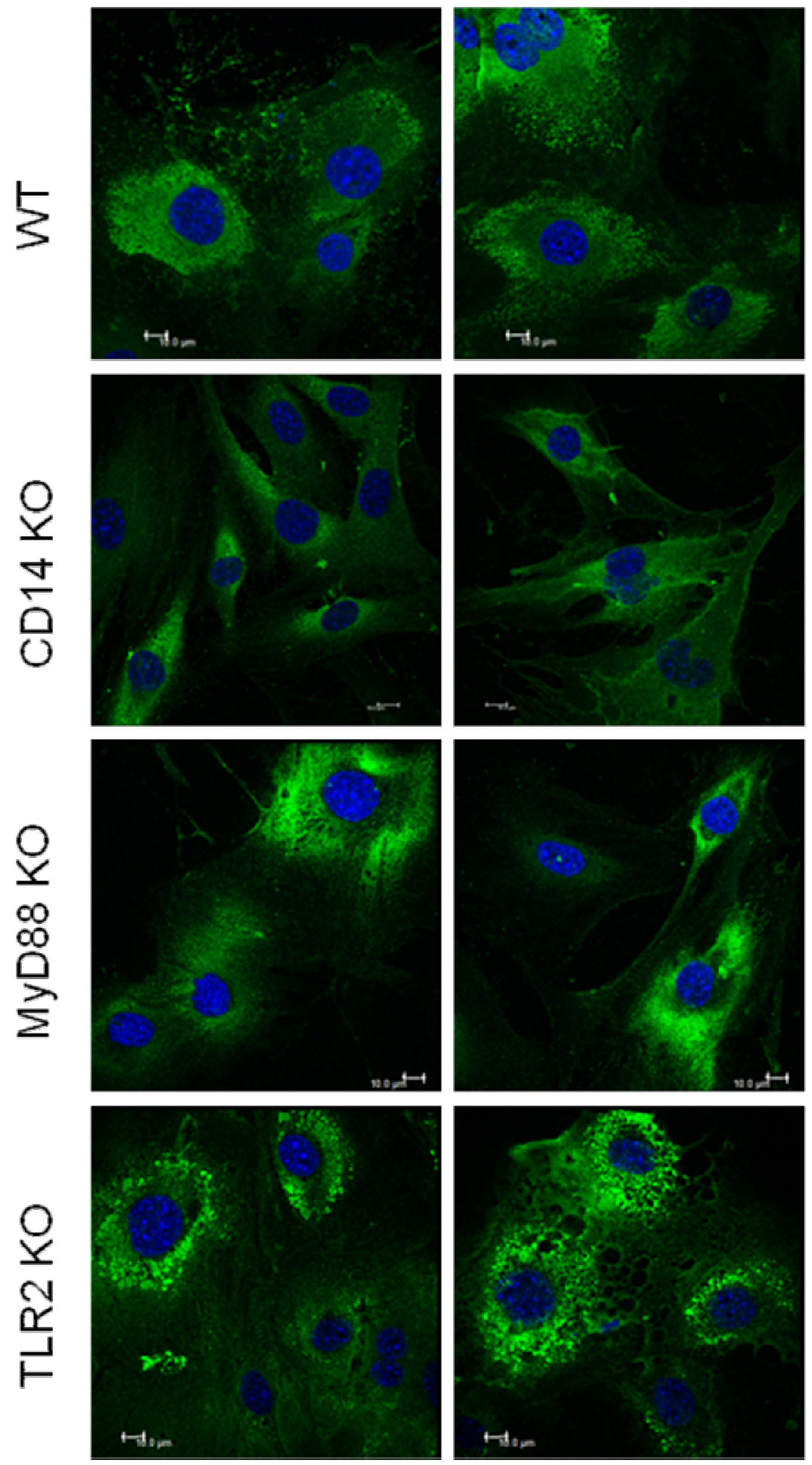

Figura 13 - Análise da expressão de colágeno Tipo I por fibroblastos gengivais após a estimulação com LPS. Fibroblastos de camundongos do grupo controle (WT), TLR2KO, CD14KO e MyD88KO foram estimulados com LPS e, após 24horas, analisados por imunofluorescência para a detecção de e colágeno tipo I (verde), como indicado nas imagens. O núcleo foi marcado com DAPI (azul). Barra de escala=10 $\mu \mathrm{m}$. 



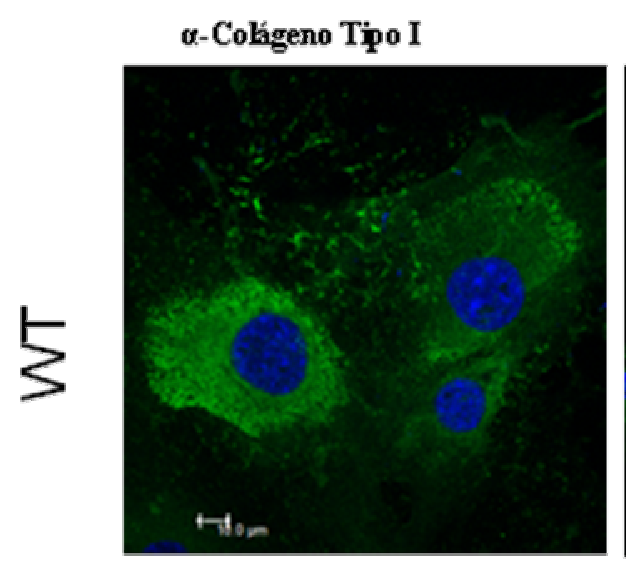

\section{a-Coh̆geno Típo IPPam3CSK4}
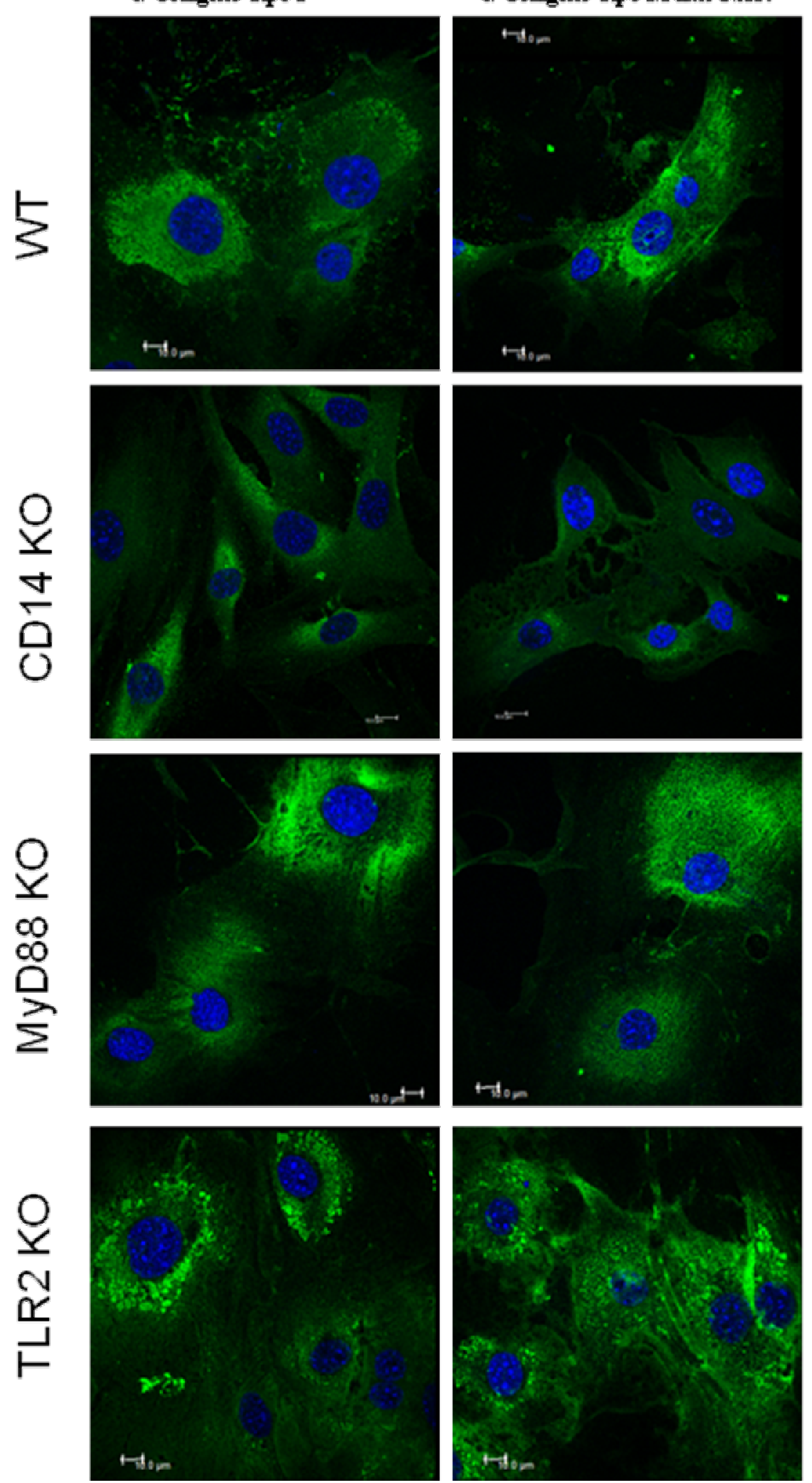

Figura 14 - Análise da expressão de colágeno Tipo I por fibroblastos gengivais após a estimulação com Pam3CSK4. Fibroblastos de camundongos do grupo controle (WT), TLR2KO, CD14KO e MyD88KO foram estimulados com Pam3CSK4 e, após 24horas, analisados por imunofluorescência para a detecção de colágeno tipo I (verde), como indicado nas imagens. O núcleo foi marcado com DAPI (azul). Barra de escala=10 $\mu \mathrm{m}$. 


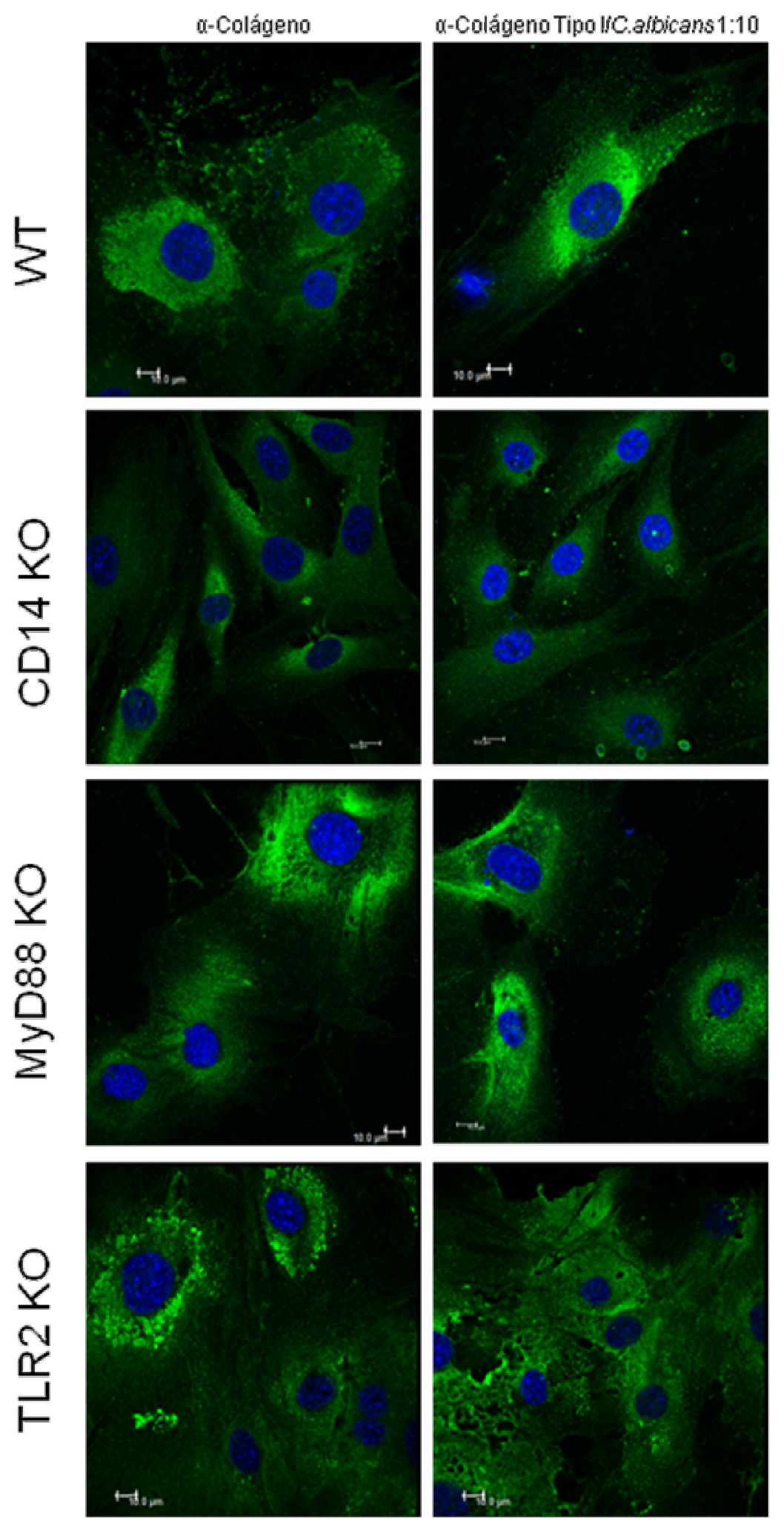

Figura 15 - Análise da expressão de colágeno Tipo I por fibroblastos gengivais após a estimulação com $C$. albicans morta (1:10). Fibroblastos de camundongos do grupo controle (WT), TLR2KO, CD14KO e MyD88KO foram estimulados com C.albicans morta na proporção 1:10 e, após 24horas, analisados por imunofluorescência para a detecção de e colágeno tipo I (verde), como indicado nas imagens. O núcleo foi marcado com DAPI (azul). Barra de escala $=10 \mu \mathrm{m}$. 



\section{Produção de citocinas por fibroblastos gengivais e pulpares após a estimulação com agonistas de TLR2, TLR4 e Candida albicans.}

\subsection{Produção de TGF- $\beta$, IL-1 $\beta$, TNF- $\alpha$, IL-13 e IL-6 por fibroblastos gengivais.}

Relatos na literatura têm demonstrado que Candida albicans induz a produção de citocinas por fibroblastos (ALVARES et al., 1995, COKER; LAURENT, 1998, OKIJI; HARDGREAVES; GOODIS, 2002, SAWADA et al., 2013). Para avaliar o perfil de produção de citocinas (TGF- $\beta$, IL-1 $\beta$, TNF- $\alpha$, IL-13 e IL-6) por fibroblastos gengivais, as células foram cultivadas por 24 e 48 horas na presença de antígenos e as citocinas produzidas avaliadas por ELISA.

A estimulação com LPS e Pam3C induziu a produção de IL-1 $\beta$ por fibroblastos do grupo controle (Figura 16A), e LPS também induziu a produção desta citocina por fibroblastos de animais TLR2KO, após 24 horas de cultivo (Figura 16B). De modo relevante, após $48 \mathrm{~h}$ de cultivo, baixos níveis de IL-1 $\beta$ foram detectados em cultura de fibroblastos de animais do grupo TLR2KO, independente do estimulo empregado (Figura 17B). A estimulação com Candida morta (1:5) inibiu a produção de IL-1 $\beta$ por fibroblastos gengivais de animais MyD88KO e CD14KO (Figura 16C e 16D), sendo que este antígeno também inibiu a produção desta citocina por fibroblastos de animais MyD88KO, após cultivo por 48 horas (Figura 17C). Enquanto que Candida morta na proporção de 1:10 e Candida viva (1:5) inibiram a produção de IL-1 $\beta$ por fibroblastos gengivais de animais TLR2KO e MyD88KO (Figura 16B e 16C). A estimulação com TGF- $\beta$ não induziu alteração significativa na produção de IL-1 $\beta$ por fibroblastos gengivais de todos os grupos analisados (Figura 16). 

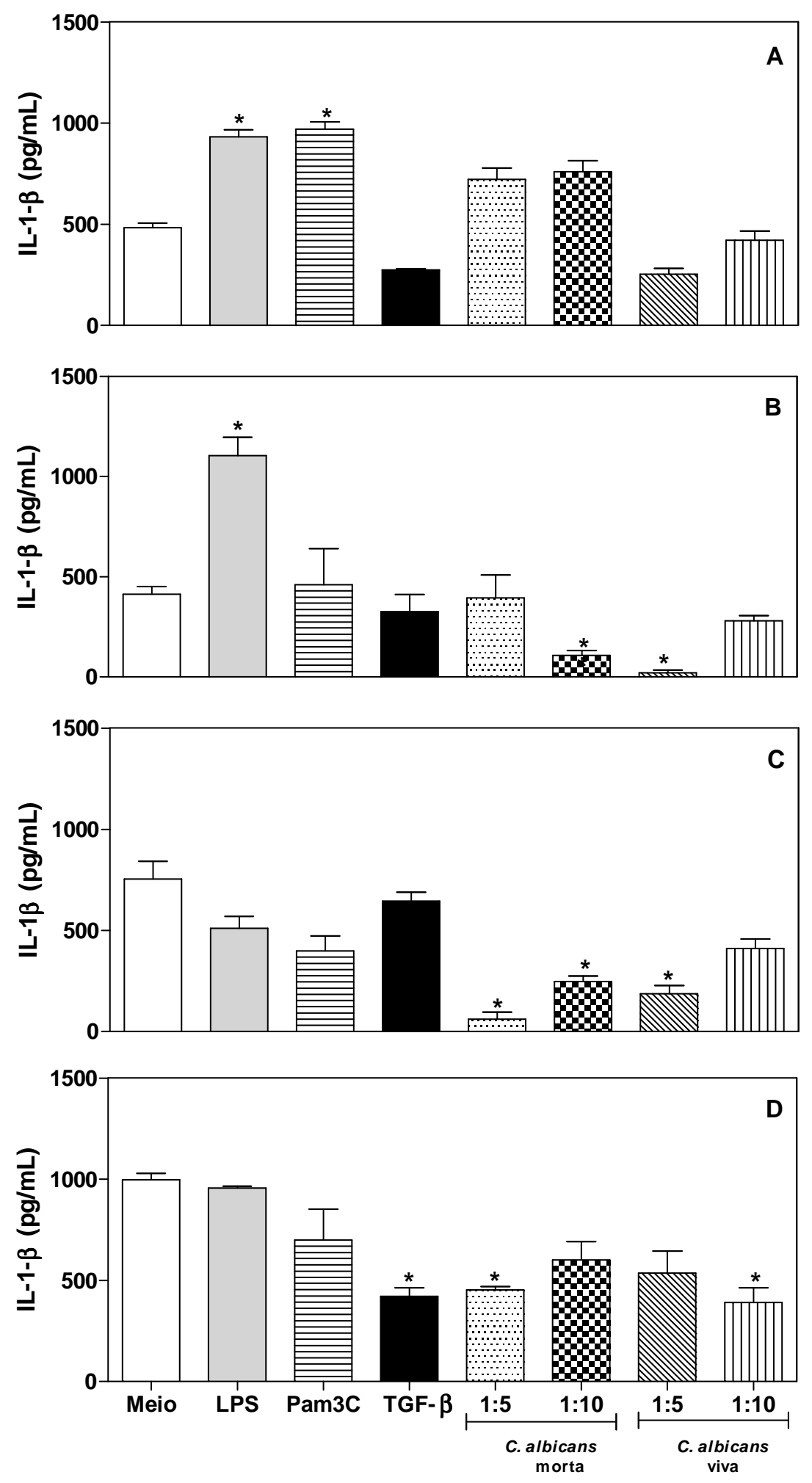

Figura 16 - Produção de IL-1ß por fibroblastos gengivais. Fibroblastos gengivais de camundongos do grupo controle WT (A), TLR2 KO (B), MyD88 KO (C) e CD14 KO (D) foram cultivados na ausência de estímulo (meio), com LPS (100ng/ml), PAM3C $(1 \mu \mathrm{g} / \mathrm{ml})$, TGF- $\beta, C$. albicans viva e morta nas proporções 1:5 e 1:10. Após 24horas, o sobrenadante das culturas foi coletado e a concentração de IL-1 $\beta$ determinada por ELISA. Dados representativos de três experimentos independentes. Os resultados foram avaliados pelo teste de ANOVA seguido pelo teste de Bonferroni. ${ }^{*} \mathrm{P}<0,05$. 

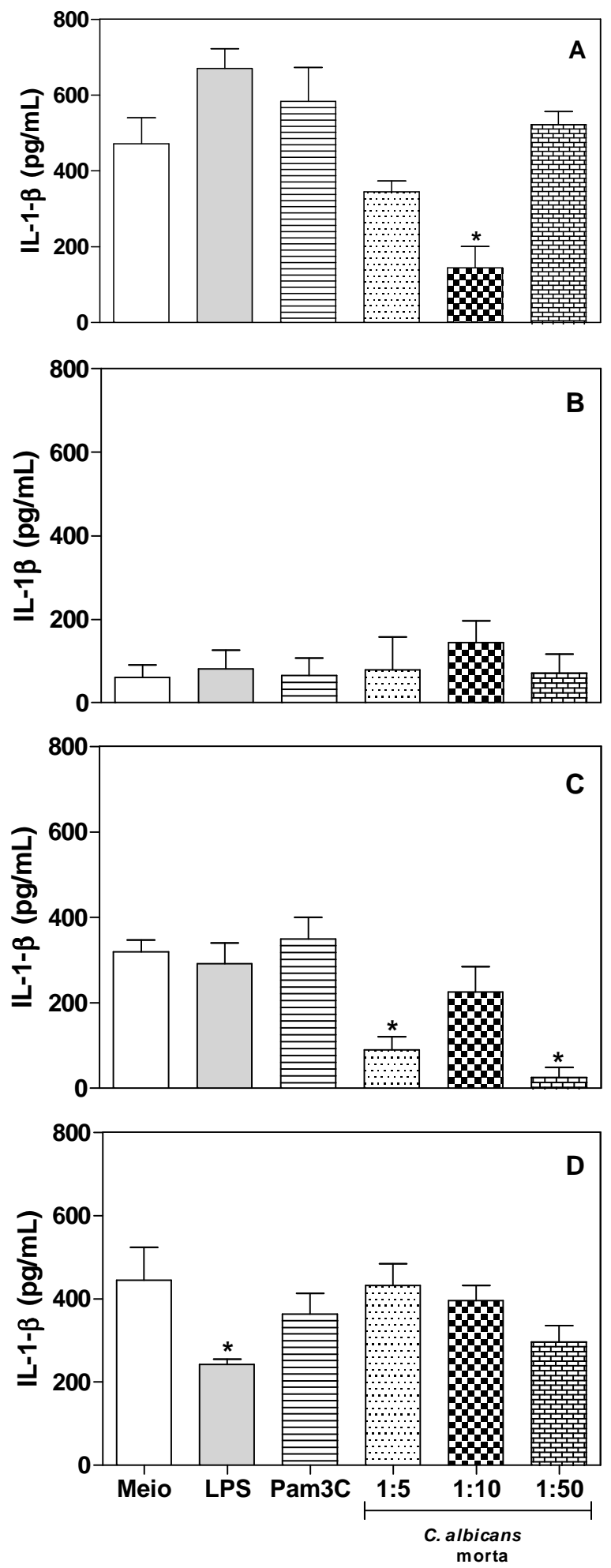

Figura 17 - Produção de IL-1ß por fibroblastos gengivais. Fibroblastos gengivais de camundongos do grupo controle WT (A), TLR2 KO (B), MyD88 KO (C) e CD14 KO (D) foram cultivados na ausência de estímulo (meio), com LPS (100ng/ml), PAM3C $(1 \mu \mathrm{g} / \mathrm{ml}), C$. albicans morta nas proporções 1:5, 1:10 e 1:50. Após 48horas, o sobrenadante das culturas foi coletado e a concentração de IL-1 $\beta$ determinada por ELISA. Dados representativos de três experimentos independentes. Os resultados foram avaliados pelo teste de ANOVA seguido pelo teste de Bonferroni. $* \mathrm{P}<0,05$. 
A estimulação com LPS e Pam3C não induziu alterações significativas quanto produção de TGF- $\beta$ por fibroblastos de todos os grupos testados (Figura 18), independente do tempo de cultivo. A estimulação por LPS inibiu a produção desta citocina por fibroblastos de animais do grupo CD14KO, após 48 horas de cultivo (Figura 19D). A estimulação com LPS e Candida morta (1:5) inibiu a produção de TGF- $\beta$ por fibroblastos gengivais de animais do grupo CD14KO após 48h (Figura 19 D).

A estimulação com LPS e Pam3C induziu alta produção de IL-6 por fibroblastos do grupo CD14KO (Figura 20D e 21D), após 24 e 48 horas de cultivo. LPS também induziu aumento significativo na produção desta citocina por fibroblastos de animais TLR2KO, somente após 24 horas de estimulação (Figura 20B). A estimulação com Candida morta (1:5 e 1:10) e Candida viva (1:10) induziu a produção de IL-6 por fibroblastos gengivais de animais do grupo TLR2KO (Figura 20B), após 24 horas. De modo relevante, após 48h de cultivo, baixos níveis de IL-6 foram detectados em cultura de fibroblastos de animais do grupo TLR2KO, quando estimulados com Pam3C, Candida morta (1:10 e 1:50) (Figura 21B). Enquanto que Pam3C inibiu a produção de IL-6 por fibroblastos gengivais de animais TLR2KO (Figura 21B). A estimulação com TGF- $\beta$ não induziu alteração significativa na produção de IL-6 por fibroblastos gengivais de todos os grupos analisados (Figura 20). Baixos níveis de IL-6 foram detectados nas culturas de fibroblastos gengivais do grupo MyD88KO (Figura 20C e 21C).

Em relação à produção de IL-13, os resultados evidenciaram que a estimulação com Pam3C induziu a produção de IL-13 por fibroblastos gengivais do grupo MyD88KO (Figura $22 \mathrm{C}$ e $23 \mathrm{C}$ ), e diminuiu a produção desta citocina por fibroblastos de animais do grupo controle e TLR2KO, após 24 horas de cultivo (Figura 22B). TGF- $\beta$ induziu a produção de IL13 por fibroblastos de animais TLR2KO, após 24 horas de cultivo (Figura 22B). Candida morta (1:10) induziu a produção de IL-13 por fibroblastos de animais do grupo controle e MyD88KO, independente do tempo e, após 48 horas, induziu aumento na produção de IL-13.

A estimulação com Candida viva (1:10) inibiu a produção de IL-13 por fibroblastos de todos os grupos analisados. Enquanto que a estimulação com Candida viva (1:5) induziu aumento na produção de IL-13 por células de animais TLR2KO e inibiu a produção por células de animais MyD88KO (Figura 22B e 22C). De modo relevante, após 48h de cultivo, baixos níveis de IL-13 foram detectados em cultura de fibroblastos de animais do grupo controle estimulados com LPS (Figura 23A). 

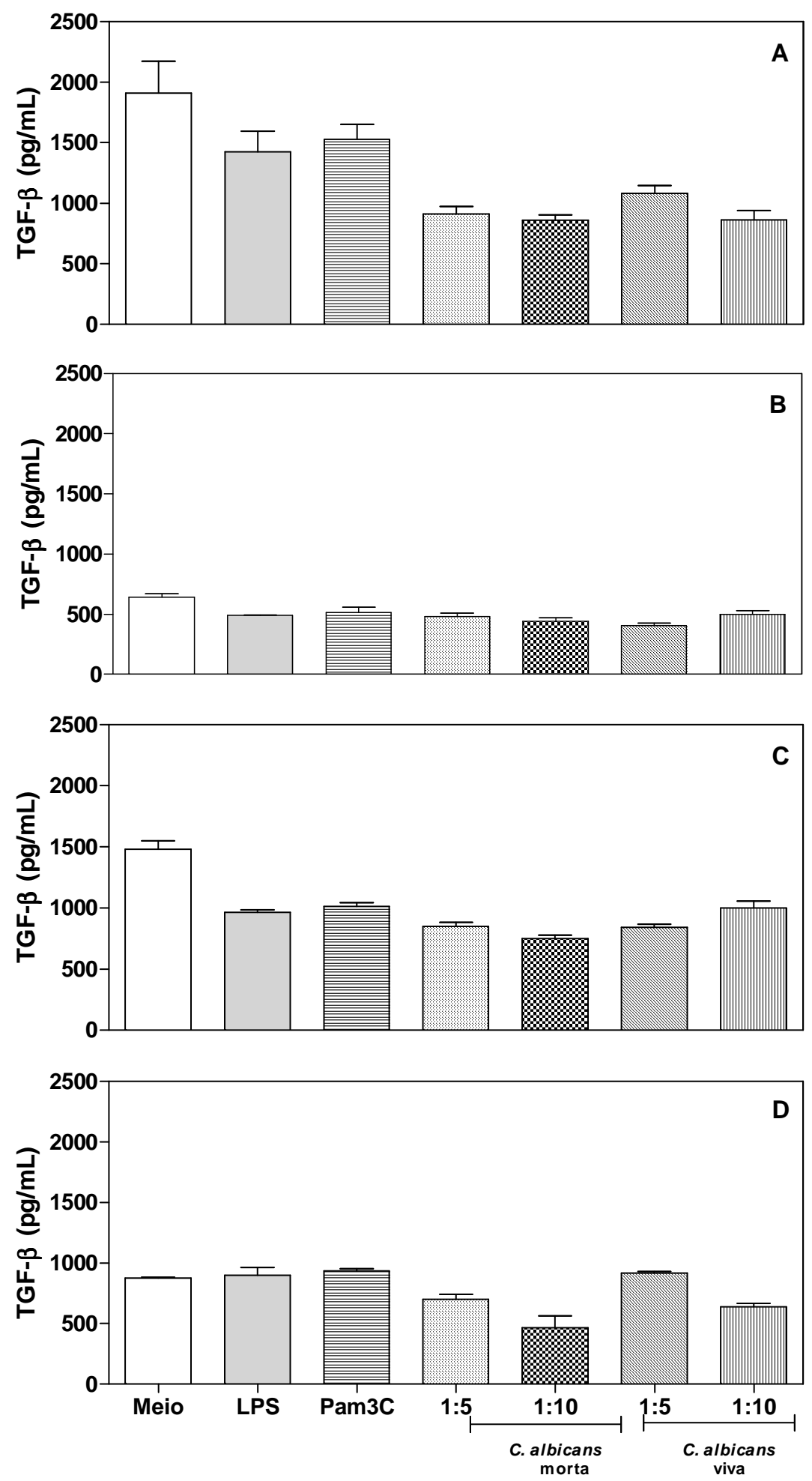

Figura 18- Produção de TGF- $\beta$ por fibroblastos gengivais. Fibroblastos gengivais de camundongos do grupo controle WT (A), TLR2 KO (B), MyD88 KO (C) e CD14 KO (D) foram cultivados na ausência de estímulo (meio), com LPS (100ng/ml), PAM3C (1 $\mu \mathrm{g} / \mathrm{ml}), C$. albicans viva e morta nas proporções 1:5 e 1:10. Após 24horas, o sobrenadante das culturas foi coletado e a concentração de TGF- $\beta$ determinada por ELISA. Dados representativos de três experimentos independentes. Os resultados foram avaliados pelo teste de ANOVA seguido pelo teste de Bonferroni. $* \mathrm{P}<0,05$. 

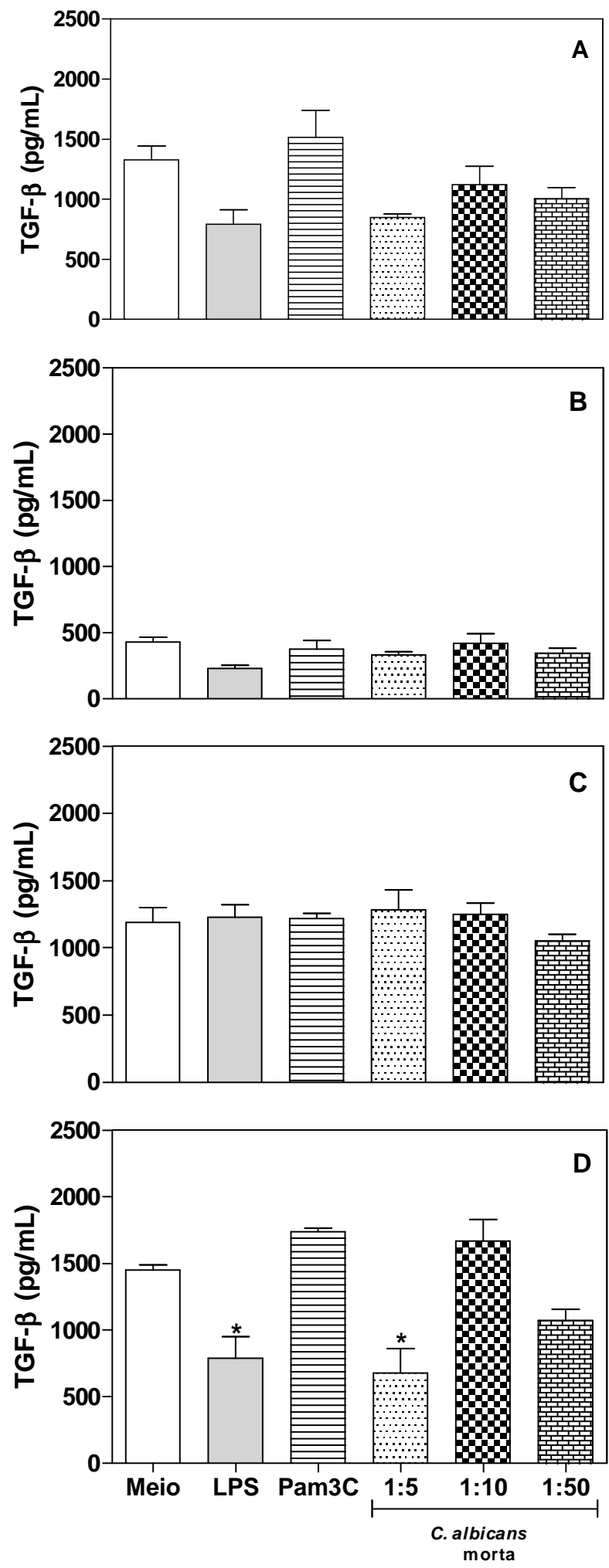

Figura19- Produção de TGF- $\beta$ por fibroblastos gengivais. Fibroblastos gengivais de camundongos do grupo controle WT (A), TLR2 KO (B), MyD88 KO (C) e CD14 KO (D)

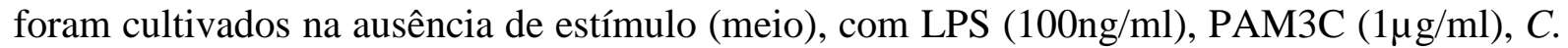
albicans morta nas proporções 1:5, 1:10 e 1:50. Após 48horas, o sobrenadante das culturas foi coletado e a concentração de TGF- $\beta$ determinada por ELISA. Dados representativos de três experimentos independentes. Os resultados foram avaliados pelo teste de ANOVA seguido pelo teste de Bonferroni. ${ }^{*} \mathrm{P}<0,05$. 

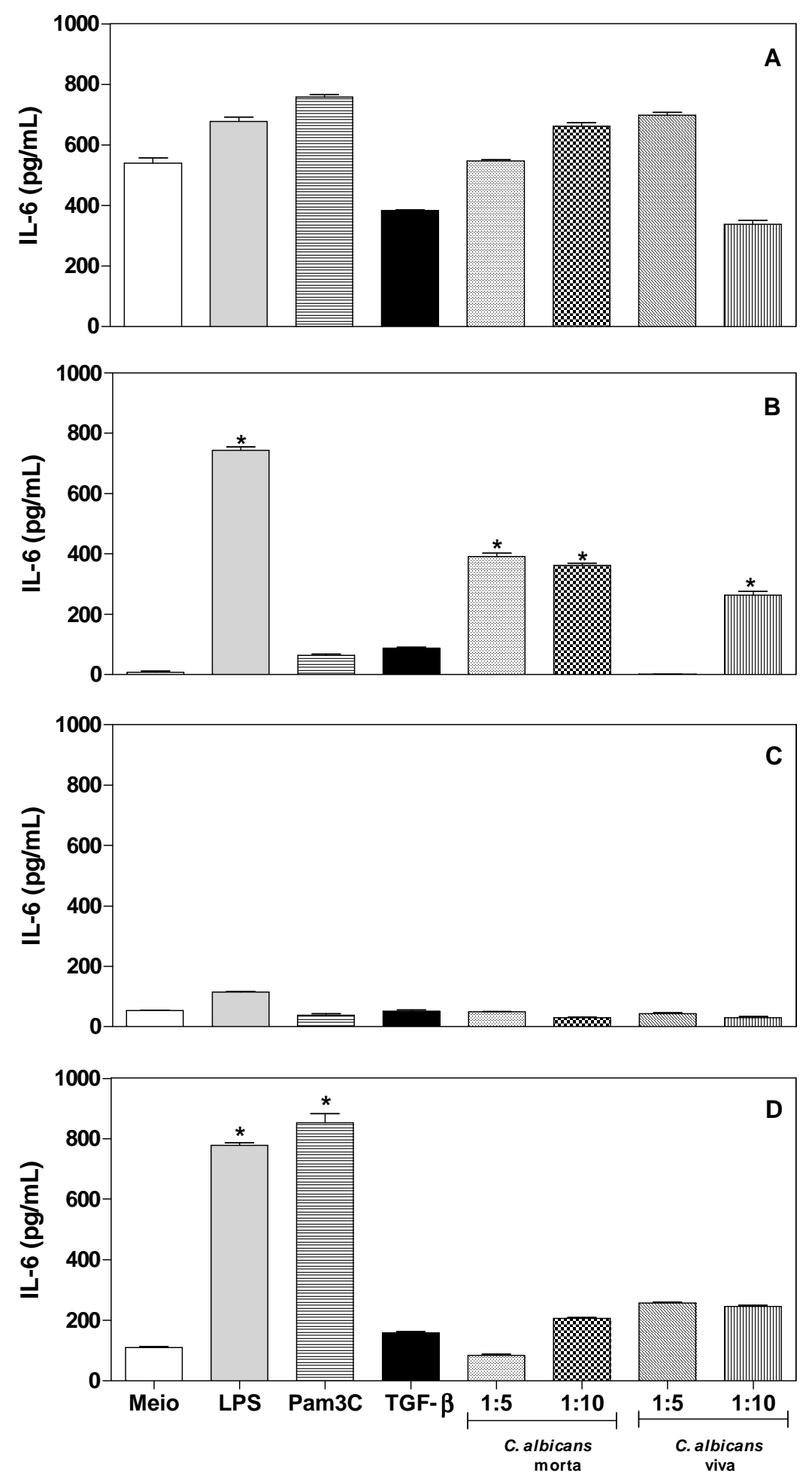

Figura 20 - Produção IL-6 por fibroblastos gengivais. Fibroblastos gengivais de camundongos do grupo controle WT (A), TLR2 KO (B), MyD88 KO (C) e CD14 KO (D) foram cultivados na ausência de estímulo (meio), com LPS $(100 \mathrm{ng} / \mathrm{ml})$, PAM3C $(1 \mu \mathrm{g} / \mathrm{ml})$, TGF- $\beta, C$. albicans viva e morta nas proporções 1:5 e 1:10. Após 24horas, o sobrenadante das culturas foi coletado e a concentração de IL-6 determinada por ELISA. Dados representativos de três experimentos independentes. Os resultados foram avaliados pelo teste de ANOVA seguido pelo teste de Bonferroni. $* \mathrm{P}<0,05$. 

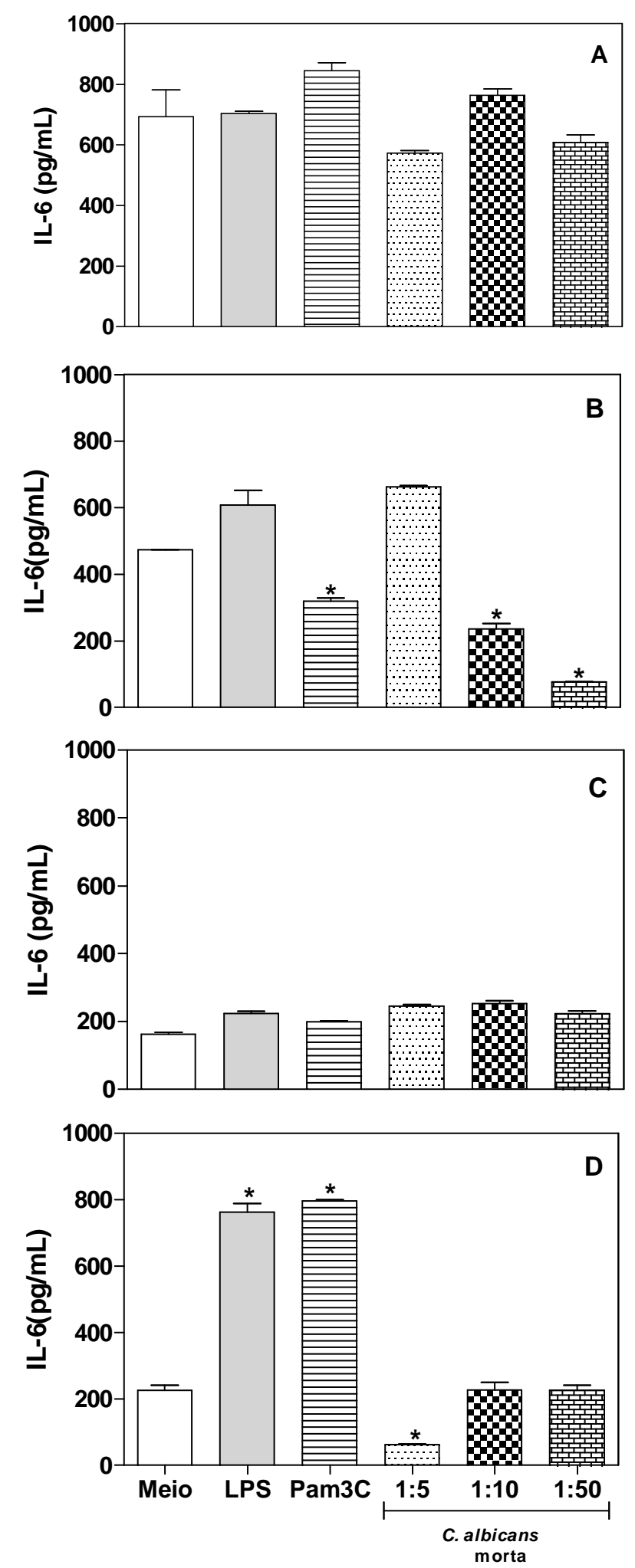

Figura 21- Produção IL-6 por fibroblastos gengivais. Fibroblastos gengivais de camundongos do grupo controle WT (A), TLR2 KO (B), MyD88 KO (C) e CD14 KO (D)

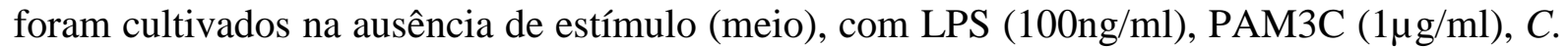
albicans morta nas proporções 1:5, 1:10 e 1:50. Após 48horas, o sobrenadante das culturas foi coletado e a concentração de IL-6 determinada por ELISA. Dados representativos de três experimentos independentes. Os resultados foram avaliados pelo teste de ANOVA seguido pelo teste de Bonferroni. $* \mathrm{P}<0,05$. 

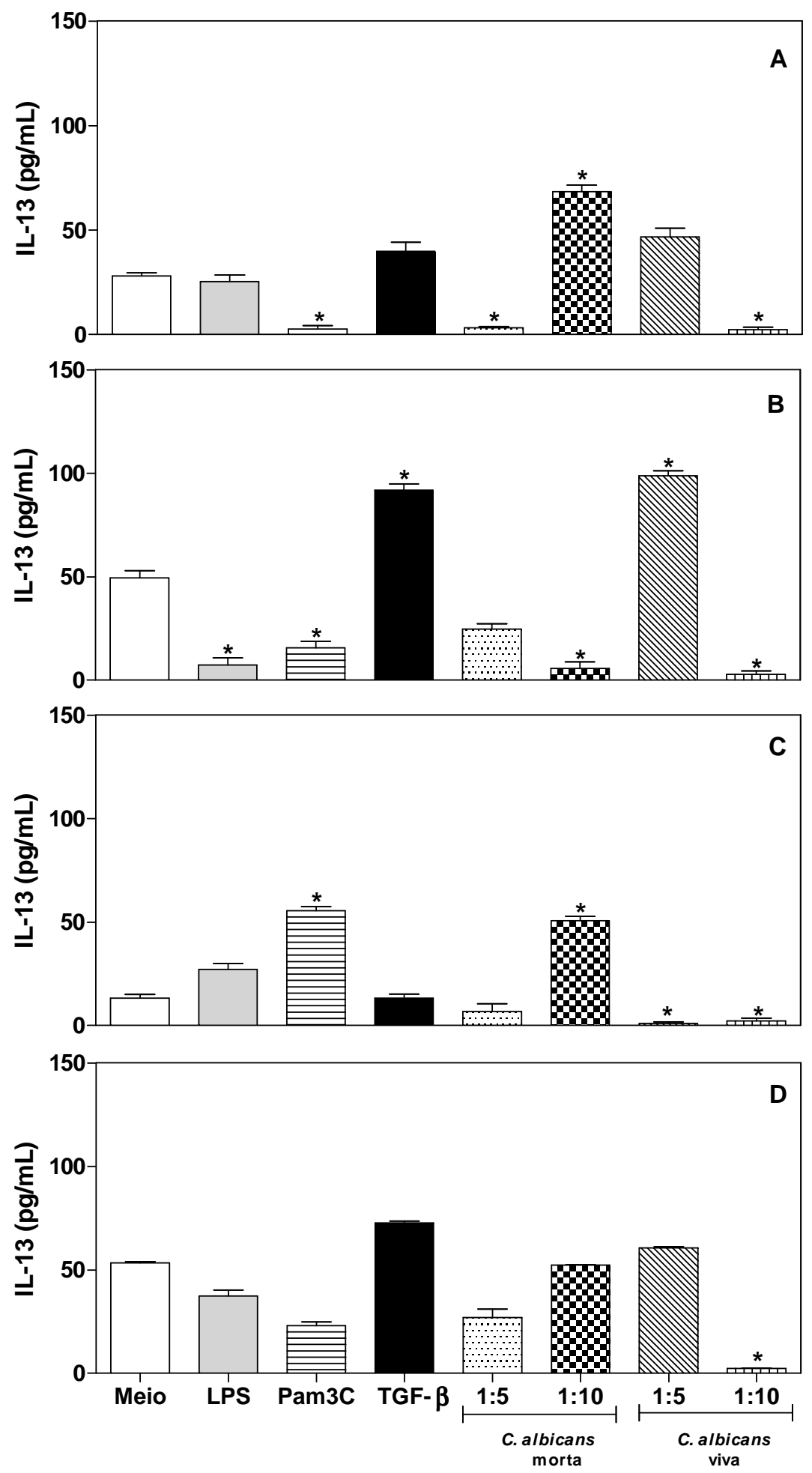

Figura 22 - Produção IL-13 por fibroblastos gengivais. Fibroblastos gengivais de camundongos do grupo controle WT (A), TLR2 KO (B), MyD88 KO (C) e CD14 KO (D) foram cultivados na ausência de estímulo (meio), com LPS $(100 \mathrm{ng} / \mathrm{ml})$, PAM3C $(1 \mu \mathrm{g} / \mathrm{ml})$, TGF- $\beta, C$. albicans viva e morta nas proporções 1:5 e 1:10. Após 24horas, o sobrenadante das culturas foi coletado e a concentração de IL-13 determinada por ELISA. Dados representativos de três experimentos independentes. Os resultados foram avaliados pelo teste de ANOVA seguido pelo teste de Bonferroni. ${ }^{*} \mathrm{P}<0,05$. 

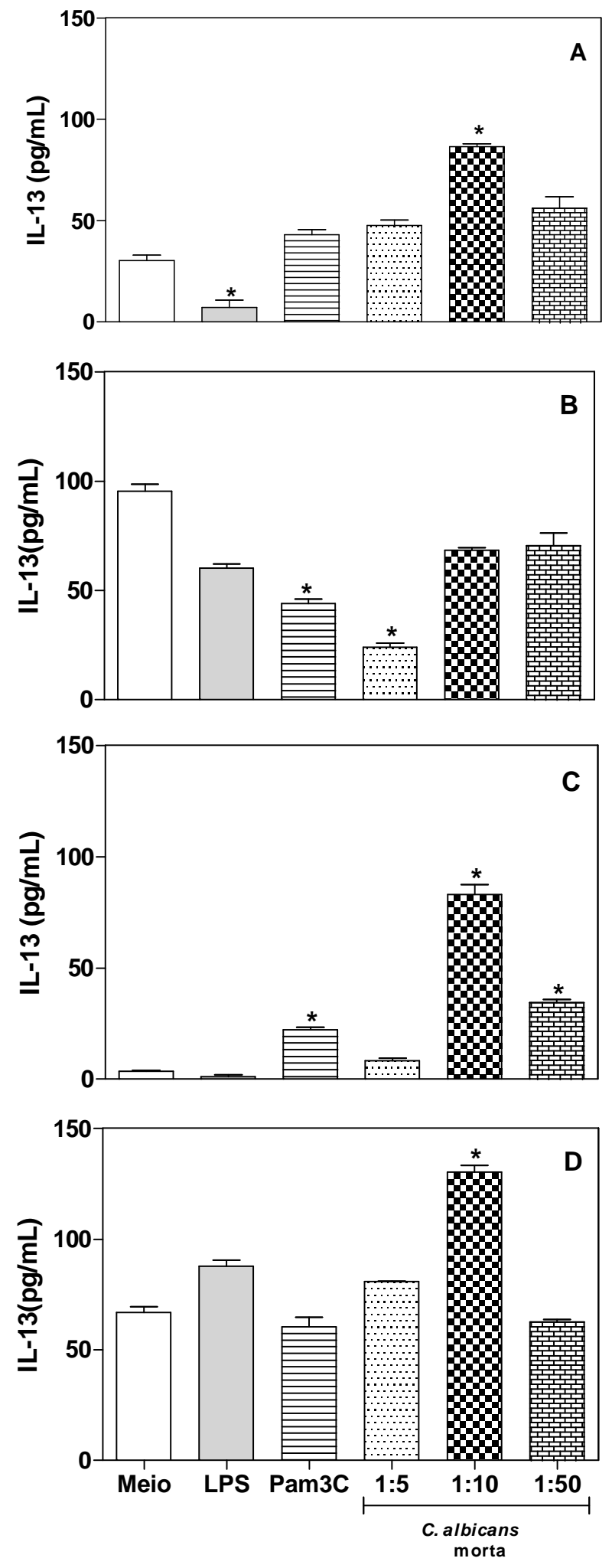

Figura 23 - Produção IL-13 por fibroblastos gengivais. Fibroblastos gengivais de camundongos do grupo controle WT (A), TLR2 KO (B), MyD88 KO (C) e CD14 KO (D)

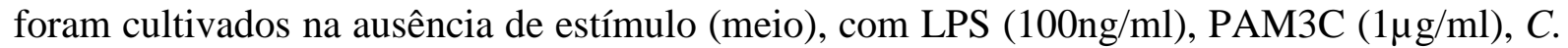
albicans morta nas proporções 1:5, 1:10 e 1:50. Após 48horas, o sobrenadante das culturas foi coletado e a concentração de IL-13 determinada por ELISA. Dados representativos de três experimentos independentes. Os resultados foram avaliados pelo teste de ANOVA seguido pelo teste de Bonferroni. $* \mathrm{P}<0,05$. 
Em relação à produção de TNF- $\alpha$, os resultados evidenciaram baixos níveis desta citocina nas culturas de fibroblastos gengivais de animais do grupo TLR2KO, MyD88KO, e CD14KO, independente do estímulo empregado e do tempo de cultura (Figura 24B-D e 25B-D). A estimulação com LPS, Pam3C, Candida morta e viva induziram a produção de TNF- $\alpha$ por fibroblastos do grupo controle, sendo mais evidente após a estimulação por 24 horas com Candida viva (1:10) (Figura 24A). Altos níveis de TNF- $\alpha$ foram detectados em cultura de fibroblastos de animais do grupo controle cultivados com os diferentes estímulos por 48 horas, quando comparado com as células cultivadas apenas na presença de meio (Figura 25A). De modo relevante, a estimulação com Candida morta (1:5) induziu aumento significativo na produção de TNF- $\alpha$ por fibroblastos de animais do grupo MyD88KO (Figura 25C). 

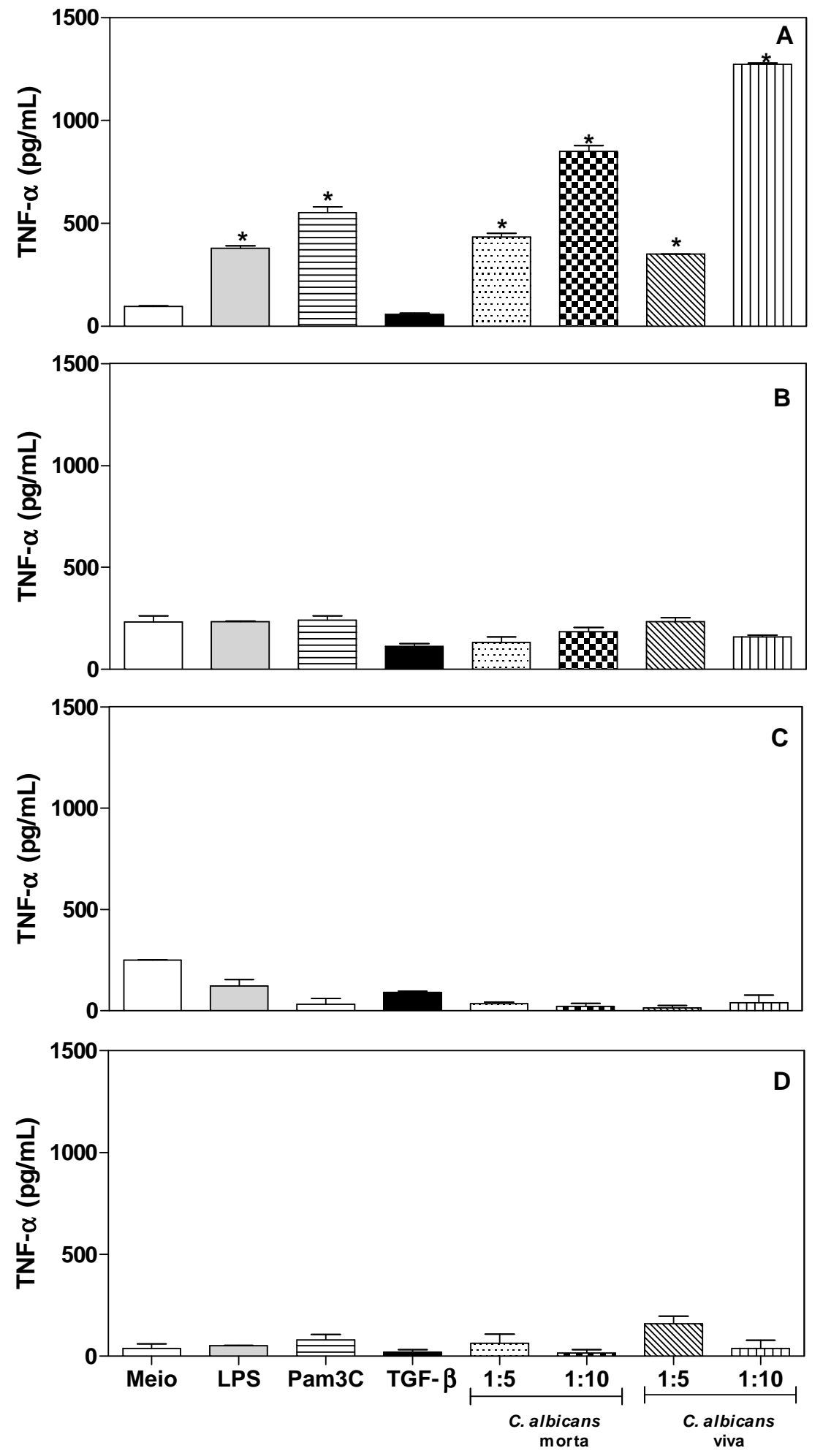

Figura 24 - Produção de TNF- $\alpha$ por fibroblastos gengivais. Fibroblastos gengivais de camundongos do grupo controle WT (A), TLR2 KO (B), MyD88 KO (C) e CD14 KO (D) foram cultivados na ausência de estímulo (meio), com LPS $(100 \mathrm{ng} / \mathrm{ml})$, PAM3C $(1 \mu \mathrm{g} / \mathrm{ml})$, TGF- $\beta, C$. albicans viva e morta nas proporções 1:5 e 1:10. Após 24horas, o sobrenadante das culturas foi coletado e a concentração de TNF- $\alpha$ determinada por ELISA. Dados representativos de três experimentos independentes. Os resultados foram avaliados pelo teste de ANOVA seguido pelo teste de Bonferroni. $* \mathrm{P}<0,05$. 

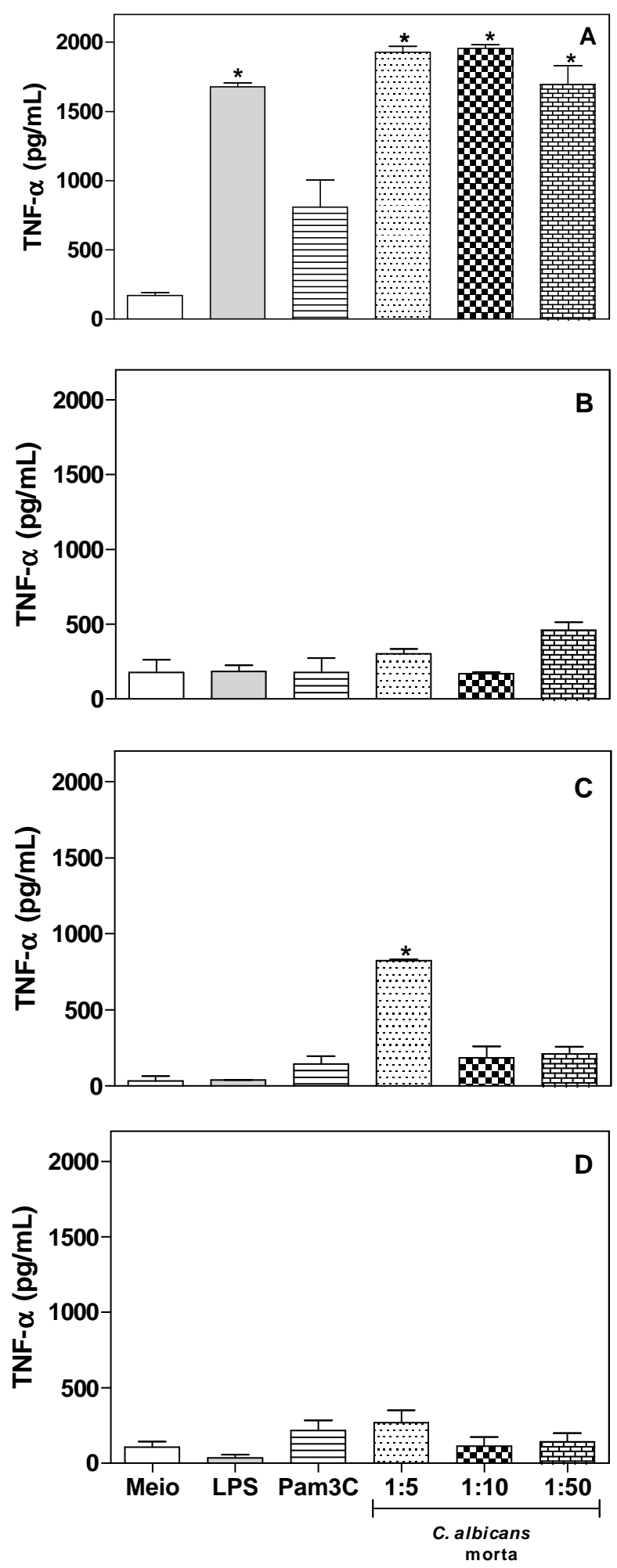

Figura 25 - Produção de TNF- $\alpha$ por fibroblastos gengivais. Fibroblastos gengivais de camundongos do grupo controle WT (A), TLR2 KO (B), MyD88 KO (C) e CD14 KO (D) foram cultivados na ausência de estímulo (meio), com LPS (100ng/ml), PAM3C $(1 \mu \mathrm{g} / \mathrm{ml}), C$. albicans morta nas proporções 1:5, 1:10 e 1:50. Após 48horas, o sobrenadante das culturas foi coletado e a concentração de TNF- $\alpha$ determinada por ELISA. Dados representativos de três experimentos independentes. Os resultados foram avaliados pelo teste de ANOVA seguido pelo teste de Bonferroni. $* \mathrm{P}<0,05$. 


\subsection{Produção de TGF- $\beta$, IL-1ß, TNF- $\alpha$, IL-13 e IL-6 por fibroblastos pulpares.}

Após a análise da produção de citocinas por fibroblastos gengivais, avaliou-se a produção de TGF- $\beta$, IL-1 $\beta$, TNF- $\alpha$, IL-13 e IL-6 por fibroblastos pulpares isolados de animais do grupo controle e deficiente de CD14 (CD14KO).

Os resultados evidenciaram que a estimulação com LPS induziu a produção de IL-1 $\beta$ por fibroblastos do grupo controle (Figura 26A). Enquanto que a estimulação com Candida albicans morta na proporção de 1:5 inibiu a produção desta citocina por fibroblastos do grupo controle. A estimulação com os antígenos testados não alterou de modo significativo à produção de IL-1 $\beta$ por fibroblastos pulpares de animais do grupo CD14KO (Figura 26B).

A estimulação com os diferentes antígenos não alterou de modo significante a produção de TGF- $\alpha$ por fibroblastos de pulpares de animais do grupo controle e CD14KO (Figura 27A). Os resultados evidenciaram uma leve diminuição da produção desta citocina por fibroblastos de animais CD14KO após a estimulação com Candida morta (1:5, 1:10 e 1:50), mas esta diminuição não foi significante (Figura 27B).

Em relação à produção de IL-6 por fibroblastos pulpares, os resultados evidenciaram que a estimulação com LPS, Pam3C e Candida morta (1:5, 1:10 e 1:50) não alterou significativamente a produção de IL-6 por fibroblastos do grupo controle (Figura 28A). Contudo, a estimulação com estes antígenos induziu significativamente a produção de IL-6 por fibroblastos pulpares de animais do grupo CD14KO, sendo este valor mais significante após a estimulação com Pam3C (Figura 28B).

Os resultados evidenciaram que a estimulação com os antígenos não alterou significativamente a produção de IL-13 por fibroblastos pulpares do grupo controle (Figura 29A). Candida morta (1:10) induziu aumento significante na produção de IL-13 por fibroblastos pulpares de animais do grupo CD14KO (Figura 29B).

Em relação à maior produção de $\mathrm{TNF}-\alpha$, os resultados evidenciaram altos níveis desta citocina em culturas de fibroblastos pulpares de animais do grupo controle (Figura 30A). A estimulação com LPS e Candida morta (1:50) induziu a produção de TNF- $\alpha$ por fibroblastos do grupo controle (Figura 30A). Fibroblastos de animais CD14KO cultivados na presença apenas de meio produzem níveis elevados de TNF- $\alpha$ (Figura 30B), e a estimulação com os antígenos levou a redução significante na produção desta citocina (Figura 30B). 

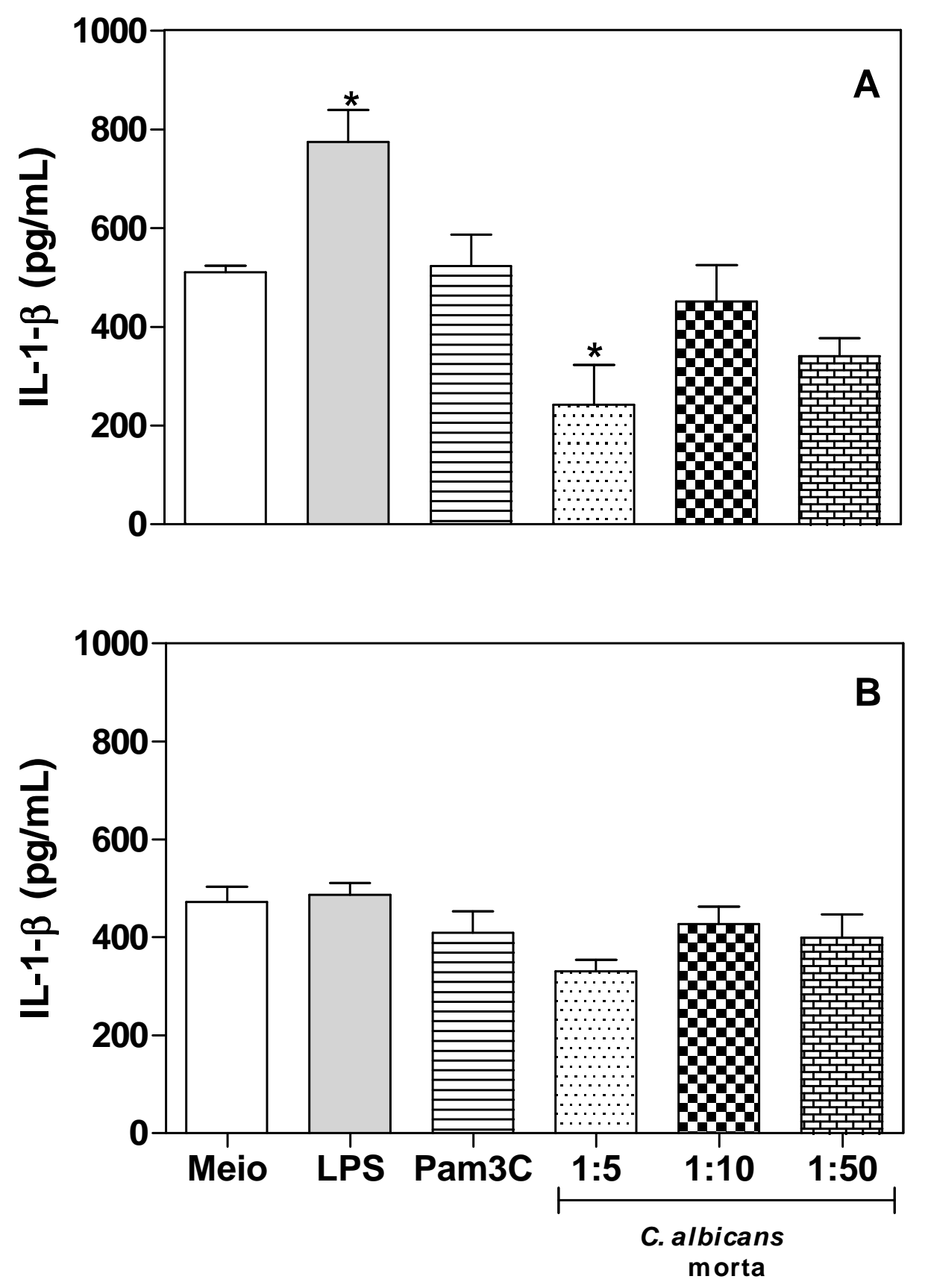

Figura 26 - Produção de IL-1ß por fibroblastos pulpares. Fibroblastos pulpares de camundongos do grupo controle (WT) (A) e CD14 KO (B) foram cultivados na ausência de estímulo (meio), com LPS (100ng/ml), PAM3C $(1 \mu \mathrm{g} / \mathrm{ml}), C$. albicans morta nas proporções 1:5, 1:10 e 1:50. Após 48 horas, o sobrenadante das culturas foi coletado e a concentração de IL-1 $\beta$ determinada por ELISA. Dados representativos de três experimentos independentes. Os resultados foram avaliados pelo teste de ANOVA seguido pelo teste de Bonferroni. ${ }^{*} \mathrm{P}<0,05$. 

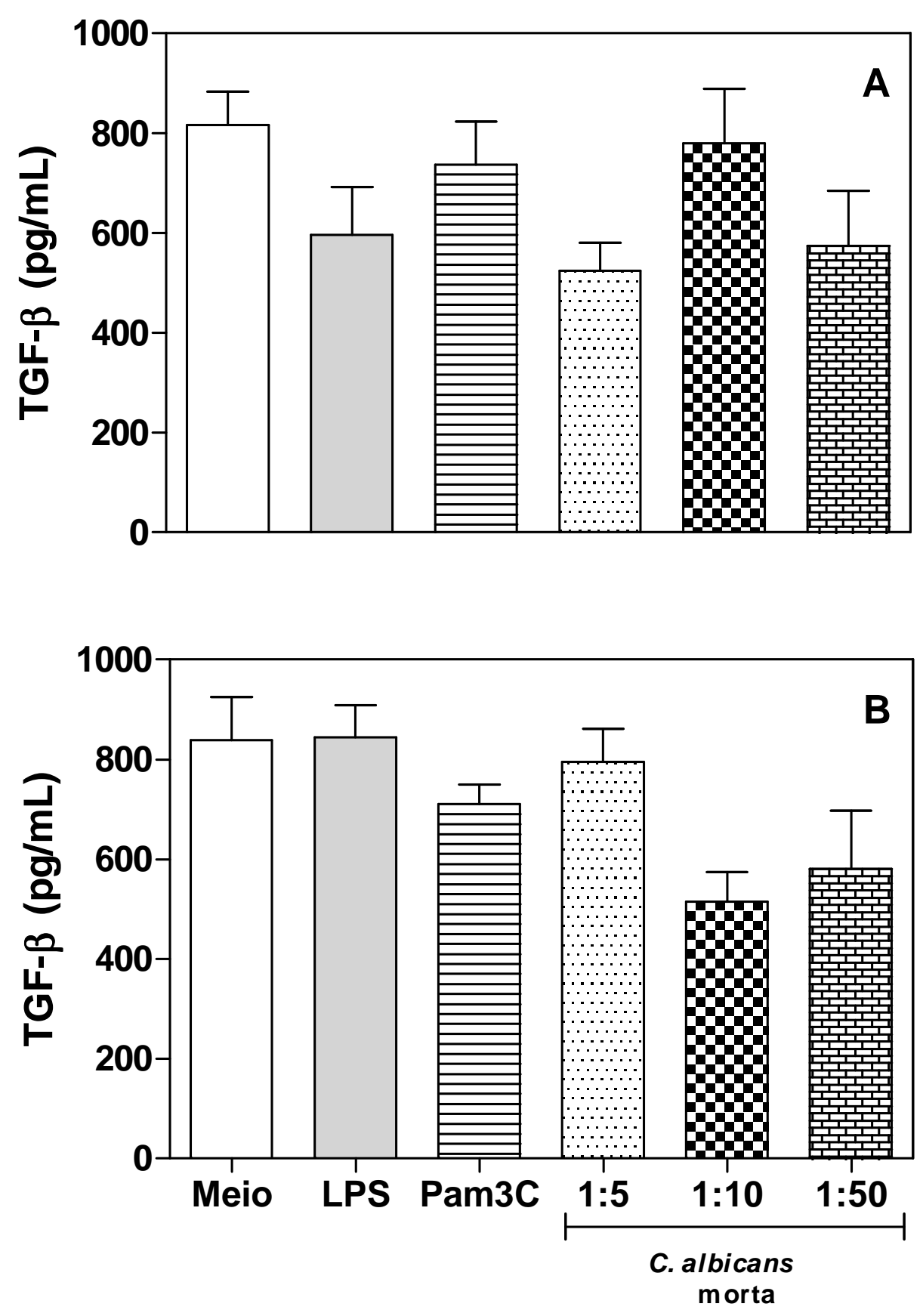

Figura 27 - Produção de TGF- $\beta$ por fibroblastos pulpares. Fibroblastos pulpares de camundongos do grupo controle (WT) (A) e CD14 KO (B) foram cultivados na ausência de estímulo (meio), com LPS (100ng/ml), PAM3C $(1 \mu \mathrm{g} / \mathrm{ml})$, C. albicans morta nas proporções 1:5, 1:10 e 1:50. Após 48 horas, o sobrenadante das culturas foi coletado e a concentração de TGF- $\beta$ determinada por ELISA. Dados representativos de três experimentos independentes. Os resultados foram avaliados pelo teste de ANOVA seguido pelo teste de Bonferroni. $* \mathrm{P}<0,05$. 

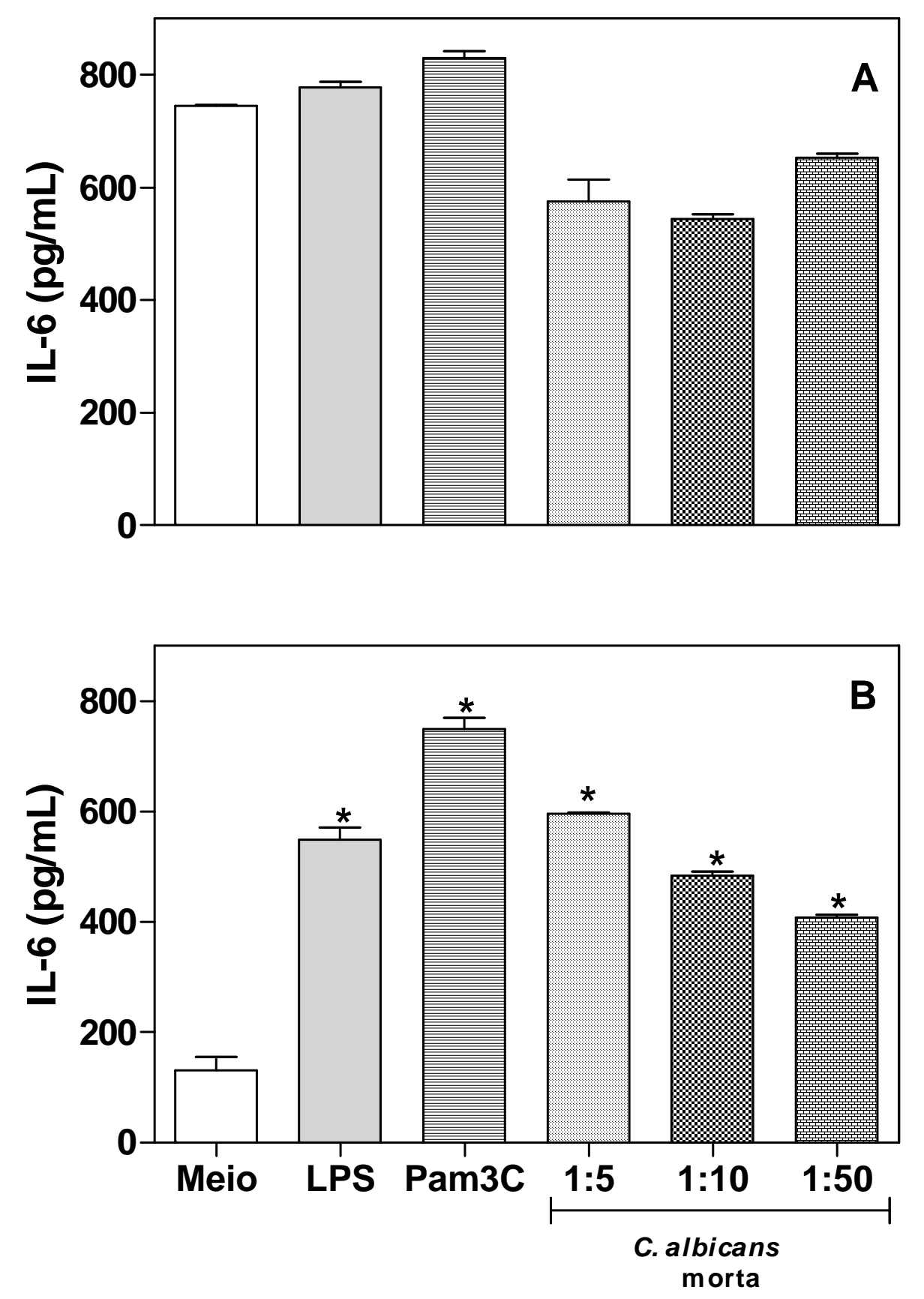

Figura 28- Produção de IL-6 por fibroblastos pulpares. Fibroblastos pulpares de camundongos do grupo controle (WT) (A) e CD14 KO (B) foram cultivados na ausência de estímulo (meio), com LPS (100ng/ml), PAM3C $(1 \mu \mathrm{g} / \mathrm{ml})$, C. albicans morta nas proporções 1:5, 1:10 e 1:50. Após 48 horas, o sobrenadante das culturas foi coletado e a concentração de IL-6 determinada por ELISA. Dados representativos de três experimentos independentes. Os resultados foram avaliados pelo teste de ANOVA seguido pelo teste de Bonferroni. ${ }^{*} \mathrm{P}<0,05$. 

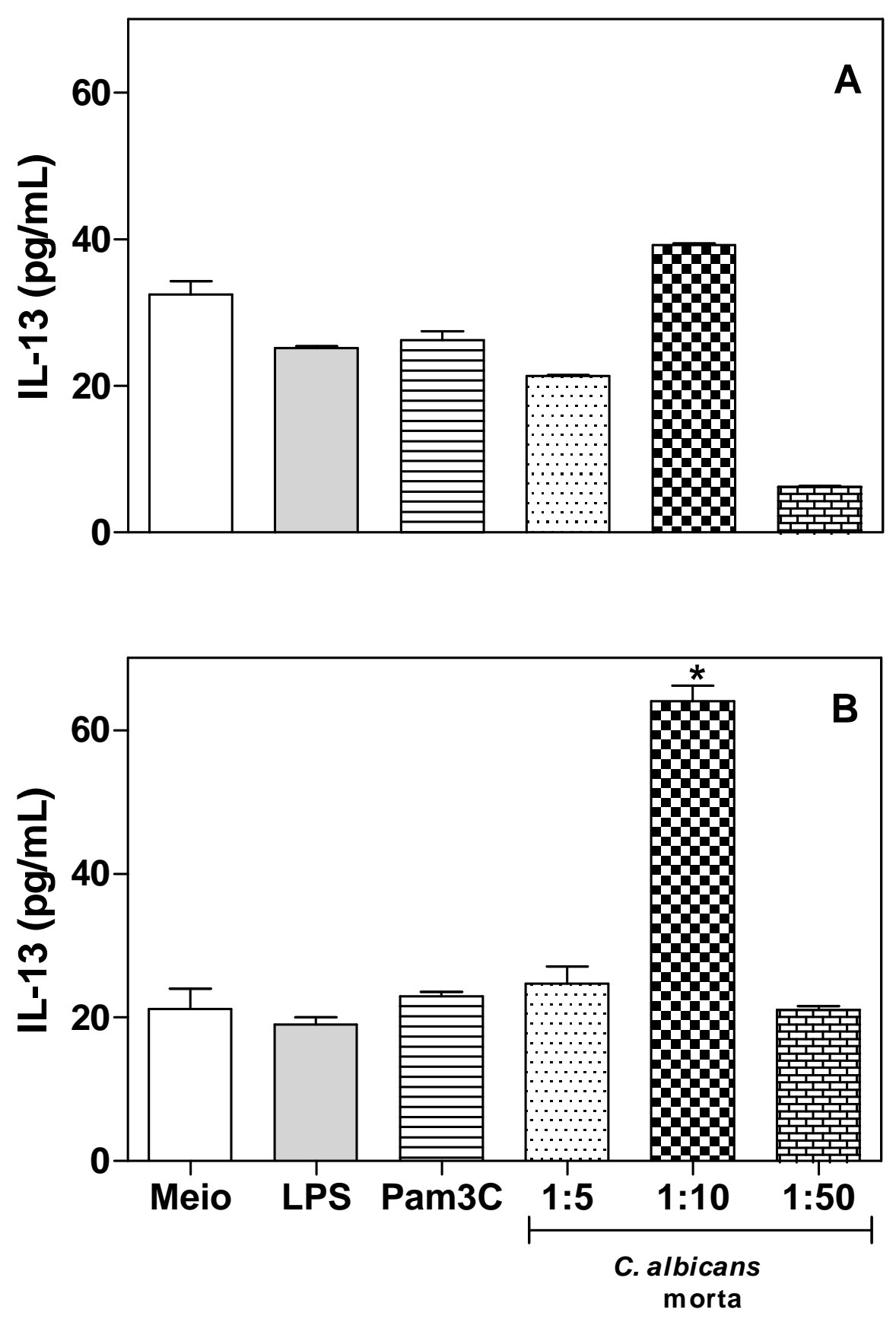

Figura 29- Produção de IL-13 por fibroblastos pulpares. Fibroblastos pulpares de camundongos do grupo controle (WT) (A) e CD14 KO (B) foram cultivados na ausência de estímulo (meio), com LPS (100ng/ml), PAM3C $(1 \mu \mathrm{g} / \mathrm{ml}), C$. albicans morta nas proporções 1:5, 1:10 e 1:50. Após 48horas, o sobrenadante das culturas foi coletado e a concentração de IL-13 determinada por ELISA. Dados representativos de três experimentos independentes. Os resultados foram avaliados pelo teste de ANOVA seguido pelo teste de Bonferroni. ${ }^{*} \mathrm{P}<0,05$. 

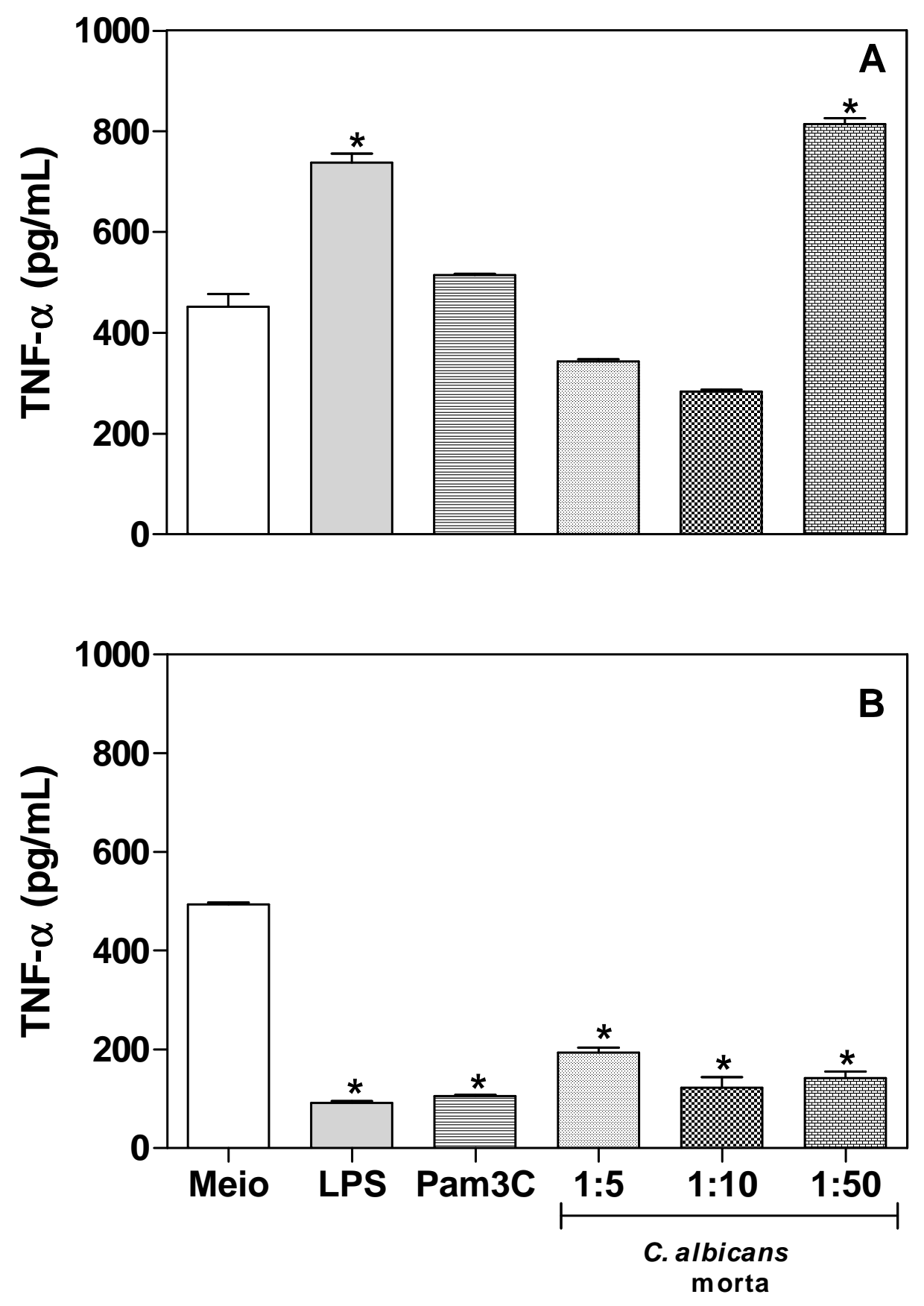

Figura 30 - Produção de TNF-a por fibroblastos pulpares. Fibroblastos pulpares de camundongos do grupo controle WT e CD14 KO foram cultivados na ausência de estímulo (meio), com LPS $(100 \mathrm{ng} / \mathrm{ml})$, PAM3C $(1 \mu \mathrm{g} / \mathrm{ml})$, C. albicans morta nas proporções 1:5, 1:10 e 1:50. Após 48 horas, o sobrenadante das culturas foi coletado e a concentração de TNF- $\alpha$ determinada por ELISA. Dados representativos de três experimentos independentes. Os resultados foram avaliados pelo teste de ANOVA seguido pelo teste de Bonferroni. ${ }^{*} \mathrm{P}<0,05$. 



\section{Discussão $_{\text {in }}$}



O sistema imune inato utiliza uma variedade de receptores de reconhecimento de padrões para identificar o agente agressor. Esses receptores podem ser expressos na superfície da célula, em compartimentos intracelulares, ou segregado para o sangue e fluidos teciduais (GLAROS; LARSEN, 2009; VADILLO; PELAYO, 2012). As principais funções dos receptores de reconhecimento de padrão incluem opsonização, ativação de complemento e cascatas de coagulação, fagocitose, a ativação de vias de sinalização pró-inflamatórias e indução de apoptose. Vários receptores da superfície celular expressos em fibroblastos funcionam como receptores de reconhecimento de padrão que medeiam à ativação destas células após o reconhecimento de micro-organismos.

A primeira indicação de que os TLRs de mamíferos podem funcionar como receptor de reconhecimento de padrões veio com a descrição de um homólogo humano de Toll de Drosophila, agora conhecido como TLR4 (MEDZHITOV, 2001; UNDERHILL; OZINSKY 2002). Os receptores do tipo Toll diferem uns dos outros, principalmente, na especificidade de ligação e nos padrões de expressão. Vários TLRs estão envolvidos no reconhecimento de uma variedade de PAMPs. Os receptores TLRs estão presentes em vários tipos celulares, incluindo linfócitos T e B, células endoteliais, epiteliais, fibroblastos e células neoplásicas, e também células da imunidade inata como neutrófilos, monócitos/macrófagos, células dendríticas, células NK e mastócitos ativando mecanismos de resposta imediata contra patógenos (TAKEDA; AKIRA et al., 2004; CHANG, 2010).

Os fibroblastos são as células mais abundantes no tecido pulpar e gengival (CHIEGO, 2002). Apresentam hetereogeneidade fenotípica em um mesmo tecido (HARRIS, 1994), e as diferenças funcionais e de fenótipo desempenham papel fundamental na susceptibilidade intrínseca de diferentes órgãos a agressões e processos inflamatórios, uma vez que desequilíbrios na regulação das células de defesa e alterações na microbiota patogênica podem acarretar no aparecimento da sintomatologia clínica de algumas doenças, como as periodontopatias e periapicopatias (HOGABOAM, et al., 1998; BROUTY-BOYE et al., 2000; PAP et al., 2000). Para a compreensão dos fenômenos imunológicos e inflamatórios que afetam o tecido gengival e pulpar é relevante o conhecimento sobre a ativação de fibroblastos, nestes tecidos, e seu papel no desenvolvimento da resposta imune e inflamatória. A contribuição de fibroblastos no desenvolvimento da resposta imune em outros tecidos já foi descrita (TRACKMAN; KANTARCI, 2004; YANG et al., 2013; BORG et al., 2013). Contudo, poucos são os relatos a cerca do papel de receptores do tipo Toll no reconhecimento 
de Candida albicans por fibroblastos gengivais e pulpares. Dada a importância de se conhecer mais sobre o papel de fibroblastos no contexto de inflamação no microambiente pulpar e gengival, o presente estudo investigou o papel de receptores de reconhecimento de patógenos (TLR2 e CD14) e da molécula adaptadora MyD88 no reconhecimento de Candida albicans por fibroblastos gengivais e pulpares. -

Buscando esclarecer quais seriam as principais diferenças fenotípicas de fibroblastos provenientes de cada tecido (polpa e gengiva) e se estes apresentavam variações órgãoespecíficas nas classes de moléculas biologicamente ativas, isolamos fibroblastos da polpa e gengiva de camundongos do grupo controle e deficientes de TLR2, CD14 e MyD88, e inicialmente, avaliamos a morfologia destas células. Os resultados evidenciaram que, apesar de oriundas de tecidos diferentes, os fibroblastos gengivais e pulpares apresentarem aspecto morfológico semelhante. Tanto os fibroblastos gengivais quanto os pulpares apresentaram fenótipo fusiforme com longas extensões citoplasmáticas e núcleos elípticos bem definidos. Contrário com nossas observações, estudo com fibroblastos de tecido humano relatou diferenças morfológicas entre fibroblastos gengivais e pulpares (MARTINEZ; ARAÚJO, 2004). Os autores relataram que fibroblastos pulpares apresentaram citoplasma fusiforme e fibroblastos gengivais possuem citoplasma piramidal ou em forma de estrela com núcleo arredondado.

Outro aspecto avaliado em nosso estudo foi o tempo em que os fibroblastos levaram para aparecer a partir dos explants (fragmentos teciduais) durante a cultura primária. Neste tópico, os resultados evidenciaram diferenças significantes entre os fibroblastos isolados do tecido gengival e pulpar, e também entre fibroblastos gengivais dos diferentes grupos. Fibroblastos isolados do tecido gengival de camundongos do grupo controle (WT), TLR2KO e CD14KO apresentaram velocidade de crescimento maior que fibroblastos gengivais de animais MyD88KO. A dificuldade no estabelecimento da cultura de células provenientes desses animais e a cinética mais lenta de crescimento das mesmas pode ter sido influenciada pela deficiência da proteína adaptadora MyD88. Estudos relatam que os diferentes tecidos de camundongos MyD88KO apresentam poucos fibroblastos e 60\% a menos deposição de colágeno (MÅNSSON et al., 2012). Tal fato poderia explicar a demora no surgimento de fibroblastos a partir do tecido gengival de animais deficientes de MyD88. De fato, a ausência de MyD88 também parece influenciar o surgimento de outros tipos celulares a partir de fragmentos de tecido, como por exemplo, cardiomiócitos e células pancreáticas. 
Cardiomiócitos de camundongos MyD88KO demoram mais para surgir e sofrem apoptose mais facilmente, em comparação com cardiomiócitos de camundongos do grupo controle e TLR4KO (ZHU et al., 2006). As células pancreáticas de camundongos MyD88KO ficam senescentes mais rapidamente que células provenientes de animais sem essa proteína adaptadora (BOLLYKY et al., 2009). As diferenças com relação à cinética de crescimento também foram observadas por fibroblastos pulpares. Os fibroblastos pulpares apresentaram surgimento e proliferação celular extremamente lentos, em comparação com os fibroblastos gengivais. Um fator que poderia influenciar o surgimento de fibroblastos pulpares seria o número de células no tecido. Dados da literatura demonstram que fibroblastos pulpares necessitam de mais tempo para surgir a partir de explants (COUBLE et al., 2000; GRONTHOS et al., 2000; NAKAO et al., 2004; SAITO et al., 2004). Além disso, fibroblastos pulpares proveniente de animais deficiente de TLR2 e MyD88 não entraram em confluência e, por permanecerem um longo período em cultura, as células ficavam vacuolizadas e senescentes. Como observado para fibroblastos gengivais, à ausência de CD14 não influenciou o surgimento e cinética de crescimento de fibroblastos pulpares, levando-nos a inferir que a sinalização via este receptor não regularia estes aspectos da fisiologia de fibroblastos.

Fibroblastos são células importantes na produção de muitos componentes do tecido conjuntivo, como os componentes da matriz extracelular e o colágeno (OKIJI; HARDGREAVES; GOODIS, 2002). Assim, em seguida, analisamos a expressão de colágeno tipo I por fibroblastos gengivais. A ausência de TLR2, CD14 e MyD88 não influenciou a produção de colágeno tipo I por fibroblastos gengivais. De modo semelhante ao observado em nosso estudo, dados da literatura evidenciaram que a ausência de MyD88 e CD14 não interferiu com a produção de colágeno tipo I por fibroblastos isolados do tecido renal (SKUGINNA et al., 2011). Contudo, a ausência de TLR2 diminui a síntese de colágeno tipo I por fibroblastos provenientes do tecido renal de humanos e essas diferenças entre os estudos, poderiam apontar para o fato de que dependendo do tecido do qual as células são isoladas, os receptores do tipo Toll poderiam de alguma forma influenciar na produção de colágeno tipo I (MIYAZAKI et al., 2012). A estimulação com LPS, Pam3CSK4 e C.albicans morta 1:10 não afetaram significativamente na expressão de colágeno tipo I por fibroblastos do grupo controle, TLR2KO e MyD88KO. Contudo, fibroblastos de animais CD14KO apresentaram baixa imunomarcação para colágeno Tipo I e a estimulação com qualquer um dos antígenos, $\underline{\text { não alterou o perfil de expressão desta molécula. Nossos achados estão de acordo com o }}$ 
estudo com fibroblastos isolados de ovário, no qual os autores mostraram que os receptores TLR4/CD14 são requeridos para o reconhecimento de LPS pelas células, para haver maior expressão e produção de colágeno (SPRONG et al., 2011). Fibroblastos gengivais provenientes de animais deficientes de TLR2, CD14 e TLR4 foram estimulados com LPS de A. actinomycetemcomitans e expressaram menos colágeno (TAKAHASHI et al., 2008). Os resultados mostraram que CD14 expresso por fibroblastos gengivais murinos está envolvido com reconhecimento de LPS bacteriano e induz ativação de fibroblastos gengivais e a produção de colágeno tipo I.

Está bem estabelecido que o sistema imune utiliza TLRs para o reconhecimento de patógenos, e que este reconhecimento desencadeia a produção de inúmeros mediadores que contribuem para o controle da infecção. Fibroblastos podem desempenhar importante papel na mediação da resposta inflamatória por expressarem receptores do tipo toll (TLR1, TLR2, TLR3, TLR4, TLR5, TLR6 e TLR9) (NEUFERT et al., 2001; TAKEDA, 2004; MATSUMOTO et al., 2003; MAHANONDA et al., 2007; NAHUM et al., 2012). Estudos anteriores demonstraram que fibroblastos pulpares expressam TLR2, TLR3 e TLR4 e gengivais expressam TLR1 a TLR9 (STAQUET et al., 2008; PARK et al., 2010; INTO et al., 2010; WARA-ASWAPATI et al., 2012). Em nosso estudo, confirmamos e ampliamos estes resultados, e mostramos que a expressão de TLR2 e TLR4 por fibroblastos gengivais pode ser regulada pela proteína adaptadora MyD88 e a molécula CD14, enquanto que a expressão de TLR3 é regulada apenas por CD14. Embora a questão de como a sinalização via a proteína adaptora MyD88, independente da estimulação por antígenos microbianos, possa regular a expressão de receptores de tipo Toll por fibroblastos gengiviais está além do escopo do presente estudo, é tentador especular que as diferenças podem estar relacionadas a aspectos importantes da cascata de sinalização intracelular. Camundongos MyD88KO são incapazes de

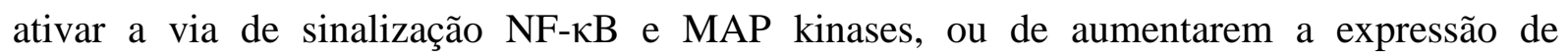
moléculas de MHC e moléculas co-estimulatórias em resposta a IL-1 e muitos ligantes de TLR, incluindo peptideoglicanos e CpG (KAWAI et al., 1999; SCHNARE et al., 2000; TAKEUCHI et al., 2000). Entretanto, LPS (agonista de TLR4) ativa a via de NF-אB e MAP kinases (embora de forma mais tardia) na ausência de MyD88 (KAWAI et al., 1999). Além disso, células dendríticas deficientes de MyD88 estimuladas com LPS mantêm a habilidade de aumentar a expressão de moléculas co-estimulatórias e MHC (KAISHO et al., 2001). Desta forma, MyD88 é necessário para a sinalização de alguns TLR(s), como TLR2 e TLR9, o mesmo pode ser dispensável por alguns sinais induzidos por TLR4. Outras respostas 
inflamatórias podem ser completamente dependentes dessa molécula adaptadora, qualquer que seja o estímulo. Camundongos MyD88KO não produzem IL-12 após estimulação com diferentes PAMPS, incluindo LPS e CpG DNA (SCHNARE et al., 2000; KAISHO et al., 2001). Um estudo mais detalhado sobre as vias de sinalização e cinética é necessário para resolver esse problema. Seja qual for a explicação para esse fenômeno, os dados sugerem que a via de sinalização desencadeada pela proteína adaptadora MyD88 é importante para a indução da expressão constitutiva de TLR2 e TLR4 por fibroblastos gengivais.

Em relação aos sinais mediados via a molécula CD14, em estudo com células da glia, foi relatado que a expressão de TLR2 é diminuída por células provenientes de camundongos CD14KO e esse receptor teria a função de agonista endógeno de TLR2 (BSIBSI et al., 2007). De modo contrário, a ausência de CD14 e TLR4 não interfere com a expressão de TLR2 por macrófagos murinos (HAZEKI et al., 2003). Dados da literatura indicam que existe uma relação entre os receptores TLR2, CD14 e a proteína adaptadora MyD88 e a expressão de TLR4 pelas células do tecido adiposo murino (POULAIN-GODEFROYet al., 2010). Portanto, acreditamos que os resultados do nosso estudo irão fornecer dados importantes para melhor entendimento do papel desses receptores e da proteína adaptadora MyD88 na fisiologia de fibroblastos gengivais murinos.

Tendo estabelecido a expressão de receptores do tipo Toll por fibroblastos gengivais, e sabendo que estes receptores têm um papel relevante no reconhecimento de patógenos, o nosso próximo passo foi avaliar o envolvimento destes receptores no reconhecimento de Candida albicans por fibroblastos gengivais e pulpares. Para tal inicialmente avaliamos a ativação dos fibroblastos após o estimulo com Candida e agonistas de TLR2 e TLR4.

Lipopolissacarídeo (agonista de TLR4), Pam3CSK4 (agonista de TLR2) e C. albicans viva (1:5) induziram aumento na percentagem de fibroblastos de camundongos do grupo controle expressando TLR2. O aumento da expressão de TLR2 induzido por um agonista de TLR4 e Candida albicans pode ter conseqüências clínicas relevantes, porque esta via pode levar a amplificação na resposta celular mediada por TLR2 a antígenos bacterianos e fúngicos nas doenças periodontais e pulpares.

Como mencionado anteriormente, a deficiência de MyD88 e CD14 leva a baixa expressão de TLR2 por fibroblastos e a estimulação com agonistas de TLR2 e TLR4 não induziu aumento na expressão deste receptor. Tal dado reforça nossa suposição de que via de 
sinalização desencadeada pela proteína adaptadora MyD88 é importante para controlar funções de fibroblastos, neste caso específico, a expressão de TLR2 e TLR4. Sobre a correlação da molécula CD14 e a expressão de TLR2 e TLR4, é estabelecido na literatura que primeiro os ligantes destes receptores ligam-se a uma molécula adaptadora antes de se ligarem aos receptores TLRs. CD14 liga ao agonista de TLR4 (LPS) e ao agonista de TLR2 (Pam3CSK4), e a formação do complexo ligante-CD14 é o pré-requisito para a ligação com TLR4/MD2 ou TLR2/TLR1, respectivamente, para induzir a ativação celular (DEBIERREGROCKIEGO, 2007). Desta forma, acreditamos que a ausência de CD14 poderia influenciar na expressão de TLR2 e TLR4 o que implicaria na ausência de reconhecimento de agonistas de TLR2 e TLR4. Assim, podemos inferir que TLR2 expresso na superfície celular de fibroblastos gengivais murinos é necessário para o reconhecimento de LPS e C. albicans, mas para isso, é necessário o envolvimento da molécula CD14 e da proteína adaptadora MyD88.

Um estudo recente mostrou que os fibroblastos de prepúcio humano e pulmão expressam TLR3 na superfície celular (HARWANI et al., 2007). No entanto, em nosso estudo, demonstramos a presença de TLR3 intracelular, mas não na superfície de fibroblastos gengivais. A expressão TLR por fibroblastos pode ser diferente em locais anatômicos distintos. Mais estudos são necessários para identificar e comparar o significado fisiológico da expressão intracelular e de superfície de TLR3. A expressão na superfície celular de TLR3 por fibroblastos é interessante porque TLR3 reconhece dsRNA, um subproduto da replicação viral (TATEMATSU et al., 2013). Pam3CSK4 (agonista de TLR2) induziu a expressão de TLR3 (CD283) por fibroblastos do grupo controle e deficientes de MYD88. A estimulação por bactérias e fungos através de TLR2 é capaz de mediar à indução de citocinas antiinflamatórias (AKIRA; TAKEDA, 2004), e as citocinas regulam a expressão de receptores do tipo Toll por diferentes tipos celulares. Assim, acreditamos que a produção de citocinas seria o fator relacionado com a expressão de TLR3 por fibroblastos gengivais após o reconhecimento de agonistas de TLR2. Candida albicans inativada pelo calor (1:5) induziu aumento significativo na percentagem de fibroblastos $\mathrm{TLR}^{+}$em amostras de camundongos TLR2KO e Candida albicans viva (1:5) na expressão deste receptor por células de animais MyD88KO. Não há na literatura nenhuma evidência sobre um aumento da expressão de TLR3 por fibroblastos gengivais após a estimulação destas células com $C$. albicans, por isso os resultados do presente estudo trazem grande contribuição para o melhor entendimento acerca do reconhecimento de $C$. albicans por receptores de reconhecimento de padrão e como esta sinalização influenciaria a ativação dos fibroblastos e modularia a expressão de TLR3. 
Sendo que a indução da expressão de TLR3 após o reconhecimento do fungo poderia ter implicações significativas em situações onde há infecções comitentes do tecido periodontal e pulpar. Herpes vírus tem sido associado com a etiologia e gravidade das doenças periodontais (JOHNSON, 2010; SLOTS, 2011). A expressão de TLR3, assim, sugere um papel de fibroblastos em resposta a infecção viral.

A expressão de TLR4 por fibroblastos gengivais de animais do grupo controle foi modulada negativamente pela estimulação com $C$. albicans viva (1:5) e morta (1:10). Uma explicação para este fenômeno seria a modulação na expressão de TLR4 por fibroblastos gengivais através de sinais mediados pelo reconhecimento do fungo por outro grupamento de receptores do tipo Toll. De fato, nossos resultados mostraram que a expressão de TLR4 por fibroblastos gengivais de animais TLR2KO é aumentada após a estimulação com C. albicans viva (1:10). Esses resultados poderiam indicar que os sinais mediados por TLR2 influenciariam a expressão de TLR4 por fibroblastos gengivais e do ligamento periodontal (TAMAI et al., 2002; TANG et al., 2011). Outro fator que controlaria a expressão de TLR4 por fibroblastos gengivais, após o reconhecimento de C. albicans, seria a produção de citocinas. Várias citocinas regulam a expressão de TLRs. IFN- $\gamma$ prima fagócitos para responderem ao LPS, aumenta a expressão de TLR4 por monócitos, macrófagos humanos e fibroblastos sinoviais humanos (ROELOFS et al., 2009). Apesar de TLR4 estar mais relacionado com o reconhecimento de LPS, esta molécula também tem sido implicada no reconhecimento de acido lipoteicoico, proteínas do choque (heat shock protein, hsp60), e a proteína de fusão de vírus respiratório (HROMADNIKOVA et al., 2008; GUTIÉRREZVENEGAS, 2011). Apesar de não termos especificado qual antígeno de C. albicans seria reconhecido por fibroblastos gengivais deficientes de TLR2, não podemos descartar a possibilidade de que antígenos do fungo sejam reconhecidos via TLR4 e modulem de forma autocrina a expressão deste receptor. De fato, dados da literatura relatam a importância de TLR4 para o reconhecimento de $C$. albicans por células epiteliais e macrófagos murinos. A ausência deste receptor em macrófagos murinos resultou em menor quimiotaxia de neutrófilos para o local da infecção, menor produção de TNF- $\alpha$ e óxido nítrico, com disseminação e persistência do patógeno nos linfonodos e baço (NETEA; KULLBERG, 2010; GASPAROTO et al., 2010).

Outro mecanismo que explicaria a diminuição na percentagem de fibroblastos TLR $4^{+}$ (CD284) em amostras do grupo controle seria a indução de apoptose de fibroblastos gengivais 
mediada pelo reconhecimento de Candida albicans. Contudo, não há evidências na literatura que estabeleça correlação entre a indução de apoptose em fibroblastos após o reconhecimento de C.albicans através de receptores do Tipo Toll.

Fibroblastos expressam constitutivamente moléculas de adesão como, por exemplo, VCAM, ICAM-1(CD54) e CD44. Estas moléculas constituem a principal família de receptores que medeiam interações entre as células e matriz extracelular, influenciando direta ou indiretamente na adesão, migração, proliferação e diferenciação de outras células da imunidade (De ARCANGELIS; GEORGES-LABOUESSE, 2000). Por isso, avaliamos se a estimulação destas células com diferentes antígenos poderia alterar a expressão das moléculas de adesão ICAM-1 (CD54) e CD44.

A expressão de ICAM por fibroblastos humanos é importante para a resposta inflamatória no tecido periodontal (CHANG et al., 2013). Em nosso estudo, verificou-se que LPS induz aumento na expressão da molécula de adesão ICAM-1 (CD54) por fibroblastos gengivais de camundongos WT e deficientes de TLR2. Sabe-se que o reconhecimento de LPS ocorre através do complexo TLR4/CD14/MD-2, resultando em um aumento da expressão de ICAM-1 (KUMAGAI et al., 2005). Após estimulação com diferentes patógenos e seus produtos, bem como com citocinas, fibroblastos gengivais secretam vários mediadores solúveis como IFN- $\gamma$, PGE2, IL-1, IL-6, IL-8 e aumentam a expressão de HLA-DR e ICAM-1 (TAKAHASHI et al., 1994; MIRANDA-CARÚS, 2004). Nossos achados não estão em acordo com estudos que mostraram que em fibroblastos intersticiais isolados de camundongos TLR2KO e estimulados com antígenos bacterianos, há uma diminuição da expressão de ICAM-1, dificultando o processo de adesão destas células (SORENSEN et al., 2011).

CD14 é expresso em monócitos, macrófagos e em algumas outras células, como por exemplo, os fibroblastos, e é responsável pelo reconhecimento padrão de componentes da superfície celular das bactérias tais como LPS e peptideoglicanos. Estudos recentes têm demonstrado que a produção de citocinas inflamatórias é mediada por CD14 e TLR4 expressos por fibroblastos gengivais humanos em resposta ao LPS de P.gingivalis. A expressão de CD44 pode ser modulada positiva ou negativamente a partir do reconhecimento de diferentes patógenos por fibroblastos gengivais. A molécula adaptadora Myd88 é necessária durante o reconhecimento de C. albicans e outros antígenos por fibroblastos gengivais, uma vez que a ausência desta molécula acarreta em diminuição da expressão de 
CD44. A estimulação feita com C. albicans morta (1:5) induz um aumento de fibroblastos $\mathrm{CD}_{4} 4^{+}$em amostras do grupo controle, mas diminuiu a percentagem de células positivas para este marcador em amostras de camundongos TLR2KO. De modo diferente, C. albicans viva (1:5) diminui a percentagem de fibroblastos $\mathrm{CD}_{4} 4^{+}$em amostras do grupo TLR2KO e CD14KO, o que pode significar que de alguma forma, o aumento da expressão de CD44 depende de um mecanismo que envolve os sinais mediados por TLR2 e CD14. Esta modulação diferencial da expressão de CD44 por fibroblastos gengivais poderia ser explicada pela produção de citocinas. TNF- $\alpha$ e IL-1 $\beta$ não alteraram a expressão de CD44 por fibroblastos de ligamento periodontal de humanos in vitro (HIRANO et al., 1997). Algumas citocinas, como a TGF- $\beta$ e IL-13 aumentam a expressão deste receptor (SCHIERANO et al., 2001).

Após analisarmos o envolvimento dos receptores do tipo Toll no reconhecimento de Candida albicans por fibroblastos gengivais e pulpares; analisamos se a ausência de TLR2, CD14 e da molécula adaptadora MyD88 interferiria na resposta proliferativa destas células após estimulação com Candida e agonistas de TLR2 e TLR4. Fibroblastos gengivais de camundongos dos grupos MyD88KO, CD14KO e controle evidenciaram um potencial proliferativo crescente ao longo do tempo independente do estímulo; contudo, a ausência do receptor TLR2 interferiu com proliferação fisiológica destas células. A estimulação com Candida morta induziu alterações no perfil proliferativo dos fibroblastos, sendo que as maiores diferenças foram observadas na cultura de células provenientes de animais deficientes de TLR2, que apresentaram a maior resposta proliferativa. Diferente das nossas observações, fibroblastos intersticiais renais de camundongos TLR2KO apresentam baixa resposta proliferativa e menor expressão de moléculas de adesão como ICAM-1 e VCAM após a estimulação antigênica (SORENSEN et al., 2011). A ausência de TLR2 acentua a proliferação de fibroblastos gengivais após a estimulação com C. albicans (1:50), provavelmente por alteração no perfil de produção de citocinas.

Outro aspecto importante para maior elucidação do reconhecimento de C. albicans e outros patógenos através de receptores do tipo Toll por fibroblastos gengivais e pulpares é o perfil de produção de citocinas. TGF- $\beta$ é uma citocina pleiotrópica (pode atuar sobre muitos tipos de células) e assim como outras citocinas possui efeito anti-inflamatório. TGF- $\beta$ é produzido por uma variedade de células e participa do reparo tecidual, pela indução da proliferação, diferenciação e migração de odontoblastos e células da polpa (MELIN et al., 
2000). TGF- $\beta$ apresenta papel regulatório na produção de colágeno tipo 1 (TZIAFAS et al., 1998). A ausência de TGF- $\beta$ provavelmente contribui para maior destruição tecidual (BABEL et al., 2006). A estimulação com LPS, Pam3CSK4, C.albicans viva e morta, não induziu alterações significativas quanto à produção de TGF- $\beta$ por fibroblastos gengivais. Da mesma forma, o desafio com os diferentes antígenos não alterou de modo significativo a produção desta citocina por fibroblastos pulpares de animais WT e CD14KO. Contudo, a estimulação com LPS e C. albicans morta (1:5) inibiu a produção desta citocina por fibroblastos gengivais de animais do grupo CD14KO, após 48 horas de cultivo. De modo similar, fibroblastos isolados de tecido adiposo humano, que expressavam menos TLR4/CD14, apresentaram falhas no reconhecimento de LPS bacteriano e menor produção de TGF- $\beta$ (WANG et al., 2012).

Algumas citocinas, como TNF- $\alpha$ estimulam a produção local de quimiocinas que atuam na amplificação e manutenção da resposta inflamatória local, além de exercerem papel relevante na osteoclastogênese, estimulando a reabsorção e inibindo a neoformação óssea (GRAVES; COCHRAN, 2003). Os fibroblastos gengivais murinos do grupo controle quando estimulados com todos os antígenos, exceto TGF- $\beta$, produziram níveis significativos de TNFa. A deficiência de TLR2, MyD88 e CD14 levou a uma diminuição na produção desta citocina, exceto quando o estímulo foi feito com $C$. albicans morta (1:5) em células gengivais MyD88KO. O reconhecimento de $P$. gingivalis por TLR2 presente em fibroblastos gengivais, assim como o do ácido lipoteicoico de $S$. aureus por fibroblastos pulpares humanos é fundamental para resultar em aumento da produção de citocinas, como TNF- $\alpha$ (ADACHI et al., 2007; JUNG et al., 2009). Da mesma forma, fibroblastos sinoviais humanos somente quando estimulados com agonistas de TLR2 (Pam3CSK4 e LPS) e TLR4 (LPS de Escherichia coli e LPS P. gingivalis) produzem grandes quantidades de TNF- $\alpha$, levando os autores a concluírem que o reconhecimento antigênico feito por TLR2/MyD88 e TLR4/MyD88, são os responsáveis por esse aumento (ZARIC et al., 2011; WARAASWAPATI et al., 2012). Não há relatos na literatura sobre reconhecimento de $C$. albicans através de TLR(s) por fibroblastos gengivais murinos e sua correlação com a produção de TNF- $\alpha$ por estas células. Atualmente, observam-se apenas dados relacionados com a produção de TNF- $\alpha$ por macrófagos, neutrófilos e monócitos após o reconhecimento do fungo. Nossos resultados evidenciaram que fibroblastos pulpares do grupo controle produziram níveis significativos de TNF- $\alpha$, após estimulação com LPS e C. albicans morta (1:50); entretanto as células deficientes de CD14 produzem níveis menores desta citocina. Como a ausência do 
receptor não interferiu na produção de TNF- $\alpha$ por células que não receberam estímulo, ousamos especular, que os antígenos podem ter feito com que as células da polpa entrassem em apoptose. Essa hipótese é corroborada por um estudo em que algumas células da polpa de humanos quando submetidas à estimulação com LPS de diversas espécies bacterianas, entraram em apoptose (HIRAO et al., 2009). Portanto, baseado em nossos dados, podemos inferir que fibroblastos gengivais e pulpares reconhecem $C$. albicans através de receptores de padrão e esses receptores estão envolvidos diretamente com a produção de TNF- $\alpha$ por estas células.

A citocina IL-6 pode ser produzida por macrófagos, monócitos, neutrófilos, linfócitos, células endoteliais e fibroblastos (TAKASHIBA; NARUISHI; MURAYAMA, 2003)._ IL-6 em níveis elevados está associada com a patogênese de várias doenças inflamatórias como, por exemplo, a periodontite (TAKAHASHI et al., 1994). Verificou-se que tecido pulpar inflamado contem níveis elevados de IL-6 (BARKHORDAR et al., 1999). Tal fato indicaria que IL-6 poderia ter importante papel na mediação da resposta imune e inflamatória desenvolvida no tecido pulpar e gengival após a infecção. LPS estimulou a produção de IL-6 por células de camundongos deficientes de TLR2 e de CD14, e Pam3CSK4 induziu a produção de IL-6 por fibroblastos gengivais e pulpares de camundongos CD14KO. A estimulação de fibroblastos gengivais e pulpares com C.albicans morta (1:5) induziu a produção de IL-6 por células de animais deficientes de TLR2. Baixa ou ausente foi a produção de IL-6 por fibroblastos gengivais de camundongos deficientes de MyD88. Semelhante aos nossos achados, um estudo mostrou que o reconhecimento microbiano por TLR2 e TLR4 é requerido por fibroblastos gengivais humanos para produção de IL-6 e IL-8, mas para que isso seja possível, é necessário o envolvimento da proteína adaptadora, MyD88 (MOCHIZUKI et al., 2004). Também foi evidenciado na literatura que células dendríticas do sangue periférico humano reconhecem os componentes da parece celular de C. albicans por um mecanismo dependente de TLR2/MyD88 e TLR4/MyD88 (PIETRELLA et al., 2006). Portanto, podemos concluir que MyD88 é requerido para ativar as vias de sinalização que acarretem na produção de IL-6 por fibroblastos gengivais.

IL-1 $\beta$ é produzida principalmente por macrófagos, monócitos, miócitos, células endoteliais, queratinócitos, linfócitos e fibroblastos. Sua função pró-inflamatória está relacionada com a exacerbação da fase aguda da inflamação. Além disso, esta citocina estimula a atividade de osteoclastos (HAVEMOSE-POULSEN; HOLMSTRUP, 2007). Como 
estabelecido na literatura, o reconhecimento de LPS por células do sistema imune é independe de TLR2. Assim, como esperado, LPS induziu aumento na produção de IL-1 $\beta$ por fibroblastos do grupo controle e deficientes de TLR2, enquanto que Pam3CSK4 induziu a produção desta citocina por células de camundongos do grupo controle. De modo relevante, nossos resultados mostraram que $C$. albicans morta diminui a produção de IL-1 por fibroblastos do grupo controle e deficientes de MyD88. Da mesma forma, após 24 horas de cultura, uma diminuição nos níveis de IL-1 $\beta$ foi observada em cultura de fibroblastos gengivais TLR2KO e MyD88KO estimulados com C.albicans morta (1:10) e C. albicans viva (1:5) e (1:10). Portanto, podemos inferir que o reconhecimento de $C$. albicans por fibroblastos gengivais influencia na produção de IL-1 $\beta$, de forma dependente de TLR2. Semelhante aos nossos achados, a literatura demonstra que outros tipos de células como macrófagos, neutrófilos, monócitos e células $\mathrm{T}$ reguladoras reconhecem através de TLR2 e TLR4 patógenos bacterianos e C. albicans, resultando na produção de citocinas anti-inflamatórias e pró-inflamatórias como IL-1 $\beta$ (NETEA et al., 2004; MURCIANO et al., 2008; GOSH et al., 2010). Corroborando com nossos dados, fibroblastos pulpares humanos estimulados somente com ácido lipoteicoico (agonista de TLR2) produzem IL-1 $\beta$ e IL-8 (KELLER et al., 2010).

A citocina IL-13 possui ação anti-inflamatória e tem por função induzir regeneração tecidual e neoformação óssea e são produzidas por célula natural killer (NK), basófilos, eosinófilos e fibroblastos (KATO-KOGOE et al., 2010). IL-13 pode estar envolvida com a síntese de colágeno, independente de TGF- $\beta$ e acarretar na proliferação de células musculares e por isso pode contribuir para a fibrose tecidual (ORIENTE et al., 2000; BOSSE et al., 2008). A citocina IL-13 ativa muitas outras células, incluindo macrófagos, mastócitos, linfócitos B e células nervosas, contribuindo potencialmente para o quadro patológico (HERSHEY, 2003). Ademais, IL-13 promove a transcrição das metaloproteinases da matriz (MMP 2, 9, 12 e 14) e diminui a síntese de MMP-1, além disso pode ainda estar atuando em sinergismo com TGF- $\beta$ para aumentar os níveis dos inibidores de metaloproteinases (TIMP)-1 por fibroblastos teciduais em mecanismo pró-fibrótico (LEE et al., 2006; LEONARDI et al., 2003, ZHOU et al., 2005). C. albicans morta (1:10) induziu a produção de IL-13 por fibroblastos gengivais e pulpares do grupo controle e de camundongos deficientes de MyD88 e CD14 (após 48 horas). Estes dados indicam que estas vias não estariam envolvidas com a produção de IL-13 por fibroblastos gengivais após o reconhecimento de C. albicans, entretanto, a literatura é muito restrita em mostrar uma correlação entre fibroblastos 
gengivais/pulpares, TLR(s) e produção de IL-13, uma vez que, não há nenhum estudo sobre a produção de IL-13 após estimulação deste tipo de células com C. albicans.

Como base nos resultados apresentados, o presente estudo demonstra que fibroblastos gengivais e pulpares reconhecem Candida albicas e produzem TNF- $\alpha$ e IL-13. Além disso, demonstramos que os receptores TLR2, TLR4/CD14 e a molécula adaptadora MyD88 estão envolvidos no reconhecimento de $C$. albicans por fibroblastos e na produção de citocinas. Estes resultados evidenciam que fibroblastos da polpa e da gengiva interagem com o fungo e poderiam desempenhar papel importante no início da resposta inflamatória. 

Conclusão 

Com base nos resultados apresentados, pode-se concluir que:

1. Fibroblastos gengivais e pulpares apresentaram características morfológicas semelhantes;

2. Fibroblastos gengivais deficientes de MyD88 apresentam velocidade de surgimento e crescimento lentos;

3. Fibroblastos pulpares demoraram mais tempo para surgir a partir dos fragmentos teciduais e tem velocidade de crescimento lento;

4. A ausência de CD14 afeta produção de colágeno Tipo I por fibroblastos gengivais;

5. Fibroblastos gengivais expressaram TLR2, TLR3, TLR4 e as moléculas de adesão ICAM-1 e CD44;

6. Fibroblastos gengivais reconhecem C. albicans e produzem TNF- $\alpha$ e IL-13;

7. A produção de TNF- $\alpha$ por fibroblastos gengivais após o reconhecimento de $C$. albicans é dependente de TLR2, TLR4/CD14 e da via de sinalização que envolve a proteína adaptadora MyD88;

8. A produção de IL-13 por fibroblastos gengivais após a estimulação com $C$. albicans inativada pelo calor é dependente de TLR2, enquanto que por $C$. albicans viva é independente de TLR2;

9. Fibroblastos pulpares reconhecem $C$. albicans e produzem TNF- $\alpha$ por via dependente da molécula CD14/TLR4. 



\section{Referências}



Adachi T, Nakanishi T, Yumoto H, Hirao K, Takahashi K, Mukai K, et al. Caries-related bacteria and cytokines induce CXCL10 in dental pulp. J Dent Res. 2007;86(12):1217-22.

Aderem A, Ulevitch RJ. Toll-like receptors in the induction of the innate immune response. Nature. 2000;406(6797):782-7.

Ahmad-Nejad P, Häcker H, Rutz M, Bauer S, Vabulas RM, Wagner H. Bacterial CpG-DNA and lipopolysaccharides activate Toll-like receptors at distinct cellular compartments. Eur $\mathbf{J}$ Immunol. 2002;32(7):1958-68.

Akira S, Takeda K. Toll-like receptor signalling. Nat Rev Immunol. 2004;4(7):499-511.

Akira S, Uematsu S, Takeuchi O. Pathogen recognition and innate immunity. Cell. 2006;124(4):783-801.

Allenspach-Petrzilka GE, Guggenheim B. Bacterial invasion of the periodontium; an important factor in the pathogenesis of periodontitis? J Clin Periodontol. 1983;10(6):609-17.

Alvares O, Klebe R, Grant G, Cochran DL. Growth factor effects on the expression of collagenase and TIMP-1 in periodontal ligament cells. J Periodontol. 1995;66(7):552-8.

Asif K, Kothiwale SV. Phagocytic activity of peripheral blood and crevicular phagocytes in health and periodontal disease. J Indian Soc Periodontol. 2010;14(1):8-11.

Babel N, Cherepnev G, Babel D, Tropmann A, Hammer M, Volk HD, et al. Analysis of tumor necrosis factor-alpha, transforming growth factor-beta, interleukin-10, IL-6, and interferon-gamma gene polymorphisms in patients with chronic periodontitis. J Periodontol. 2006;77(12):1978-83.

Barkhordar RA, Hayashi C, Hussain MZ. Detection of interleukin-6 in human dental pulp and periapical lesions. Endod Dent Traumatol. 1999;15(1):26-7. 
Barkhordar RA, Ghani QP, Russell TR, Hussain MZ. Interleukin-1beta activity and collagen synthesis in human dental pulp fibroblasts. J Endod. 2002;28(3):157-9.

Barksby HE, Lea SR, Preshaw PM, Taylor JJ. The expanding family of interleukin-1 cytokines and their role in destructive inflammatory disorders. Clin Exp Immunol. 2007;149(2):217-25.

Bianco P, Gehron Robey P. Marrow stromal stem cells. J Clin Invest. 2000;105(12):1663-8.

Bollyky PL, Bice JB, Sweet IR, Falk BA, Gebe JA, Clark AE, et al. The toll-like receptor signaling molecule Myd88 contributes to pancreatic beta-cell homeostasis in response to injury. PLoS One. 2009;4(4):e5063.

Bossé Y, Thompson C, Audette K, Stankova J, Rola-Pleszczynski M. Interleukin-4 and interleukin-13 enhance human bronchial smooth muscle cell proliferation. Int Arch Allergy Immunol. 2008;146(2):138-48.

Botero TM, Shelburne CE, Holland GR, Hanks CT, Nör JE. TLR4 mediates LPS-induced VEGF expression in odontoblasts. J Endod. 2006;32(10):951-5.

Brown GD. Innate antifungal immunity: the key role of phagocytes. Annu Rev Immunol. 2011;29:1-21.

Brouty-Boyé D, Pottin-Clémenceau C, Doucet C, Jasmin C, Azzarone B. Chemokines and CD40 expression in human fibroblasts. Eur J Immunol. 2000;30(3):914-9.

Bsibsi M, Bajramovic JJ, Van Duijvenvoorden E, Persoon C, Ravid R, Van Noort JM, et al. Identification of soluble CD14 as an endogenous agonist for Toll-like receptor 2 on human astrocytes by genome-scale functional screening of glial cell derived proteins. Glia. 2007;55(5):473-82. 
Buckley CD, Pilling D, Lord JM, Akbar AN, Scheel-Toellner D, Salmon M. Fibroblasts regulate the switch from acute resolving to chronic persistent inflammation. Trends Immunol. 2001;22(4):199-204.

Calderone RA, Fonzi WA. Virulence factors of Candida albicans. Trends Microbiol. 2001;9(7):327-35.

Canabarro A, Valle C, Farias MR, Santos FB, Lazera M, Wanke B. Association of subgingival colonization of Candida albicans and other yeasts with severity of chronic periodontitis. J Periodontal Res. 2012.

Cassone A, Cauda R. Candida and candidiasis in HIV-infected patients: where commensalism, opportunistic behavior and frank pathogenicity lose their borders. AIDS. 2012;26(12):1457-72.

Cervantes JL, Weinerman B, Basole C, Salazar JC. TLR8: the forgotten relative revindicated. Cell Mol Immunol. 2012;9(6):434-8.

Chang ZL. Important aspects of Toll-like receptors, ligands and their signaling pathways. Inflamm Res. 2010;59(10):791-808.

Chang LC, Kuo HC, Chang SF, Chen HJ, Lee KF, Lin TH, et al. Regulation of ICAM-1 expression in gingival fibroblasts infected with high-glucose-treated P.gingivalis. Cell Microbiol. 2013.

Chen JK, Hoshi H, McKeehan WL. Transforming growth factor type beta specifically stimulates synthesis of proteoglycan in human adult arterial smooth muscle cells. Proc Natl Acad Sci U S A. 1987;84(15):5287-91.

Christersson LA, Zambon J, Dunford R, Grossi, Genco R. Specific subgingival bacteria and diagnosis of gingivitis and periodontitis. J Dent Res. 1989;68:1633-39. 
Chung KJ, Hill WB. Studies on the pink, adenine-deficient strains of Candida albicans. I. Cultural and morphological characteristics. Sabouraudia. 1970;8(1):48-59.

Coker RK, Laurent GJ. Pulmonary fibrosis: cytokines in the balance. Eur Respir J. 1998;11(6):1218-21.

Cotter G, Kavanagh K. Adherence mechanisms of Candida albicans. Br J Biomed Sci. 2000;57(3):241-9.

Couble ML, Farges JC, Bleicher F, Perrat-Mabillon B, Boudeulle M, Magloire H. Odontoblast differentiation of human dental pulp cells in explant cultures. Calcif Tissue Int. 2000;66(2):129-38.

De Arcangelis A, Georges-Labouesse E. Integrin and ECM functions: roles in vertebrate development. Trends Genet. 2000;16(9):389-95.

De Bernardis F, Mondello F, San Millàn R, Pontòn J, Cassone A. Biotyping and virulence properties of skin isolates of Candida parapsilosis. J Clin Microbiol. 1999;37(11):3481-6.

Debierre-Grockiego F, Campos MA, Azzouz N, Schmidt J, Bieker U, Resende MG, et al. Activation of TLR2 and TLR4 by glycosylphosphatidylinositols derived from Toxoplasma gondii. J Immunol. 2007;179(2):1129-37.

Delsing CE, Bleeker-Rovers CP, Kullberg BJ, Netea MG. Treatment of candidiasis: insights from host genetics. Expert Rev Anti Infect Ther. 2012;10(8):947-56.

d'Ostiani CF, Del Sero G, Bacci A, Montagnoli C, Spreca A, Mencacci A, et al. Dendritic cells discriminate between yeasts and hyphae of the fungus Candida albicans. Implications for initiation of T helper cell immunity in vitro and in vivo. J Exp Med. 2000;191(10):1661-74.

Ekuni D, Yamanaka R, Yamamoto T, Miyauchi M, Takata T, Watanabe T. Effects of mechanical stimulation by a powered toothbrush on the healing of periodontal tissue in a rat model of periodontal disease. J Periodontal Res. 2010;45(1):45-51. 
Farah CS, Ashman RB, Challacombe SJ. Oral candidosis. Clin Dermatol. 2000;18(5):553-62.

Farah CS, Gotjamanos T, Seymour GJ, Ashman RB. Cytokines in the oral mucosa of mice infected with Candida albicans. Oral Microbiol Immunol. 2002;17(6):375-8.

Finlay BB, Hancock RE. Can innate immunity be enhanced to treat microbial infections? Nat Rev Microbiol. 2004;2(6):497-504.

Flug M, Köpf-Maier P. The basement membrane and its involvement in carcinoma cell invasion. Acta Anat (Basel). 1995;152(2):69-84.

Gantner BN, Simmons RM, Underhill DM. Dectin-1 mediates macrophage recognition of Candida albicans yeast but not filaments. EMBO J. 2005;24(6):1277-86.

Gasparoto TH, Tessarolli V, Garlet TP, Torres SA, Garlet GP, da Silva JS, et al. Absence of functional TLR4 impairs response of macrophages after Candida albicans infection. Med Mycol. 2010;48(8):1009-17.

Genco RJ, Zambon JJ, Murray PA. Serum and gingival fluid antibodies as adjuncts in the diagnosis of Actinobacillus actinomycetemcomitans-associated periodontal disease. J Periodontol. 1985;56(11 Suppl):41-50.

Gil ML, Gozalbo D. TLR2, but not TLR4, triggers cytokine production by murine cells in response to Candida albicans yeasts and hyphae. Microbes Infect. 2006;8(8):2299-304.

Glaros T, Larsen M, Li L. Macrophages and fibroblasts during inflammation, tissue damage and organ injury. Front Biosci. 2009;14:3988-93.

Goldman RC, Sullivan PA, Zakula D, Capobianco JO. Kinetics of beta-1,3 glucan interaction at the donor and acceptor sites of the fungal glucosyltransferase encoded by the BGL2 gene. Eur J Biochem. 1995;227(1-2):372-8. 
Gonzales JR, Mann M, Stelzig J, Bödeker RH, Meyle J. Single-nucleotide polymorphisms in the IL-4 and IL-13 promoter region in aggressive periodontitis. J Clin Periodontol. 2007;34(6):473-9.

Graves DT, Cochran D. The contribution of interleukin-1 and tumor necrosis factor to periodontal tissue destruction. J Periodontol. 2003;74(3):391-401.

Gronthos S, Mankani M, Brahim J, Robey PG, Shi S. Postnatal human dental pulp stem cells (DPSCs) in vitro and in vivo. Proc Natl Acad Sci U S A. 2000;97(25):13625-30.

Guo F, Carter DE, Mukhopadhyay A, Leask A. Gingival fibroblasts display reduced adhesion and spreading on extracellular matrix: a possible basis for scarless tissue repair? PLoS One. 2011;6(11):e27097.

Gutiérrez-Venegas G, Arreguín-Cano JA, Hernández-Bermúdez C. Bradykinin promotes Toll like receptor-4 expression in human gingival fibroblasts. Int Immunopharmacol. 2012;14(4):538-45.

Gutiérrez-Venegas G, Rodríguez-Pérez CE. Toll-like receptor 3 activation promotes desensitization of histamine response in human gingival fibroblasts: Poly (I:C) induces histamine receptor desensitization in human gingival fibroblasts. Cell Immunol. 2012;273(2):150-7.

Hanke ML, Angle A, Kielian T. MyD88-dependent signaling influences fibrosis and alternative macrophage activation during Staphylococcus aureus biofilm infection. PLoS One. 2012;7(8):e42476.

Harris PK, Kletzien RF. Localization of a pioglitazone response element in the adipocyte fatty acid-binding protein gene. Mol Pharmacol. 1994;45(3):439-45.

Harwani SC, Lurain NS, Zariffard MR, Spear GT. Differential inhibition of human cytomegalovirus (HCMV) by toll-like receptor ligands mediated by interferon-beta in human foreskin fibroblasts and cervical tissue. Virol J. 2007;4:133. 
Hatakeyama J, Tamai R, Sugiyama A, Akashi S, Sugawara S, Takada H. Contrasting responses of human gingival and periodontal ligament fibroblasts to bacterial cell-surface components through the CD14/Toll-like receptor system. Oral Microbiol Immunol. 2003;18(1):14-23.

Havemose-Poulsen A, Sørensen LK, Bendtzen K, Holmstrup P. Polymorphisms within the IL-1 gene cluster: effects on cytokine profiles in peripheral blood and whole blood cell cultures of patients with aggressive periodontitis, juvenile idiopathic arthritis, and rheumatoid arthritis. J Periodontol. 2007;78(3):475-92.

Hazeki K, Masuda N, Funami K, Sukenobu N, Matsumoto M, Akira S, et al. Toll-like receptor-mediated tyrosine phosphorylation of paxillin via MyD88-dependent and independent pathways. Eur J Immunol. 2003;33(3):740-7.

Heil F, Ahmad-Nejad P, Hemmi H, Hochrein H, Ampenberger F, Gellert T, et al. The Tolllike receptor 7 (TLR7)-specific stimulus loxoribine uncovers a strong relationship within the TLR7, 8 and 9 subfamily. Eur J Immunol. 2003;33(11):2987-97.

Helovuo H, Hakkarainen K, Paunio K. Changes in the prevalence of subgingival enteric rods, staphylococci and yeasts after treatment with penicillin and erythromycin. Oral Microbiol Immunol. 1993;8(2):75-9.

Hershey GK. IL-13 receptors and signaling pathways: an evolving web. J Allergy Clin Immunol. 2003;111(4):677-90.

Hirano F, Hirano H, Hino E, Takayama S, Saito K, Kusumoto Y, et al. CD44 isoform expression in periodontal tissues: cell-type specific regulation of alternative splicing. J Periodontal Res. 1997;32(8):634-45.

Hirao K, Yumoto H, Nakanishi T, Mukai K, Takahashi K, Takegawa D, et al. Tea catechins reduce inflammatory reactions via mitogen-activated protein kinase pathways in toll-like receptor 2 ligand-stimulated dental pulp cells. Life Sci. 2010;86(17-18):654-60. 
Hirao K, Yumoto H, Takahashi K, Mukai K, Nakanishi T, Matsuo T. Roles of TLR2, TLR4, NOD2, and NOD1 in pulp fibroblasts. J Dent Res. 2009;88(8):762-7.

Hogaboam CM, Bone-Larson CL, Lipinski S, Lukacs NW, Chensue SW, Strieter RM, et al. Differential monocyte chemoattractant protein-1 and chemokine receptor 2 expression by murine lung fibroblasts derived from Th1- and Th2-type pulmonary granuloma models. J Immunol. 1999;163(4):2193-201.

Hogaboam CM, Steinhauser ML, Chensue SW, Kunkel SL. Novel roles for chemokines and fibroblasts in interstitial fibrosis. Kidney Int. 1998;54(6):2152-9.

Hromadnikova I, Nguyen TT, Zlacka D, Sedlackova L, Popelka S, Veigl D, et al. Expression of heat shock protein receptors on fibroblast-like synovial cells derived from rheumatoid arthritis-affected joints. Rheumatol Int. 2008;28(9):837-44.

Huebener P, Abou-Khamis T, Zymek P, Bujak M, Ying X, Chatila K, et al. CD44 is critically involved in infarct healing by regulating the inflammatory and fibrotic response. $\mathrm{J}$ Immunol. 2008;180(4):2625-33.

Huebener P, Abou-Khamis T, Zymek P, Bujak M, Ying X, Chatila K, et al. CD44 is critically involved in infarct healing by regulating the inflammatory and fibrotic response. $\mathrm{J}$ Immunol. 2008;180(4):2625-33.

Hughes CC. Endothelial-stromal interactions in angiogenesis. Curr Opin Hematol. 2008;15(3):204-9.

Into T, Inomata M, Shibata K, Murakami Y. Effect of the antimicrobial peptide LL-37 on Toll-like receptors 2-, 3- and 4-triggered expression of IL-6, IL-8 and CXCL10 in human gingival fibroblasts. Cell Immunol. 2010;264(1):104-9. 
Jung YO, Cho ML, Lee SY, Oh HJ, Park JS, Park MK, et al. Synergism of toll-like receptor 2 (TLR2), TLR4, and TLR6 ligation on the production of tumor necrosis factor (TNF)-alpha in a spontaneous arthritis animal model of interleukin (IL)-1 receptor antagonist-deficient mice. Immunol Lett. 2009;123(2):138-43.

Jeng JH, Lan WH, Wang JS, Chan CP, Ho YS, Lee PH, et al. Signaling mechanism of thrombin-induced gingival fibroblast-populated collagen gel contraction. Br J Pharmacol. 2006;147(2):188-98.

Johnson NW. The mouth in HIV/AIDS: markers of disease status and management challenges for the dental profession. Aust Dent J. 2010;55 Suppl 1:85-102.

Kaisho T, Akira S. Toll-like receptors and their signaling mechanism in innate immunity. Acta Odontol Scand. 2001;59(3):124-30.

Kantarcioglu AS, Yücel A. Phospholipase and protease activities in clinical Candida isolates with reference to the sources of strains. Mycoses. 2002;45(5-6):160-5.

Káposzta R, Tree P, Maródi L, Gordon S. Characteristics of invasive candidiasis in gamma interferon- and interleukin-4-deficient mice: role of macrophages in host defense against Candida albicans. Infect Immun. 1998;66(4):1708-17.

Kapteyn JC, Hoyer LL, Hecht JE, Müller WH, Andel A, Verkleij AJ, et al. The cell wall architecture of Candida albicans wild-type cells and cell wall-defective mutants. Mol Microbiol. 2000;35(3):601-11.

Kato-Kogoe N, Ohyama H, Nishimura F, Meguro M, Yoshizawa S, Okada Y, et al. Fibroblasts stimulated via HLA-II molecules produce prostaglandin $\mathrm{E}_{2}$ and regulate cytokine production from helper T cells. Lab Invest. 2010;90(12):1747-56.

Kawai T, Adachi O, Ogawa T, Takeda K, Akira S. Unresponsiveness of MyD88-deficient mice to endotoxin. Immunity. 1999;11(1):115-22. 
Keller JF, Carrouel F, Colomb E, Durand SH, Baudouin C, Msika P, et al. Toll-like receptor 2 activation by lipoteichoic acid induces differential production of pro-inflammatory cytokines in human odontoblasts, dental pulp fibroblasts and immature dendritic cells. Immunobiology. 2010;215(1):53-9.

Kullberg MC, Ward JM, Gorelick PL, Caspar P, Hieny S, Cheever A, et al. Helicobacter hepaticus triggers colitis in specific-pathogen-free interleukin-10 (IL-10)-deficient mice through an IL-12- and gamma interferon-dependent mechanism. Infect Immun. 1998;66(11):5157-66.

Kumagai N, Fukuda K, Fujitsu Y, Lu Y, Chikamoto N, Nishida T. Lipopolysaccharideinduced expression of intercellular adhesion molecule-1 and chemokines in cultured human corneal fibroblasts. Invest Ophthalmol Vis Sci. 2005;46(1):114-20.

Kawai T, Akira S. Signaling to NF-kappaB by Toll-like receptors. Trends Mol Med. 2007;13(11):460-9.

Landmann R, Müller B, Zimmerli W. CD14, new aspects of ligand and signal diversity. Microbes Infect. 2000;2(3):295-304.

Lee HK, Dunzendorfer S, Soldau K, Tobias PS. Double-stranded RNA-mediated TLR3 activation is enhanced by CD14. Immunity. 2006;24(2):153-63.

Lesley J, Gál I, Mahoney DJ, Cordell MR, Rugg MS, Hyman R, et al. TSG-6 modulates the interaction between hyaluronan and cell surface CD44. J Biol Chem. 2004;279(24):25745-54.

Lemaitre B, Reichhart JM, Hoffman JA. Drosophila host defense: Diferencial induction of antimicrobial peptide genes after infections by various classes of microorganisms.Proc Natl Aca Sci. 1997; (94):14614-14619. 
Leonardi A, Cortivo R, Fregona I, Plebani M, Secchi AG, Abatangelo G. Effects of Th2 cytokines on expression of collagen, MMP-1, and TIMP-1 in conjunctival fibroblasts. Invest Ophthalmol Vis Sci. 2003;44(1):183-9.

Mahanonda R, Sa-Ard-Iam N, Montreekachon P, Pimkhaokham A, Yongvanichit K, Fukuda MM, et al. IL-8 and IDO expression by human gingival fibroblasts via TLRs. J Immunol. 2007;178(2):1151-7.

Martínez MM, Mendaza P, Daza RM, Sánchez G, Martín P, Martín JE, et al. [Study of the in vitro sensitivity of yeasts with the ATB-Fungus system]. Rev Esp Quimioter. 1998;11(3):2513.

Matsumoto M, Funami K, Tanabe M, Oshiumi H, Shingai M, Seto Y, et al. Subcellular localization of Toll-like receptor 3 in human dendritic cells. J Immunol. 2003;171(6):3154-62.

Medzhitov R, Janeway C Jr. Innate immunity. N Engl J Med. 2000;343(5):338-44.

Melin M, Joffre-Romeas A, Farges JC, Couble ML, Magloire H, Bleicher F. Effects of TGFbeta1 on dental pulp cells in cultured human tooth slices. J Dent Res. 2000;79(9):168996.

Mencacci A, Del Sero G, Cenci E, d'Ostiani CF, Bacci A, Montagnoli C, et al. Endogenous interleukin 4 is required for development of protective $\mathrm{CD} 4+\mathrm{T}$ helper type 1 cell responses to Candida albicans. J Exp Med. 1998;187(3):307-17.

Miller YI, Viriyakosol S, Worrall DS, Boullier A, Butler S, Witztum JL. Toll-like receptor 4dependent and -independent cytokine secretion induced by minimally oxidized low-density lipoprotein in macrophages. Arterioscler Thromb Vasc Biol. 2005;25(6):1213-9.

Miranda-Carús ME, Balsa A, Benito-Miguel M, Pérez de Ayala C, Martín-Mola E. IL-15 and the initiation of cell contact-dependent synovial fibroblast- $T$ lymphocyte cross-talk in rheumatoid arthritis: effect of methotrexate. J Immunol. 2004;173(2):1463-76. 
Murakami K, Tanaka M, Usui T, Kawabata D, Shiomi A, Iguchi-Hashimoto M, et al Follistatin-related protein/follistatin-like 1 evokes an innate immune response via CD14 and toll-like receptor 4. FEBS Lett. 2012;586(4):319-24.

Murciano C, Yáñez A, O'Connor JE, Gozalbo D, Gil ML. Influence of aging on murine neutrophil and macrophage function against Candida albicans. FEMS Immunol Med Microbiol. 2008;53(2):214-21.

Misra V, Grondin A, Klamut HJ, Rauth AM. Assessment of the relationship between genotypic status of a DT-diaphorase point mutation and enzymatic activity. Br J Cancer. 2000;83(8):998-1002.

Månsson LE, Montero M, Zarepour M, Bergstrom KS, Ma C, Huang T, Man C, Grassl GA, Vallance BA. MyD88 signaling promotes both mucosal homeostatic and fibrotic responses during Salmonella-induced colitis. Am J Physiol Gastrointest Liver Physiol. 2012; 303(3):G311-23.

Marinova-Mutafchieva L, Taylor P, Funa K, Maini RN, Zvaifler NJ. Mesenchymal cells expressing bone morphogenetic protein receptors are present in the rheumatoid arthritis joint. Arthritis Rheum. 2000;43(9):2046-55.

Martinez EF, Araújo VC. In vitro immunoexpression of extracellular matrix proteins in dental pulpal and gingival human fibroblasts. Int Endod J. 2004;37(11):749-55.

Medzhitov R. Toll-like receptors and innate immunity. Nat Rev Immunol. 2001;1(2):135-45.

Miyakawa Y, Kuribayashi T, Kagaya K, Suzuki M, Nakase T, Fukazawa Y. Role of specific determinants in mannan of Candida albicans serotype $\mathrm{A}$ in adherence to human buccal epithelial cells. Infect Immun. 1992;60(6):2493-9. 
Mochizuki S, Kobayashi M, Suzuki T, Oikawa A, Koseki T, Nishihara T, et al. Gammainterferon enhances expression of CD14/MyD88 and subsequent responsiveness to lipopolysaccharide from Actinobacillus actinomycetemcomitans in human gingival fibroblasts. J Periodontal Res. 2004;39(5):333-43.

Mohammadi Z, Dummer PM. Properties and applications of calcium hydroxide in endodontics and dental traumatology. Int Endod J. 2011;44(8):697-730.

Möller AJ, Fabricius L, Dahlén G, Ohman AE, Heyden G. Influence on periapical tissues of indigenous oral bacteria and necrotic pulp tissue in monkeys. Scand J Dent Res. $1981 ; 89(6): 475-84$.

Mueller DL. T cells: A proliferation of costimulatory molecules. Curr Biol. 2000;10(6):R22730.

Nagai Y, Akashi S, Nagafuku M, Ogata M, Iwakura Y, Akira S, et al. Essential role of MD-2 in LPS responsiveness and TLR4 distribution. Nat Immunol. 2002 Jul;3(7):667-72.

Netea MG, Kullberg BJ. Epithelial sensing of fungal invasion. Cell Host Microbe. 2010;8(3):219-20.

Nahum A, Dadi H, Bates A, Roifman CM. The biological significance of TLR3 variant, L412F, in conferring susceptibility to cutaneous candidiasis, CMV and autoimmunity. Autoimmun Rev. 2012;11(5):341-7.

Nakao K, Itoh M, Tomita Y, Tomooka Y, Tsuji T. FGF-2 potently induces both proliferation and DSP expression in collagen type I gel cultures of adult incisor immature pulp cells. Biochem Biophys Res Commun. 2004;325(3):1052-9.

Netea MG, Sutmuller R, Hermann C, Van der Graaf CA, Van der Meer JW, van Krieken JH, et al. Toll-like receptor 2 suppresses immunity against Candida albicans through induction of IL-10 and regulatory T cells. J Immunol. 2004;172(6):3712-8.111. 
Netea MG, Van Der Graaf CA, Vonk AG, Verschueren I, Van Der Meer JW, Kullberg BJ. The role of toll-like receptor (TLR) 2 and TLR4 in the host defense against disseminated candidiasis. J Infect Dis. 2002;185(10):1483-9.

Ning Y, Hu X, Ling J, Du Y, Liu J, Liu H, et al. Candida albicans survival and biofilm formation under starvation conditions. Int Endod J. 2013;46(1):62-70.

Okada H, Murakami S. Cytokine expression in periodontal health and disease. Crit Rev Oral Biol Med. 1998;9(3):248-66.

Okamoto M, Hirai H, Taniguchi K, Shimura K, Inaba T, Shimazaki C, et al. Toll-like receptors (TLRs) are expressed by myeloid leukaemia cell lines, but fail to trigger differentiation in response to the respective TLR ligands. Br J Haematol. 2009;147(4):585-7.

Oriente A, Fedarko NS, Pacocha SE, Huang SK, Lichtenstein LM, Essayan DM. Interleukin13 modulates collagen homeostasis in human skin and keloid fibroblasts. J Pharmacol Exp Ther. 2000;292(3):988-94.

Pang Y, Gara SK, Achyut BR, Li Z, Yan HH, Day CP, et al. Transforming growth factor $\beta$ signaling in myeloid cells is required for tumor metastasis. Cancer Discov. 2013 [Epub ahead of print].

Pap T, Müller-Ladner U, Gay RE, Gay S. Fibroblast biology. Role of synovial fibroblasts in the pathogenesis of rheumatoid arthritis. Arthritis Res. 2000;2(5):361-7.

Park C, Lee SY, Kim HJ, Park K, Kim JS, Lee SJ. Synergy of TLR2 and H1R on Cox-2 Activation in Pulpal Cells. J Dent Res. 2010;89(2):180-5.

Parise-Fortes MR, Marques SA, Soares AM, Kurokawa CS, Marques ME, Peracoli MT. Cytokines released from blood monocytes and expressed in mucocutaneous lesions of patients with paracoccidioidomycosis evaluated before and during trimethoprim-sulfamethoxazole treatment. Br J Dermatol. 2006;154(4):643-50. 
Pietrella D, Monari C, Retini C, Palazzetti B, Kozel TR, Vecchiarelli A. HIV type 1 envelope glycoprotein gp120 induces development of a $\mathrm{T}$ helper type 2 response to Cryptococcus neoformans. AIDS. 1999;13(16):2197-207.

Pietrella D, Bistoni G, Corbucci C, Perito S, Vecchiarelli A. Candida albicans mannoprotein influences the biological function of dendritic cells. Cell Microbiol. 2006;8(4):602-12.

Pilling D, Fan T, Huang D, Kaul B, Gomer RH. Identification of markers that distinguish monocyte-derived fibrocytes from monocytes, macrophages, and fibroblasts. PLoS One. 2009;4(10):e7475.

Poulain-Godefroy O, Le Bacquer O, Plancq P, Lecoeur C, Pattou F, Frühbeck G, et al. Inflammatory role of Toll-like receptors in human and murine adipose tissue. Mediators Inflamm. 2010;2010:823486.

Price MF, Wilkinson ID, Gentry LO. Plate method for detection of phospholipase activity in Candida albicans. Sabouraudia. 1982;20(1):7-14.

Radford DR, Challacombe SJ, Walter JD. Denture plaque and adherence of Candida albicans to denture-base materials in vivo and in vitro. Crit Rev Oral Biol Med. 1999;10(1):99-116.

Repentigny L, Aumont F, Bernard K, Belhumeur P. Characterization of Binding of Candida albicans to Small Intestinal Mucin and Its Role in Adherence to Mucosal Epithelial Cells. Infect Immun. 2000; 68(6): 3172-3179.

Rams TE, Andriolo M Jr, Feik D, Abel SN, McGivern TM, Slots J. Microbiological study of HIV-related periodontitis. J Periodontol. 1991;62(1):74-81.

Roelofs MF, Wenink MH, Brentano F, Abdollahi-Roodsaz S, Oppers-Walgreen B, Barrera P, van Riel PL, Joosten LA, Kyburz D, van den Berg WB, Radstake TR. Type I interferons might form the link between Toll-like receptor (TLR) 3/7 and TLR4-mediated synovial inflammation in rheumatoid arthritis (RA). Ann Rheum Dis. 2009;68(9):1486-93.

Romani L, Puccetti P, Bistoni F. Interleukin-12 in infectious diseases. Clin Microbiol Rev. 1997;10(4):611-36. 
Rubio NA, Puia S, Toranzo S, Brusca MI. [Fungal invasion of connective tissue in patients with gingival-periodontal disease.] Rev Iberoam Micol. 2012.

Sabroe I, Jones EC, Usher LR, Whyte MK, Dower SK. Toll-like receptor (TLR)2 and TLR4 in human peripheral blood granulocytes: a critical role for monocytes in leukocyte lipopolysaccharide responses. J Immunol. 2002 May;168(9):4701-10.

Saito T, Ogawa M, Hata Y, Bessho K. Acceleration effect of human recombinant bone morphogenetic protein- 2 on differentiation of human pulp cells into odontoblasts.

J Endod. 2004;30(4):205-8.

Sardi JC, Duque C, Mariano FS, Peixoto IT, Höfling JF, Gonçalves RB. Candida spp. in periodontal disease: a brief review. J Oral Sci. 2010;52(2):177-85.

Sawada S, Chosa N, Ishisaki A, Naruishi K. Enhancement of gingival inflammation induced by synergism of IL-1 $\beta$ and IL-6. Biomed Res. 2013;34(1):31-40.

Schnare M, Holt AC, Takeda K, Akira S, Medzhitov R. Recognition of CpG DNA is mediated by signaling pathways dependent on the adaptor protein MyD88. Curr Biol. 2000 21;10(18):1139-42.

Scheres N, Laine ML, Sipos PM, Bosch-Tijhof CJ, Crielaard W, de Vries TJ, et al. Periodontal ligament and gingival fibroblasts from periodontitis patients are more active in interaction with Porphyromonas gingivalis. J Periodontal Res. 2011;46(4):407-16.

Schierano G, Bellone G, Manzella C, Preti G, Emanuelli G. In vitro effect of transforming growth factor-beta on adhesion molecule expression by human gingival fibroblasts cultured in the presence of a titanium abutment. J Periodontol. 2001;72(12):1658-65.

Schröter C, Hipler UC, Wilmer A, Künkel W, Wollina U. Generation of reactive oxygen species by Candida albicans in relation to morphogenesis. Arch Dermatol Res. 2000;292(5):260-4. 
Skuginna V, Lech M, Allam R, Ryu M, Clauss S, Susanti HE, Römmele C, Garlanda C, Mantovani A, Anders HJ. Toll-like receptor signaling and SIGIRR in renal fibrosis upon unilateral ureteral obstruction. PLoS One. 2011;6(4):e19204.

Senet JM. Risk factors and physiopathology of candidiasis. Rev Iberoam Micol. 1997;14(1):6-13.

Shimazu R, Akashi S, Ogata H, Nagai Y, Fukudome K, Miyake K, et al. MD-2, a molecule that confers lipopolysaccharide responsiveness on Toll-like receptor 4. J Exp Med. 1999;189(11):1777-82.

Shimizu MT, Jorge AO, Unterkircher CS, Fantinato V, Paula CR. Hyaluronidase and chondroitin sulphatase production by different species of Candida. J Med Vet Mycol. 1995;33(1):27-31.

Silva AC, Faria MR, Fontes A, Campos MS, Cavalcanti BN. Interleukin-1 beta and interleukin-8 in healthy and inflamed dental pulps. J Appl Oral Sci. 2009;17(5):527-32.

Siqueira JF Jr, Sen BH. Fungi in endodontic infections. Oral Surg Oral Med Oral Pathol Oral Radiol Endod. 2004;97(5):632-41.

Smith RS, Smith TJ, Blieden TM, Phipps RP. Fibroblasts as sentinel cells. Synthesis of chemokines and regulation of inflammation. Am J Pathol. 1997;151(2):317-22.

Soikkonen K, Wolf J, Salo T, Tilvis R. Radiographic periodontal attachment loss as an indicator of death risk in the elderly. J Clin Periodontol. 2000; (2):87-92.

Sörensen I, Susnik N, Inhester T, Degen JL, Melk A, Haller H, et al. Fibrinogen, acting as a mitogen for tubulointerstitial fibroblasts, promotes renal fibrosis. Kidney Int. 2011;80(10):1035-44. 
Sprong T, Ley Pv, Abdollahi-Roodsaz S, Joosten L, Meer Jv, Netea M, et al. Neisseria meningitidis lipid A mutant LPSs function as LPS antagonists in humans by inhibiting TLR 4-dependent cytokine production. Innate Immun. 2011;17(6):517-25.

Tamai R, Sakuta T, Matsushita K, Torii M, Takeuchi O, Akira S, Akashi S, Espevik T, Sugawara S, Takada H. Human gingival CD14(+) fibroblasts primed with gamma interferon increase production of interleukin-8 in response to lipopolysaccharide through up-regulation of membrane CD14 and MyD88 mRNA expression. Infect Immun. 2002;70(3):1272-8.

Tatematsu M, Nishikawa F, Seya T, Matsumoto M. Toll-like receptor 3 recognizes incomplete stem structures in single-stranded viral RNA. Nat Commun. 2013;4:1833

Takashiba S, Naruishi K, Murayama Y. Perspective of cytokine regulation for periodontal treatment: fibroblast biology. J Periodontol 2003;74:103-10.

Takahashi K, Takashiba S, Nagai A, Takigawa M, Myoukai F, Kurihara H, et al. Assessment of interleukin-6 in the pathogenesis of periodontal disease. J Periodontol. 1994;65(2):147-53.

Takashiba S, Naruishi K, Murayama Y. Perspective of cytokine regulation for periodontal treatment: fibroblast biology. J Periodontol. 2003;74(1):103-10.

Takeuchi T, Harris JL, Huang W, Yan KW, Coughlin SR, Craik CS. Cellular localization of membrane-type serine protease 1 and identification of protease-activated receptor- 2 and single-chain urokinase-type plasminogen activator as substrates. $J$ Biol Chem. 2000;275(34):26333-42.

Trackman PC, Kantarci A. Connective tissue metabolism and gingival overgrowth. Crit Rev Oral Biol Med. 2004;15(3):165-75.

Trevani AS, Chorny A, Salamone G, Vermeulen M, Gamberale R, Schettini J, Raiden S, Geffner J. Eur J Immunol. 2003;(11):3164-74. 
Tziafas D, Alvanou A, Papadimitriou S, Gasic J, Komnenou A. Effects of recombinant basic fibroblast growth factor, insulin-like growth factor-II and transforming growth factor-beta 1 on dog dental pulp cells in vivo. Arch Oral Biol. 1998;43(6):431-44.

Takahashi K. Microbiological, pathological, inflammatory, immunological and molecular biological aspects of periradicular disease. Int Endod J. 1998;31(5):311-25.

Takahashi N, Kobayashi M, Takaki T, Takano K, Miyata M, Okamatsu Y, et al. Actinobacillus actinomycetemcomitans lipopolysaccharide stimulates collagen phagocytosis by human gingival fibroblasts. Oral Microbiol Immunol. 2008;23(3):259-64.

Takashiba S, Naruishi K, Murayama Y. Perspective of cytokine regulation for periodontal treatment: fibroblast biology. J Periodontol. 2003;74(1):103-10.

Takeda K, Akira S. Microbial recognition by Toll-like receptors. J Dermatol Sci. 2004;34(2):73-82.

Tang L, Zhou XD, Wang Q, Zhang L, Wang Y, Li XY, et al. Expression of TRAF6 and proinflammatory cytokines through activation of TLR2, TLR4, NOD1, and NOD2 in human periodontal ligament fibroblasts. Arch Oral Biol. 2011;56(10):1064-72.

Toole BP, Yu Q, Underhill CB. Hyaluronan and hyaluronan-binding proteins. Probes for specific detection. Methods Mol Biol. 2001;171:479-85.

Torres AV, Carson JJ, Balish E. NO is not directly candidacidal for Candida albicans. Infect Immun. 1995;63(2):1142-1144.

Tziafas D, Alvanou A, Papadimitriou S, Gasic J, Komnenou A. Effects of recombinant basic fibroblast growth factor, insulin-like growth factor-II and transforming growth factor-beta 1 on dog dental pulp cells in vivo. Arch Oral Biol. 1998;43(6):431-44.

Uehara A, Takada H. Functional TLRs and NODs in human gingival fibroblasts. J Dent Res. 2007;86(3):249-54. 
Underhill DM, Ozinsky A. Toll-like receptors: key mediators of microbe detection. Curr Opin Immunol. 2002;14(1):103-10.

Vadillo E, Pelayo R. Toll-like receptors in development and function of the hematopoietic system. Rev Invest Clin. 2012;64(5):461-76.

Valera F, Brassesco MS, Castro-Gamero AM, Cortez MA, Queiroz RG, Tone LG, et al. In vitro effect of glucocorticoids on nasal polyps. Braz J Otorhinolaryngol. 2011;77(5):605-10.

van der Graaf CA, Netea MG, Verschueren I, van der Meer JW, Kullberg BJ. Differential cytokine production and Toll-like receptor signaling pathways by Candida albicans blastoconidia and hyphae. Infect Immun. 2005;73(11):7458-64.

Verweij PE, Brinkman K, Kremer HP, Kullberg BJ, Meis JF. Aspergillus meningitis: diagnosis by non-culture-based microbiological methods and management. J Clin Microbiol. 1999;37(4):1186-9.

Villamón E, Gozalbo D, Roig P, O'Connor JE, Fradelizi D, Gil ML. Toll-like receptor-2 is essential in murine defenses against Candida albicans infections. Microbes Infect. 2004;6(1):1-7.

Wagner H. Endogenous TLR ligands and autoimmunity. Adv Immunol. 2006;91:159-73.

Waltimo TM, Sen BH, Meurman JH, Ørstavik D, Haapasalo MP. Yeasts in apical periodontitis. Crit Rev Oral Biol Med. 2003;14(2):128-37.

Wang J, Si Y, Wu C, Sun L, Ma Y, Ge A, et al. Lipopolysaccharide promotes lipid accumulation in human adventitial fibroblasts via TLR4-NF- $\kappa$ B pathway. Lipids Health Dis. 2012;11:139.

Wang PL, Azuma Y, Shinohara M, Ohura K. Toll-like receptor 4-mediated signal pathway induced by Porphyromonas gingivalis lipopolysaccharide in human gingival fibroblasts. Biochem Biophys Res Commun. 2000;273(3):1161-7. 
Wara-Aswapati N, Chayasadom A, Surarit R, Pitiphat W, Boch JA, Nagasawa T, et al. Induction of Toll-Like Receptor Expression by Porphyromonas Gingivalis. J Periodontol. 2012.

Whetton AD, Graham GJ. Homing and mobilization in the stem cell niche. Trends Cell Biol. 1999;9(6):233-8.

White TC, Agabian N. Candida albicans secreted aspartyl proteinases: isoenzyme pattern is determined by cell type, and levels are determined by environmental factors. J Bacteriol. 1995;177(18):5215-21.

Yamamoto Y, Retzlaff C, He P, Klein TW, Friedman H. Quantitative reverse transcriptionPCR analysis of Legionella pneumophila-induced cytokine mRNA in different macrophage populations by high-performance liquid chromatography. Clin Diagn Lab Immunol. 1995;2(1):18-24.

Yordanov M, Dimitrova P, Danova S, Ivanovska N. Candida albicans double-stranded DNA can participate in the host defense against disseminated candidiasis. Microbes Infect. $2005 ; 7(2): 178-86$.

Zaric SS, Coulter WA, Shelburne CE, Fulton CR, Zaric MS, Scott A, et al. Altered Toll-like receptor 2-mediated endotoxin tolerance is related to diminished interferon beta production. $\mathbf{J}$ Biol Chem. 2011;286(34):29492-500.

Zvaifler NJ, Marinova-Mutafchieva L, Adams G, Edwards CJ, Moss J, Burger JA, et al. Mesenchymal precursor cells in the blood of normal individuals. Arthritis Res. 2000;2(6):477-88.

Zhang S, Wang QQ, Zhang CF, Soo I. Identification of dominant pathogens in periapical lesions associated with persistent apical periodontitis. Chin J Dent Res. 2010;13(2):115-21. 
Zhou S, Halle A, Kurt-Jones EA, Cerny AM, Porpiglia E, Rogers M, Golenbock DT, Finberg RW. Lymphocytic choriomeningitis virus (LCMV) infection of CNS glial cells results in TLR2-MyD88/Mal-dependent inflammatory responses. J Neuroimmunol. 2008;194(1-2):7082.

Zhu X, Zhao H, Graveline AR, Buys ES, Schmidt U, Bloch KD, et al. MyD88 and NOS2 are essential for toll-like receptor 4-mediated survival effect in cardiomyocytes. Am J Physiol Heart Circ Physiol. 2006;291(4):H1900-9. 
Anexo 



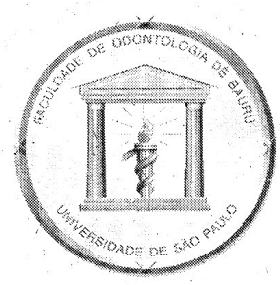

\section{Universidade de São Paulo Faculdade de Odontologia de Bauru}

Comissão de Ética no Ensino e Pesquisa em Animais

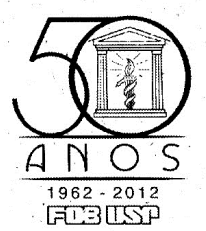

CEEPA-Proc. № 039/2009

Bauru, 6 de maio de 2013.

Senhora Professora,

Em atenção à solicitação de Vossa Senhoria (inclusão dos grupos de animais CD14KO e MyD88KO) para obtenção de mais resultados no projeto de pesquisa denominado "Avaliação do papel de receptores do tipo Toll (TLR-2 e TLR-4) no reconhecimento de Candida albicans por fibroblastos murinos", de autoria de Cláudia Ramos Pinheiro, sob sua orientação, aprovado por esta Comissão em 12.5.2010 e, em decorrência, a alteração do título para "Reconhecimento de Candida albicans pu." fibroblastos murinos: avaliação do envolvimento de receptores de reconhecimento de patógenos (TLR2 e CD14) e a proteína adaptadora MyD88", informamos que após análise por um relator, referida solicitação foi considerada APROVADA ad referendum desta Comissão.

Lembramos que ao término da pesquisa os autores deverão enviar um relatório final com os resultados obtidos para análise e emissão de parecer, o qual poderá ser utilizado para publicação em revistas científicas.

Atenciosamente,

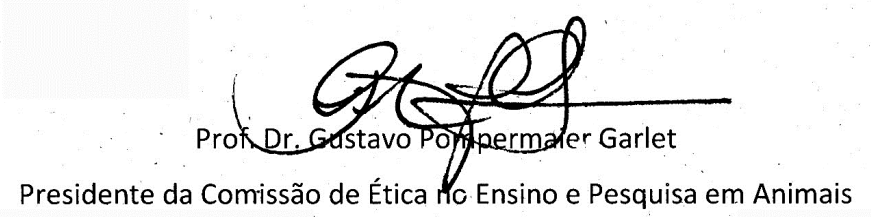

Profa Dra Ana Paula Campanelli

Docente do Departamento de Ciências Biológicas

Al. Dr. Octávio Pinheiro Brisolla, 9-75 - Bauru-SP - CEP 17012-101 - C.P. 73 e-mail: mferrari@fob.usp.br - Fone/FAX (0xx14) 3235-8356

http://www.fob.usp.br 